\title{
Advances in identifying GM plants: toward the routine detection of 'hidden' and 'new' GMOs
}

Yves Bertheau, INRA honorary Directeur de recherche, honorary scientist at Centre d'Ecologie et des Sciences de la Conservation (CESCO), Muséum national d'Histoire naturelle, Centre National de la Recherche Scientifique, Sorbonne Université, France
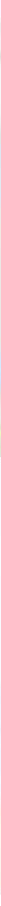


\section{Advances in identifying GM plants: toward the routine detection of 'hidden' and 'new' GMOs}

Yves Bertheau, INRA honorary Directeur de recherche, honorary scientist at Centre d'Ecologie et des Sciences de la Conservation (CESCO), Muséum national d'Histoire naturelle, Centre National de la Recherche Scientifique, Sorbonne Université, France

1 Summary

2 Background to 'hidden' and 'new' GMOs

3 Sources of detection targets

4 Transmission of detection targets towards commercial varieties

5 Gathering the data into manageable decision tools

6 Proof of concept

7 Conclusion

8 Where to look for further information

9 References

\section{Summary}

The growing knowledge in genetics, epigenomics, epitranscriptomics and the 3D - or even 4D - genome structure provides an increasing number of detection targets that can be used to identify species or genetic lines, whether modified or not. Biotic and abiotic stresses also induce numerous unintentional genetic, epigenetic and epitranscriptomic modifications. Those changes are transmissible and can be ordered in regions and classified. The detection target is characterised by the mutagenesis technique used. For instance, the detection of transgenic GMO or SDN3 modification of new breeding techniques (NBTs) will target the junctions of fragment insertions into the genome. Each insertion induces epigenetic, and probably epitranscriptomic, changes which can also be targeted. In addition, one group of markers is linked to the trait(s) introduced or modified by the breeder, whose sequence could be used in quantification and 'screening'. The other target will be a subset of the elements of a matrix approach (as described elsewhere in this book). General selection markers, 
such as those used for plant breeding, together with mutagenesis techniquespecific markers, could differentiate genetically modified organisms (GMOs) of any origin. They can be used to quantify and certify, through a global approach to the organism, that the trait modification is artefactual and not 'natural'. The growing mastery of single-cell sequencing techniques should soon make it possible to differentiate the modifications, for example, due to each step of a CRISPR-Cas transformation of cells in culture. This chapter will focus mainly on detection targets based on nucleic acids, DNA and RNA, modified or unmodified, for their routine use in private and enforcement detection laboratories to comply with food labelling and European traceability rules. The chapter uses the wording 'hidden' GMOs and 'new' GMOs as defined by the French non-governmental organisations (NGOs) and farmers' union at the origin of the 2018 European Court of Justice ruling.

\subsection{Introduction}

Traditional breeding resulted from 10000 years in the domestication syndrome, which is a genetic erosion over time causing a drastic reduction in the variability available for breeding in recent decades (Ahmar et al., 2020; Meyer et al., 2012). Genetic diversity is nevertheless necessary for the creation of new varieties adapted to the changing needs of agricultural production: adaptation to the pedoclimatic conditions of new production regions, resistance to constantly evolving parasites and pathogens, increase in yields, or finally, the production or the suppression of the production of molecules sought after or avoided by consumers or industry, all despite a reduced resilience of crops (Ceccarelli and Grando, 2020; Gepts, 2006; Louwaars, 2018; Zampieri et al., 2020a,b).

The use of simple and generally single adapted traits is carried out by (i) time-consuming crossings between more or less divergent populations of the domestic species, (ii) the introgression of traits from more or less related wild species, (iii) the in vivo, and then in vitro random generation of mutations and epimutations and finally (iv) the introduction of sequences from other species by transgenesis to various techniques for modifying genomes and epigenomes (Glenn et al., 2017; Li et al., 2016; Miki and McHugh, 2004; Olsen and Wendel, 2013a; Van Tassel et al., 2020; Xue et al., 2019; Witcombe et al., 2013). Transgenesis techniques were well-received in the ' 90 s because they offered strong patent protection for the transgenic lines created, together with a rather relatively rapid return on investment for the simple introgressed traits. Transgenesis appeared to be an excellent economical alternative where companies could commercialise new features, while the unpredictability and the lack of means for selecting complex features showed the bottlenecks of costly screenings of populations obtained from of in vitro random mutagenesis (Birch, 1997). Those issues of random mutagenesis were only solved with the 
development after 2000 of the TILLING method (Targeting Induced Local Lesions in Genomes), the implementations of massive screening platforms and the support of marker-assisted selection methods (McCallum et al., 2000a,b).

After a few failures, such as a market withdrawal of delayed-ripening tomato and frost-resistant strawberries, the first soybean crops from transgenesis arrived in European ports in 1996. GMOs intended for food and feed uses have met a very mixed reception in countries, particularly European ones, with a strong culinary tradition and productions under official quality signs (Frewer et al., 2013). As a result, their marketing in Europe is subject to prior authorisation, with a traceability requirement to ensure that consumers can exercise their freedom of choice, and to separate food from drug or industrial GMOs, and, finally post-marketing environmental monitoring for those authorised for cultivation (dissemination). Genetically modified plants are generally considered a sandbox of technologies that mobilise huge economic means and interests before applications to animals. They are characterised by a constant battle between retailers and seed companies to determine who effectively controls the food-processing supply chains, and require a labelling and traceability system, as it is the standard for food in the EU (Bertheau, 2013a, Bonfini et al., 2001; Corrado, 2016; Dwinger et al., 2007; Davison and Bertheau, 2008). Additionnaly, several stakeholders also question the definition of GMOs in front of new techniques for modifying genomes and epigenomes. In the meantime, citizens/consumers make a clear distinction through personal risk/ benefit analyses between GMOs intended for food and those intended for therapeutic applications.

GMOs are relative newcomers to food supply chains and are generally indistinguishable from homologs familiar to consumers. Thus, as previously seen, the various supply chains have developed reliable tools to identify their presence (industrial GMOs) and their (relative) absence in conventional products.

The controversy about transgenic GMOs has continued with the arrival of 'new techniques' of genome and epigenome modifications, the NBTs, that could lead to new products whose status would, this time, differ entirely from one world region to another. The controversy has also resurfaced with the recent rulings of the European Court of Justice (ECJ) and the French Conseil d'État (FCE), which recalled that, under the terms of Directive 2001/18, all products derived from in vitro techniques that had not been proven safe by a long history of use in 2001 were non-exempted GMOs. Besides the GMOs exempted from the application of the 2001/18 directive, we thus now have to distinguish the transgenic GMO, the 'hidden' GMOs (due to in vitro random mutagenesis) and the 'new' GMOs developed with NBT techniques.

The basic idea of transgenic, 'hidden' and 'new' GMOs is that life is a kind of large Meccano with interchangeable parts, a view reinforced by the large and rough syntenies observed between species. In this overall reductionist vision, 
the transfer of genetic or epigenetic information should be easy because of a simple correlation between genotype and phenotype. A trait would thus be easily transposable and reusable. Such a trait expressed in one gene pool would therefore be transferable, without difficulty, to another gene pool.

Indeed, the controversy reflects a Meccano understanding of the genome based on the molecular biology of the' 70 s and a risk-taking position, depending on whether or not unintentional modifications are taken into account as having impacts in unknown environmental circumstances (Deng et al, 2008; Ladics etal., 2015; Odorico et al., 2018; Weckwerth et al., 2004 ). For instance, this issue of considering or ignoring unintended changes raises the question of whether we should be concerned that a simple point mutation, a Single-Nucleotide Variant (SNV), can influence gene expression by distally altering regions' proximity of different chromosomes in our current understanding of genome structure and regulation based on Topologically Associated Domain (TAD) (Finn and Misteli, 2019). Similarly are silent mutations changing the proteins' 3D structure and enzymatic activities relevant to risk assessment (Anonymous, 2006; Chamary and Hurst, 2009; Kimchi-Sarfaty et al., 2007).

In this simplified view of genomes and epigenomes, the genomic data should have allowed the transfer of genes from one organism to another, hoping that the syntenies observed between species would allow easy transpositions of the corresponding sequences' behaviour. However, a substantial complexity had to be faced: the definition of genes is continuously evolving, and greater understanding has shown that genomes have a three-dimensional regulatory organisation with unexpected overlapping genes (Cattoni et al., 2017; 2015). Therefore, understanding the genotype-phenotype relationship currently remains a distant holy grail (Bennetzen et al., 2004; Gerstein et al., 2007; Jakobson et al., 2019; Portin and Wilkins, 2017; Scherrer and Jost, 2007; Yaish, 2017; Zhao et al., 2019). Regulation systems are far more complex than was expected in the 1970s (Gerstein et al., 2007, 2012; Hinman and Cary, 2017). An 'encoding' sequence can give rise to several different proteins by, for example, alternative splicing into cellular networks, by exon skipping or shuffling, intron retention, etc. that vary according to the cellular environment (Baralle and Giudice, 2017; Chaudhary et al., 2019; Clark et al., 2019; Dvinge, 2018; Park et al., 2018). Moonlighting proteins are proteins whose functions may differ according to the phase of the cell cycle (Chen et al., 2018; Jeffery, 2015; Singh and Bhalla, 2020). Finally, biotic environmental factors, such as the microbiota, for instance, are known to interfere differentially with the plant genotype, some being pathogens in vitro but not in vivo (Li et al., 2018; Quambusch and Winkelmann, 2018; Quiroga et al., 2017). All these factors are currently not considered in risk assessments and will not be for the new GMOs.

These numerous technical and biological bottlenecks affect the ability to rapidly and accurately transfer genes, traits and regulations from one species to 
another or even among cultivars of the same species. Despite this reality, a strong economy of promises has been developed around the NBT-derived products due to the enormous economic impact for seed companies, marketing patented seeds each year in a race towards some technical innovation (Zhang et al., 2016). This chapter will examine whether the current frame of GMO detection, presented in the previous chapter, fits the purpose of routine detection, identification and quantification of 'hidden' and 'new' (NBT derived) GMOs by (i) identifying the sources and targets of detection, (ii) proposing a routine detection scheme and (iii) let suspect the technique at the origin of the GMO.

\section{Background to 'hidden' and 'new' GMOs}

Transgenic, 'hidden' and 'new' GMOs, which are derived from NBT techniques and more particularly gene editing, have in common several in vitro steps whose importance in the GMO status has been recently reminded by the ECJ and FCE. We will mainly focus on nuclear changes, while numerous unintended modifications are also occurring in organelles.

\subsection{New breeding techniques}

NBTs do not have a formal definition, as it has varied since its first release. This term appeared in 2007 following questioning of the Commission by the Dutch COGEM ${ }^{1}$ as to the GMO status or not of products issued from various new techniques or from old ones renamed. In its first version, it included: the grafting of a non-GM scion on a GM grafting base, floral dip and agroinfiltration, and various techniques of modification of genomes and epigenomes by $\mathrm{OdM}^{2}$, $\mathrm{RNAi}^{3}$, alteration by nucleases (meganucleases, ZFN, TALEN, then CRISPRCas), null segregant, and finally synthetic biology with its multiple definitions (Regalado, 2015b; Schaart and Visser, 2009). They thus covered genetic, epigenetic and epitranscriptomic modifications, while only the genetic ones are assessed in the GMO notifiers' dossiers. At least some of them have recently been renamed 'New/Novel Genomic Techniques' by the European Commission. Without a long and proven safety record prior to 2001, most of them have been recognised to be GMOs since the 2018 ruling by the ECJ.

\subsection{Related techniques common to all the GMOs}

'Related techniques' involve all the in vitro techniques used for genetic and epigenetic modifications. These related techniques include (i) protoplastisation

1 GMO Risk Assessment Agency

2 Oligonucleotide directed Mutagenesis

3 Interfering RNA 
to obtain isolated cells, (ii) in vitro culture, (iii) delivery of reagents (DNA, RNA, or RNA-associated or non-RNA-associated proteins), (iv) the selection procedure of modifying cells, $(v)$ the elimination of these same selection markers for example by the Cre-Lox recombinase system, (vi) the callus differentiation, and (vii) the regeneration of seedlings before (viii) the habituation to culture conditions. All these mutations and epimutations follow a dynamic that has not been studied in detail until now (Bertheau, 2019; Filipecki and Malepszy, 2006; Lee and Seo, 2018; Mendizabal et al., 2014). However, these old-chapped related techniques still constitute a bottleneck in large-scale technique applications that have not been mastered, as recently noted (Ledford, 2016). They are the source of the 'somaclonal variation', a sum of genetic, epigenetic and epitranscriptomic unmastered changes.

Protoplastisation, obtained by the pectocellulosic wall degradation under controlled osmotic conditions, is the first stressing step toward isolated cell cultures and plant regeneration after genome and epigenome' modifications (Leva et al., 2012; Leva and Rinaldi, 2012). This protoplastisation and the subsequent culture stages induce a series of stresses, leading to somatic cell pluripotency by as yet unknown mechanisms (Bidabadi and Jain, 2020; Caboche 2010, Fehér, 2015). These culture stages induce point mutations and indels together with more extensive changes such as chromosomal rearrangements, aneuploidy, transposable elements mobilisation, endoreplication, chromothripsis, etc., which also cause sensu lato epimutations (Bednarek and Orłowska, 2020; Filipecki and Malepszy, 2006; Fossi et al., 2019; Henry et al., 2018; Lang and Schnittger, 2020).

All in vitro cultures of isolated cells, whether or not conducted for plant regeneration, induce somaclonal variation (random variations of genomes and epigenomes) usable in plant breeding (Bado et al., 2017; Bairu et al., 2011; Bidabadi and Jain, 2020; Filipecki and Malepszy, 2006; Karp, 1995; Krishna et al., 2016; Li, X.-O. 2017; Miguel and Marum, 2011; Smulders and de Klerk, 2011; Stebbins, 1950). This variation corresponds to the cellular response to exposure to different environmental stresses, with the 'environment' starting at the cellular cytoplasmic limit (Kucab et al., 2019; Perrone and Martinelli, 2020). It can be detected even after several generations at the genetic and transcriptomic levels and maybe later at the epitranscriptomic level (Bairu et al., 2011; Batista et al., 2017; Bregitzer et al., 1998; Flint-Garcia, 2013; Han et al., 2018; Henikoff and Greally, 2016; Li, 2016; Martínez, 2018; Miyao et al., 2012; Perrone and Martinelli, 2020). The transmitted stress memory can even lead cells and their descendants to 'choose' between proliferation and quiescence (Filipecki and Malepszy, 2006; Kedziora and Purvis, 2017; Nathans et al., 2021; Yang et al., 2017). Finally, transgenerational epigenetics plays a much more critical role in evolution than initially expected (Quadrana and Colot, 2016; Weigel and Colot, 2012; Yaish, 2017). 
Each isolated cell can lead to a homogeneous or chimeric regenerated plant, whatever the modification system used - RNA, DNA or RiboNucleoProtein (RNP) (Liu, H. J. et al., 2020; Meins Jr, 1983) - as it is also observed for animals (Hennig et al., 2020). An intercellular polymorphism develops because of the instability of genomes during cell multiplication phases towards plant regeneration, an observation similar to the chimaerism observed for monozygotic human twins (Jonsson et al., 2021). This chimaerism, induced before plant regeneration, remains unstudied for in vitro cultivated plants' characterisation and unnotified in petitioners' dossiers for risk assessment. The induced callus necessary for regeneration is more susceptible to mutations than a growing plant (Altpeter et al., 2016; Bidabadi and Jain, 2020; Wang et al., 2019). Extreme effects are also observable in the progeny, such as the chromothripsis observed for potatoes regenerated from protoplasts (Fossi et al., 2019; Henry et al., 2018; Koltsova et al., 2019). Indeed, chromothripsis micronuclei can be detectably transmitted to the progeny and induced by Cas9 SDN ${ }^{4}$ (Cullot et al., 2019; Fossi et al., 2019; Leibowitz et al., 2015, 2021).

Conversely, the culture conditions used for the micro-propagation of certain plant species aim to reduce to a minimum this somaclonal variation and the induced chimaerism, which can however still be identified (Aravanopoulos, 2003; Martínez, 2018; Ruffoni and Savona, 2013; Teixeira da Silva et al., 2007; Thorpe, 2013).

The delivery of reagents, whether DNA, RNA (messenger or not) or proteins (such as RNA-associated nucleases for CRISPR-Cas RNPs ${ }^{5}$ contaminated by foreign DNA of the multiplication organism DNA despite purification steps), is a highly empirical technical phase that induces genomic and epigenomic scars (Bertheau, 2019; Khalil, 2020; Ledford, 2016).

Transgenesis and genome and epigenome editing methods share these related techniques and their unintended effects. The scars left after the excision of selection markers from modified cells is only one example (Ates et al., 2020; Bertheau, 2019; Jansing et al., 2019; Manimaran et al., 2011; Marx, 2015; Miguel and Marum, 2011; Ruffoni and Savona, 2013; Scahill et al., 2008; Volkova et al., 2020; Yau and Stewart, 2013). Therefore, most of the authors consider it necessary for the NBT to avoid all these in vitro culture phases, but the suggested options have not proven themselves (Hamada et al., 2017; Maher et al., 2020).

Random changes in somaclonal variation have been known for a long time. Still, little use was made of them after a fad phase, because of the difficulties in screening for mutations, their unpredictability and trouble managing them due to their instability (Evans, 1989). These variations became 'easily' usable after 2000, with molecular markers using the TILLING technique on high-throughput 
and costly screening platforms, as previously seen. These identification tools are adaptable for characterizing a cultivar and thus a GMO or a class of GMOs (Bhargava and Sharma, 2013; Korir et al., 2013; Kwon et al., 2005; Matsaunyane and Dubery, 2018; Singh et al., 2019; Smith and Smith, 1992).

As long as one wants to take the trouble to identify the different resultant scars, there is no technical barrier to assemble mutations and epimutations in databases to differentiate organisms' spontaneous mutations, which are mostly neutral, or are induced in vivo or in vitro (Orr et al., 2020; Shahryary et al., 2020).

\subsection{Genome stability and stresses}

An organism is generally characterised by the transmission of an integrative genome acquired through a series of trial-and-error adaptations to an environment (Balestrazzi et al., 2020; Nisa et al., 2019). The majority of stressinduced mutations and epimutations are eliminated in different ways if the modifications are not neutral or are unsuitable for the environment, leading to the unviability of the organism (Daneva et al., 2016; Morrow, 1975). This stability of genomes and epigenomes is one of the bases of the evolution and differentiation of species. Thus, only a meagre number of mutations can accumulate, as observed for the Napoléon oak, which is not an isolated case when considering multi-millennia trees and natural clones (Kuhlemeier, 2017; Ledford, 2017; Orr et al., 2020; Schmid-Siegert et al., 2017). The biotic and abiotic stress-induced mutations and epimutations are transmissible and distinguishable from the spontaneous ones (Ashapkin et al., 2016; Bednarek and Orłowska, 2020; Hahn and Nekrasov, 2019; He and Li, 2018; Kellenberger et al., 2018; Perrone and Martinelli, 2020; Quadrana and Colot, 2016; Rath, 2018; Shahryary et al., 2020). The rates of mutations, conversions, recombinations, indels and heritable epimutations can vary by several orders of magnitude due to environmental stresses. These reactions to stresses can lead to hypermutation situations (Dulieu, 2005; Filipecki and Malepszy, 2006; Perrone and Martinelli, 2020; Rath, 2018; Reddy et al., 2020; Roberts and Gordenin, 2014). Mutations and induced hypermutations can thus persist as signatures of past events. Indeed, among the hitherto unexploited factors of variability generated by mutagenesis, we can cite (i) the differences in genomes' localisation, (ii) their predictability, (iii) the densities in the form of hotspots, (iv) their proximities, (v) their locations in regions frequently transcribed or not, non-coding and (vi) participating or not in structural rearrangements, according to (vii) plant lifetimes (Kumar et al., 2014; Renny-Byfield et al., 2017; Rodgers-Melnick et al., 2015, 2016; Schmid-Siegert et al., 2017).

All heterologous intra- or extracellular DNA induces 'immune' (and inflammatory) responses in plant and animal cells. Cells can differentiate the extracellular DNA, particularly self/non-self, through its methylation profiles, and 
be remarkably inhibited by the DNA of phylogenetically close plants (Monticolo et al., 2020). Intrusive and extracellular heterologous DNA and RNA significantly impact, in a dose-dependent way, the cellular reactions and genome and epigenome organisation (Bhat and Ryu, 2016; Monticolo et al., 2020). These reactions would be especially true when a foreign vector is used after it has gone through in vitro phases that modified its self/non-self-identification pattern. With the biological mechanisms of resilience to stress, such as DNA damage repair, being constitutive, it is evident that some genomic and epigenomic scars will be shared or even appear as methods' signatures. The boundary between the two unintentional modifications will sometimes be arbitrary.

Nevertheless, the management of these data at the organism level will always distinguish the 'natural' from the 'artefacts', affecting the genomes integrity (Bertheau, 2019; Biswas et al., 2020).

\section{Sources of detection targets}

Mutations and epimutations are sometimes detectable by phenotyping, but most often by ultra-deep sequencing and coverage and recently by Southern hybridisation (Holst-Jensen et al., 2016; Kishikawa et al., 2019; Mardis, 2013; Salk et al., 2018; Sims et al., 2014; Takabatake et al., 2020a). Reliable detection needs to use the nearest genomes and epigenomes as comparators, thus sequencing at some cost the original unmodified variety instead of comparing to a consensus genome in databases (Germini et al., 2018). The ability to detect those unintended changes also relies on representative and dependable genomes and epigenomes, distinguishing the 'core genome' and pangenomes (Hurgobin and Edwards, 2017). Even these reference genomes remain difficult to constitute due to the numerous defects of sequencing techniques such as the preparation of sequencing libraries, the somatic mutations, and chromosomal rearrangements, not to mention the PCR amplification errors and significant imperfections of software in assembling and comparing sequences (Bertheau, 2019; Bolukbasi et al., 2016; Ekblom and Wolf, 2014; Newman et al., 2020; Ravindran, 2018; Robin et al., 2016; Wienert et al., 2019). Building up genomes of quality is rare, even for human ones (Ballouz et al., 2019; Bertheau, 2019; Hart et al., 2014; Michael and VanBuren, 2020; Tello-Ruiz et al., 2021). Accordingly, claims about the absence of unintended changes in genomes and epigenomes have to be examined with a very critical mind.

More generally speaking, most of these NBT, such as grafts between GMO and non-GM scions, have been very quickly recognised as generating GMOs by exchanging nucleic acids, organelles and epigenetic modifications (Hertle et al., 2021; Stegemann and Bock, 2009; Tsaballa et al., 2021; Warschefsky et al., 2016). Some transient expression techniques have also been shown 
to induce unintended insertional modifications depending on the target (protoplast, callus, tissues or the whole plant) (Canto, 2016; Tyurin et al., 2020). They are also considered GMOs by their requirement of GM expression vectors providing signatures of the method (Tyurin et al., 2020). Agroinfiltration and floral dip, initially included in NBTs for transient expressions or tissue transformations without cell cultures, mostly lead to chimaeras, despite various improvements, and form parts of a 'new' GMO signature (Maher et al., 2020; Matsuo et al., 2016; Zhang et al., 2020). In some cases, the need to use several techniques simultaneously generates superimposed scars and signatures, including plastids, while the extracted compounds are contaminated by toxic compounds and DNAs (Boettcher and McManus, 2015; Komarova et al., 2010; Mao et al., 2018; Schillberg and Finnern, 2021; Tusé et al., 2020; Tyurin et al., 2020). RNAi may result from the GMO producing, for instance, dsRNA instead of toxic protein or sprays, targeting several non-target organisms (NTO) (Ivashuta et al., 2015; Khajuria et al., 2018). Due to numerous false positives, the accurate detection of those GM products may be difficult despite their numerous off-targets and other unintended modifications (Potrykus, 1991; Marine et al., 2012).

Negative segregants are GMOs because they are derived from GMOs. Therefore, they carry the original GMO scars and signatures due to cell culture and related techniques (Bregitzer et al., 1998; Wada et al., 2020). Finally, cisgenesis and intragenesis also lead to GMOs because they involve the in vitro manipulation of DNA and cell cultures that did not have a long record of safety before 2001 while containing the usual scars and signatures. Moreover, the in vitro manipulation of DNA erases the self-non-self patterns that induce immune responses of plant cells. The origin of the introduced sequence(s) thus does not change the unintended effects and legal nature.

We will now focus on still disputed GMOs such as 'hidden' and 'new' GMOs. From a holistic point of view, of all kinds of GMO detection, four sources of detection are discernible, that is, (i) the selection signatures of cultivars and germplasms, (ii) the internal signatures of sequences used by laboratories for transforming plant cells, (iii) the scars due to the related in vitro techniques and finally, (iv) signatures resulting from the intended and unintended changes due to NBT techniques.

\subsection{Domestication syndrome and selection}

The repeated traditional selection over 10000 years has left selection signatures of human pressures in the peasants' landraces and the companies' cultivars (McLean-Rodríguez et al., 2021).

Indeed, the variability between Elite inbreds and correlated germplasms can reach tens of millions of detectable SNPs to be managed for identification 
and genomic selection (Flint-Garcia, 2013; Hake and Ross-Ibarra, 2015; Wilkesa et al., 2016). The selection signatures of both Elite and commercial varieties, which differ, organised with the in vitro numerous scars and signatures, will constitute the first data usable in identifying the natural or artefactual status of modifications (Flint-Garcia, 2013; Grainger et al., 2018; Hill et al., 2021; Olsen and Wendel, 2013a, b; Slotte, 2014; Xie et al., 2015). Due to the complex breeding schemes, whose results are more or less well predicted by modeling, germplasm uses are generally well correlated with seed companies' habits, available material, and know-how (Beckett et al., 2017; Cobb, 2019; Glenn et al., 2017; van Heerwaarden et al., 2012a,b). This ascending traceability is complementary to species typology accessible to the various techniques, which could be part of a screening stage after the integration into, e.g., decision support systems (Jansing et al., 2019).

Integrating a new trait resulting from the genetic or epigenetic modification of a more or less-related species into a commercial line requires introducing it beforehand into one or more of these Elite varieties. Nevertheless, the behaviour of this new trait in an Elite variety is difficult to predict (Crossa et al., 2017; Evangelou et al., 2019), because the genetic distance between the Elite types may be, as for corn, comparable to the one between humans and chimpanzees and because prediction tools are still not accurate. Possessing a detailed knowledge of the behaviour of Elite varieties, for which only recently a few reference genomes have been available, is therefore an absolute necessity in plant breeding (Flint-Garcia, 2013). This gene pool remains the most influential factor in the expression of introgressed traits, whatever the reign of the living world considered (Evangelou et al., 2019; Flint-Garcia, 2013; Fu et al., 2021; Mumm, 2013).

These selection signatures are a primary element of suspicion of a mutated origin of diversity, available even for unknown GMOs.

\subsection{NBT and transgenesis reagents delivery and expression tools}

The efficient delivery and expression of transgenic and NBT products is still a challenge for 'laboratory' cultivars and experienced explants. Therefore, laboratories are using the same, somewhat mastered methods of delivery, gene expression, and transformed cell selection, together with the previously experimentally tested culture conditions and regeneration media. Altogether, the sequences of the delivery and expression cassette constitute a signature of the biotech laboratories, and even of the people that have transformed the isolated cell plants (Alley et al., 2020; Nielsen and Voigt, 2018).

Agrobacterium is the most efficient delivery system with a low number of inserted copies and better stability of the insertions, but with residual evident 
scars (Bertheau, 2019; Matsaunyane and Dubery, 2018). The DSB ${ }^{6}$, induced by the insertion of Agrobacterium sequences or biolistics, generates other kinds of identifiable genomic and epigenomic scars, as performed by foreign invasive DNA and gene-editing techniques. Therefore, bacterial plasmids and chromosomal insertions, and further rearrangements or epigenetic modifications are usual in the modified plant pangenomes (Ahmad et al., 2020; Anderson et al., 2016; Bortesi and Fischer, 2015; Dalla Costa et al., 2020; Filipecki and Malepszy, 2006; Fossi et al., 2019; Gelvin, 2008; Grabowska and Filipecki, 2004; Gorbunova and Levy, 1999; Hahn and Nekrasov, 2019; Hilscher et al., 2017; Ito and Machida, 2015; Perrone and Martinelli, 2020; Reddy et al., 2020; Serrano-Benítez et al., 2020; Ulker et al., 2008; Vítor et al., 2020). Additionally, the delivering Agrobacterium strains used all belong to biovar 1, for which a signature PCR detection test is available (Gelvin, 2003; Keane et al., 1970; Spiridonova et al., 2009). Many of the transformation strains contaminating the modified genomes share the same genetic background and delivering plasmids. Such specificity can differentiate these reagents' vectors from the scars of aborted infections by natural strains (De Saeger et al., 2020; Tyurin et al., 2020).

Biolistics, the other most-used delivery system for genetic and epigenetic modification reagents, has been used for many commercially available transgenic maize varieties. The small fragmented inserts allow easy suspicion of the delivery system (Harkess, 2019; Latham et al., 2006; Takabatake et al., 2020a, b; Yadava et al., 2016). The use of microinjections, electroporation, viral vectors, polyethylene glycol nano vehicles, needles and other exotic reagents as delivery methods also provides signatures, such as chromosomal rearrangements, in nuclei and organelles for several generations, for example, as episomes (Bertheau, 2019; Burgio and Teboul, 2020; Dalakouras et al., 2020; Filipecki and Malepszy, 2006; Jansing et al., 2019; Lacroix and Citovsky, 2020; Liu et al., 2019; Lv et al., 2020).

Indeed, the delivery system of DNA, RNA (interfering, messenger, etc.) or RNP is contaminated by foreign DNA because of its preparation in other living organisms. Therefore, this DNA can be found in the 'edited' genome of modified protoplasts, as it has also been observed in animal cell cultures (Bertheau, 2019; Norris et al., 2020; Ono et al., 2019). In general, authors using 'DNA-free' reagents do not apply the minimum purification criteria such as those for 'Minimal Information for Protein Functionality Evaluation' (MIPFE) proteins (Raynal et al., 2014; Tan and Yiap, 2009; Zhang and Heyer, 2011). Since even the most purified commercial enzymes are DNA-contaminated, it is disgraceful to assert that RNP deliveries are DNA-free and that no foreign sequences have been inserted in the plants' genome and more generally speaking that NBT techniques do not leave contaminating DNA in the genomes of edited plants (Bertheau, 2019).

6 Double Strand Break 
The foreseen success did not follow the initial claims about the interest of OdM, genome editing by meganucleases, floral dip and agroinfiltration. They became relatively anecdotal with the arrival of faster, more effective and 'cheaper' techniques. The lack of reproducibility or versatility, low conversion frequency and DNA integration is also challenging (Anderson et al., 2008; Birch, 1997; Buehler et al., 2012; Germini et al., 2018; Housden and Perrimon, 2016; Potrykus, 1991; Raitskin et al., 2019; Riba et al., 2017; Sheel and Xue, 2016; Smits et al., 2019; Svoboda, 2020; Wang and Yang, 2019). As exemplified by the Cibus herbicide tolerant canola case, OdM-induced modification, a 30-year-old technique, has clearly not been meeting, up to now, the hopes initially placed on its use for plants.

The current literature hardly retains any NBTs on plants, other than the improperly named genome editing techniques, using nucleases such as ZFN, TALEN and the numerous orthologs and variants of the Cas9 nucleases (dCas9, hCas9, HypaCas9, etc.) fused or not with other enzymes' sequences (Yee, 2016). However, there are technical difficulties in applying these techniques, which require numerous and complex optimisations of the types of reagents and delivery methods, taking into account the targeted species and tissues, the use of optimimized codons and the choice of promoters and inhibitors, for example, for Cas9 and gRNA expressions (Moon et al., 2019). These differences in optimisations and activity controls contribute to the diversification of scars and signatures of the techniques used and of the laboratories that perform them (Alley et al., 2020; Nielsen and Voigt, 2018).

More generally, any sequence insertion (endogenous or heterologous, and therefore trans-, cis- or intragenesis) in the genome is accompanied by genetic and epigenetic unintentional modifications, sometimes distal, which are identifiable patterns even for unknown GMOs (Ashapkin et al., 2016; Filipecki and Malepszy, 2006; Kosicki et al., 2018; Ledford, 2020; Sullivan et al., 2015). This is in line with the self/non-self DNA and RNA recognitions (Monticolo et al., 2020).

In conclusion, all artefactual processes and tools, such as delivery systems, delivered sequences, culture media, and NBT by themselves are leaving numerous indices of all that has happened during cell cultures, transformation, selection and plant regeneration. This information can be scrutinised and managed by tools such as artificial intelligence.

\subsection{Technical scars of mutageneses}

Scars are the set of genetic, epigenetic (DNA methylation and the 'histone code') and epitranscriptomic (RNA changes) modifications associated with the in vitro techniques on isolated cells. Certain scars may constitute specific signatures of the mutagenic agents or processes used (Destefanis et al., 2021; Filipecki and Malepszy, 2006). For instance, the Single Methylation Polymorphism 
(SMP), an underused polymorphism, includes a set of markers transmissible in plants, as impressive as Single Nucleotide Polymorphism (SNP) or MNV', with different patterns related to the genetic characteristics (Ashapkin et al., 2016; Becker et al., 2011; Cattoni et al., 2017; Degalez et al., 2021; Schmitz et al., 2013; Wilkesa et al., 2016). Transgenesis and genome and epigenome editing methods share these related techniques and their unintended effects. As seen above, the delivery systems and delivered sequences leave numerous specific genetic and epigenetic scars.

As already mentioned, the selection of transformed cells remains topical due to the low transformation and regeneration efficiencies. Moreover, due to consumers' fears and the Agencies' recommendations, most of the authors attempt now to remove some of them by, for example, the Cre-Lox recombination, thus leaving new specific scars (Ates et al., 2020; Bertheau, 2019; Germini et al., 2018; Jansing et al., 2019; Miguel and Marum, 2011; Ruffoni and Savona, 2013; Volkova et al., 2020; Yau and Stewart, 2013). While antibiotic resistance and herbicide tolerances are less used due to the challenge of meeting the risky demands by the Agencies and consumers, other nonsensitive selection genes, such as phospho-mannose isomerase, are likely to be found in Elite and commercial varieties (Que et al., 2014; Yadava et al., 2016; Yau and Stewart, 2013). Therefore, most authors consider it necessary to drastically increase plant transformation efficiency or avoid all these in vitro culture phases, but the suggested options have not proven themselves to avoid or discard these transformed cells' selection signatures (Hamada et al., 2017; Maher et al., 2020).

In several instances, similar to the specific cultivars used for many purposes, several protocols and expression cassettes have become almost the standard for plant transformation and regeneration (Que et al., 2014; Yadava et al., 2016), which induce similar scars manageable by, for example, artificial intelligence or other tools used in plant breeding (Alley et al., 2020; Kim et al., 2020; Nielsen and Voigt, 2018; Tong and Nikoloski, 2021).

As chromosomal rearrangements and chromothripsis have been observed due to related techniques or the action of CRISPR-Cas nucleases and somaclonal variation (Comai and Tan, 2019; Fossi et al., 2019; Leibowitz et al., 2015, 2021), the borderline between scars and signatures may therefore be tenuous in some cases, even if the qualification does not matter, for identifying genetic and epigenetic artefactual modifications.

\subsection{Mutageneses' signatures}

By signature, we mean either an unambiguous signature such as the border fragment of a random insertion in transgenesis, or a convergent set of data 
leading to a specific identification. It is likely, bearing in mind that there are differences between animals and plants, that many of the known results in animals are valid for plants. This section will examine the signatures left by the several mutagenesis techniques applied to isolated cells - the in vivo random mutagenesis providing exempted GMOs.

Organelles, such as chloroplasts, genomes and epigenomes, participate in stress tolerance, such as heat, but are rarely studied (Ahmad et al., 2017; Liberatore et al., 2016; Wallace, 2016; Wu et al., 2020). The organelles' scars and signatures can be used in GMO identification as memories of past phenomena, especially since tiling microarrays allow exploring their genomes ( $\mathrm{Hu}$ et al., 2020; Żmieńko et al., 2011). They are already involved in cultivar identification. However, we will focus below only on nucleus signatures.

\subsubsection{Somaclonal variation and transgenesis}

The frequencies of mutations and epimutations due to somaclonal variation are still relatively low. According to the IAEA, it is usual to increase them up to one million ${ }^{8}$ times by adding chemical or physical mutagens (Brash, 2015; Dulieu, 2005; Kovalchuk et al., 2000). The development of the in vitro techniques has allowed such a switch from the previous in vivo techniques (Maluszynski et al., 1995, 2000). However, as already mentioned earlier for the somaclonal variation, the in vitro resulting mutants were effectively used in plant breeding schemes only after the TILLING method's publication (McCallum et al., 2000a; Tadele et al., 2009; Kurowska et al., 2011). These mutagenesis techniques are already covered in a previous chapter of this book.

\subsubsection{In vitro-induced random mutageneses}

The signatures of various events suffered by in vitro and in vivo animal and plant cells can be differentiated, for example, by exposure to UVA and B, infrared, free radicals, etc. (Doitsidou et al., 2016; Flibotte et al., 2010; Lehrbach et al., 2017; Li et al., 2015; Roberts and Gordenin, 2014; Smith and Yun, 2017; Vítor et al., 2020; Volkova et al., 2020; Xu et al., 2016). The changes induced by genotoxic agents, such as benzo(a)pyrene, hydrogen peroxide, aflatoxins, ethyl methanesulphonate (EMS), ${ }^{9}$ UV or N-ethyl-N-nitrosourea (ENU), can also be mapped (Brash, 2015; Burns et al., 1986; Doitsidou et al., 2016; Fitzgerald et al., 2017; Flibotte et al., 2010; Kim et al., 2006; Kucab et al., 2019; Lehrbach et al., 2017; McCarthy et al., 2020; Saini et al., 2020; Segovia et al., 2015; Sikora et al., 2011; Simon et al., 2015; Volkova et al., 2020; Wei et al., 2021). 
Although unstable because they are in high demand, some molecules, such as rDNA, could protect against mutations due to EMS and UV (Dvořáčková et al., 2015). Large deletions can be induced at the same locations (fragile chromosomal sites/recombination hotspots) by various mutagenesis agents such as EMS, fast neutrons, T-DNA, and X-rays, which could result from an ancestral recombination event (dela Paz et al., 2012; Filipecki and Malepszy, 2006; Rodgers-Melnick et al., 2015). Induced random mutations can lead to hypermutations, with some mutated sites appearing particularly unstable in cell cultures (Durkin and Glover, 2007). Identifying these sites, particularly in active gene areas, can constitute the signatures of events in the affected cells.

Several other biotic and abiotic mutagenic stresses such as drought and heating induce dramatic changes that are transmitted (Fleta-Soriano and Munné-Bosch, 2016; Jaligot and Rival, 2016; Probst and Mittelsten Scheid, 2015; Wibowo et al., 2016). Chemical, biological and physical mutagens add a new layer of mutations and epimutations whose types, locations and frequencies may be differentiated from the somaclonal variation-induced changes.

\subsubsection{NBT signatures}

As Stella and Montoya (2016) remind us, it is technically difficult and costly to attempt detection by sequencing low- and medium-frequency off-targets. Moreover, off-target detection capabilities vary significantly for the same sgRNA, gene-editing technique and the use of biased or 'unbiased' detection methods (Martin et al., 2016; Newman et al., 2020). Unintended modifications also vary between clonal cells, while unintended changes are searched only in the cell populations, thus diluting the low-frequency unintended changes (Kimberland et al., 2018; Sentmanat et al., 2018). Therefore, it is illusory to assert, as it is often done by several authors and stakeholders, that there would be no offtargets in a modified cell and that they will not be found in the progeny (Kang et al., 2020; Stella and Montoya, 2016). RNAi and ncRNA also induce many unintended effects, which can be used to identify processes (Ramesh, 2013; Ramon et al., 2014; Svoboda, 2020).

The size of the recognised/targeted sequences (on- and off-targets) differs between nuclease-based NBTs. Systematic on- and off-targets in the vicinity of, for example, a PAM sequence or of ZFN and TALEN-binding sites would constitute such a pattern signature. Additionally, targeted sequence sizes differentiate ZFN, TALEN and CRISPR-Cas techniques (see Fig. 1 for more details; Janik et al., 2020), as also shown for example, for the length of the artificial TALEN ${ }^{10}$ cleaving site (half-site 14-20 nt - Fokl site 14-24 nt - half-site

10 https://www.medecinesciences.org/en/articles/medsci/full_html/2014/02/medsci20143002p186/medsci20143 002p186.html 
14-20 nt) (Ahmad et al., 2020; Khalil, 2020). Moreover, specific sequences can be found near and at the enzyme cleavage and homologous sequence sites (e.g. different Protospacer Adjacent Motif (PAMs) for different GC contents in genomes, zinc finger sequences for ZFNs, etc.). More detailed studies should make it possible to define unambiguous signatures of nucleases such as those identified for Cas9 and Cas12a (Wienert et al., 2019). The repair of the double-stranded cut caused by Cas9 would modify the degree of CGp islet methylation in the case of the Homology-Directed Repair(HDR) but not the NonHomologous End-Joining (NHEJ) DNA repair mechanisms (Farris et al., 2020). Particular sequence-specificity of the DSB cut sites can also be distinguished (Molla and Yang, 2020). TALEN's Fokl nuclease cuts require a T in the 5 ' terminal position. TALEN also recognizes methylated cytosines compared to CRISPRCas. The reagents are also differentiated by their chromatin affinity sites (Jain et al., 2021). SMP polymorphism and its effect on genetic modification on Differentially Methylated Regions (DMRs) have not yet been studied in this case (Eichten and Borevitz, 2013; Li, Y. et al., 2017; Schmitz et al., 2013). All these 'subtle' but clear differences between nuclease-based gene-editing techniques are amenable in scars and signatures databases. The bioinformatic screening of these zones is manageable despite the thousands of PAM sequences or sequences recognized by ZFN and TALEN, which can be monitored, compared to the tens of millions of SNPs used in GWAS ${ }^{11}$ (Flint-Garcia, 2013; Li et al., 2020).

The vast number of publications on improving the specificity and efficiency, and reducing the number of off-target or unintentional on-target modifications show the widespread accidental side effects of NBT techniques (Rezza et al., 2019). In most cases, we are unable to affirm that they are not scars from in vitro cultures and related techniques (Ahmad et al., 2020; Anderson et al., 2008; Cullot et al., 2019; Gauchier et al., 2020; Germini et al., 2018; Kawall et al., 2020; Khan et al., 2017; Naeem et al., 2020; Newman et al., 2020; Peng et al., 2016; Thomas et al., 2019a, b; Wienert et al., 2019). Our inability to master these techniques is such that it is still recommended to continue working with TALEN for some species rather than with CRISPR-Cas (Jain et al., 2021; Khalil, 2020).

The method of delivery of nucleases may also play a role in leaving a distinct signature or scar. For instance, when expressed via a plasmid, a highly specific Cas nuclease may be disappointing when delivered as an RNP (Ates et al., 2020). Depending on the applied dose, RNPs can generate different amounts of microdeletion signatures (Momose et al., 2018). Similarly, the delivery of TALENs as either DNA or mRNA impacts the unintentional modifications (Jansing et al., 2019). Once again, a systematic study on the same model of the three forms of reagents (DNA, mRNA and RNP) of the nucleases and their variants should 


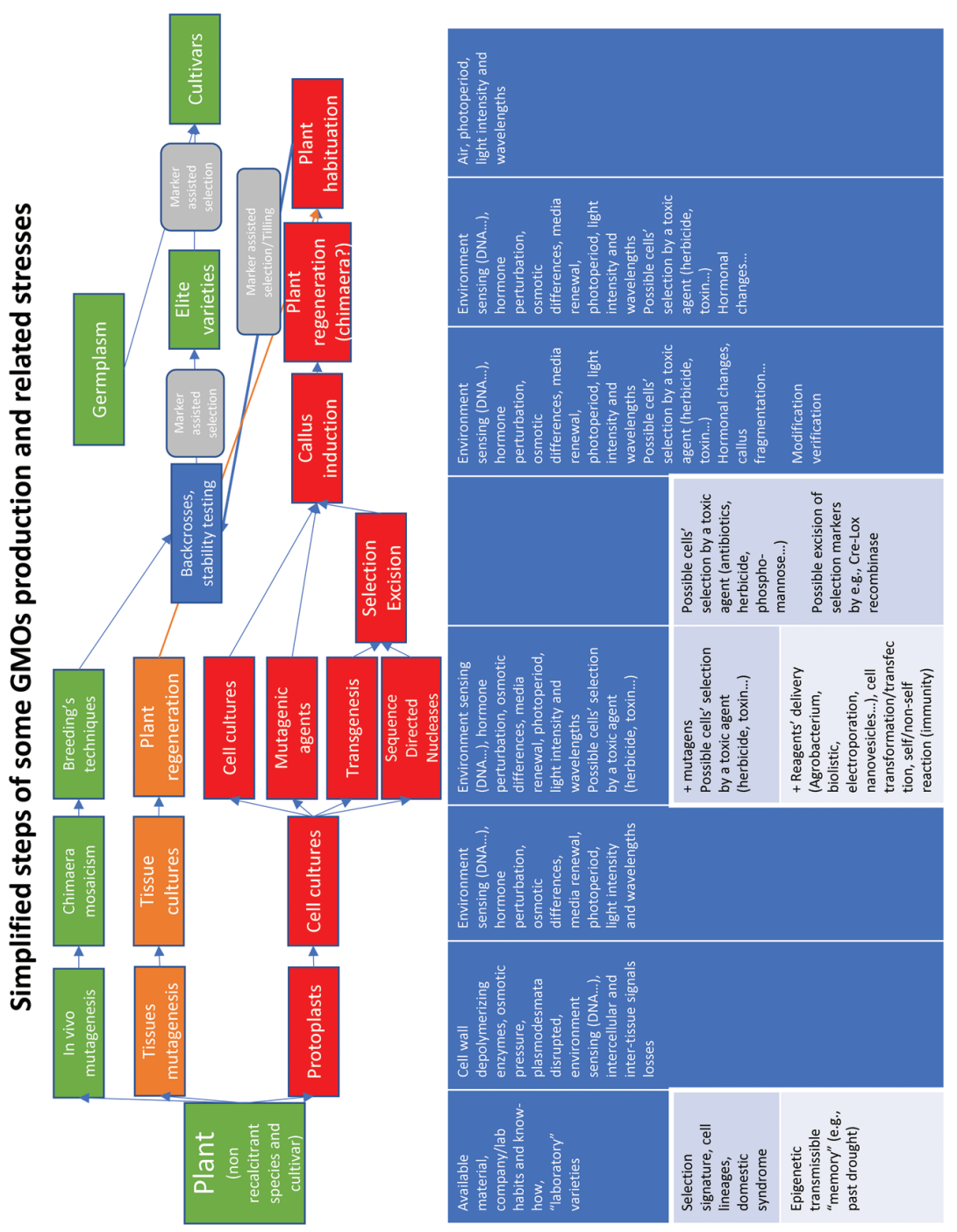

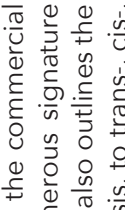

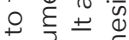
ते ब) $>$ 更 $\frac{\pi}{2}$ तล ò $\frac{1}{\pi} \varepsilon$



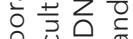
त 0 +8 잉


$=\frac{0}{0} \frac{0}{0}$ 는 तु

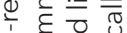
ᄃ $\ulcorner$ 일 ๑.

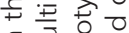
ह $+\frac{\pi}{+} \simeq$ in $0+0$ 开 $\varepsilon+\stackrel{5}{\pi}$ . 3 in 0

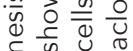
ป O) एँ $\subseteq \varepsilon$ $\varepsilon$ o $+5 \pi$ $\frac{\pi}{2} \dot{0} \pm \frac{5}{0}$

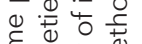

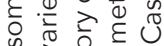
प ह $\frac{\sim}{\sim}$

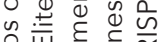
过峲 क त क क i)


勿造过

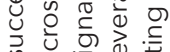
的的 $\stackrel{0}{5}+0$ 는 둥 웡 त्रे $\frac{1}{0}$ हो

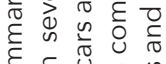

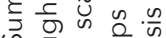

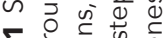
o 은 
establish a typology that can be used to identify the NBT used. Moreover, the RNAs used generally contain DNA that either contaminates or stabilises the RNAs to be introduced (Bertheau, 2019; Jansing et al., 2019). As already noted, the stabilising DNA from these frequent DNA/RNA hybridizations can integrate into the genome even during transient expressions. Therefore, the knowledge of reagent delivery through patents and risk assessment dossiers would help identify the residues and scars of these modifications.

The integration sites can also participate in the signature patterns: as in transgenesis, SDN3-type integrations, which induce many unintended effects (Schnell et al., 2015), aim to target a 'safe harbour', such as AAVS1 and Rose26 in animals, for stable insertion and expression. Such safe harbours are quite unknown in plants, except possibly in one case of rice, but systematic studies would most likely identify new ones (Altpeter et al., 2016; Cantos et al., 2014; CGB, 2004; Papapetrou and Schambach, 2016; Pérez-González and Caro, 2019; Schaart et al., 2016). Insertions at these locations actively sought by breeders would participate in the signature of an artefactual event. Otherwise, integrations are almost performed at rearrangement, gene-rich sites, distal and often telomeric and subtelomeric chromosomal regions (Filipecki and Malepszy, 2006; Svitashev and Somers, 2002). These are fragile areas, such as telomere derived ITRs, some of which are recombination hotspots or teloboxes (Aguilera and García-Muse, 2013; Dvořáčková et al., 2015; Yaish, 2017). Such characteristics may also be a part of the set of signatures or scars of genetic and epigenetic changes.

Nuclease-encoding DNA insertions are still the most efficient modification system. Such an insertion-based system imperatively requires regulation (induction or repression) systems of gene expression to avoid further unintentional cuts (Canny et al., 2018; Chen et al., 2017). Alternatively, the Cas inhibitors may also be inserted (Davidson et al., 2020; Marino et al., 2020). Such inhibitory or regulatory systems can then be retrieved as signatures in the progeny of modified plants.

The variants of the nucleases (dCas9, prime editing, base editor, etc.) do not seem to modify the ability to identify signatures. Moreover, these variants can also increase the frequency of off-targets (Jansing et al., 2019). Indeed, modifications of enzymes such as a base editor would cause up to 20 times more off-targets than Cas9. Some of these techniques that work well in cellfree systems are disappointing when applied to in vitro cultures due to the interference of cellular mechanisms and many unintended alterations and offtargets are then generated (Ahmad et al., 2020; Ates et al., 2020; Jin et al., 2019; Zuo et al., 2019).

Careful sequencing allows the detection of other unintentional modifications (Frock et al., 2015), which, like off- and on-target effects, depend on many factors (Modrzejewski et al., 2020; Modrzejewski et al., 2018; Modrzejewski 
et al., 2019). These unintended effects, the sources of signatures, appear more frequent than initially expected, despite the lack of strategies to detect them (Burgio and Teboul, 2020). Their exceptionally high number leads to what some have called 'genome chaos' (Ledford, 2020). In other cases, the number of copies which participate in the signature may increase (Skryabin et al., 2020).

As the number of genes to be incorporated in the germplasm increases, the associated breeding programs become more complex. It is, therefore, desirable for plant breeders to integrate at one time multiple traits at a few defined loci, preferably safe harbour, to facilitate subsequent breeding efforts. This proximity of stacked traits will be in itself a sign of an artefactual modification transmitted to the progeny. Moreover, the SDN3 or transgenic stacks could be gathered in clusters and delivered by a stack vector rather than being brought about by intricate crosses of Elite varieties which is another kind of artefactual signature (Glenn et al., 2017; Que et al., 2014).

The combination of sequencing, off-target prediction software, and other tools, such as artificial intelligence, would allow such NBT-induced modifications to be easily identified (Billon et al., 2020; Manghwar et al., 2020; Ravindran, 2018).

\subsection{The issue of false positive}

As in any mutagenesis technique, false positives of NBT are numerous, while reproducibility is not the topical aim of biotechnologists (Bortesi and Fischer, 2015; Lomov et al., 2019). The reality of the transformation must be verified because somaclonal variation can, in some cases, account for the observed phenotype (e.g., tolerance to an herbicide) (Anderson et al., 2008; Birch, 1997; Liu et al., 2012; Potrykus, 1991).

Numerous false positives and unintended effects undermine the reliability and acceptance of these techniques, as recently observed for Cibus' canola (Dong and Sharp, 2007; Oh and May, 2001; Ruiter et al., 2003; Voosen, 2010). The Cibus canola was one of the herbicide-tolerant crops ('hidden' GMO), which led to the 2015 French legal suit. Since 2003, Cibus seems to be the only company to continue using the OdM technique on plants, a proprietary method called RTDS ${ }^{12}$ with more than 300 patents claimed (Beetham et al., 1999; Beetham et al., 2014). The announced success led to the commercialisation of sulphonylurea-tolerant rapeseed that was the subject of an intense advertising and lobbying campaign with the European authorities (Editorial, 2015, 2017a; Fladung, 2016; Gocal, 2014; Hartung, 2020; Sauer et al., 2016; Songstad et al., 2017). However, following the publication of an article describing how to detect it (Chhalliyil et al., 2020), this canola was 'downgraded' by the company 
and Canadian Agencies to the status of an in vitro culture somaclone. This falsepositive joins the doubts expressed for years by various authors on this NBT technique's efficacy in plants (Dong and Sharp, 2007; Ruiter et al., 2003). As for Cibus, pressed by a concern for a rapid return on investment, companies may even patent data that do not correspond to the technical and claimed reality (CGB, 2004; Seymore, 2018), which can lead to wrong tracks in detecting these products and, at the very least, waste much time and money. Distinguishing and quickly eliminating these false positives and negatives is essential to assess the reliability of the candidate scars and signatures for the detection/identification of NBT products. Currently, scientific papers and patents do not appear reliable enough, meaning that the analysts will have to gather experimental data unless mandatory legal obligations are set out.

New techniques for modifying genomes and epigenomes require either tissue transformations (in vivo or in vitro) or in vitro cultures of isolated cells. The latter is generally preferred for the supposed absence or reduction of mosaicism in regenerated plants. This superimposition of unintentional modifications of the different steps increases the difficulties of correlation between genotype and phenotype by its numerous false positives or negatives. Therefore, the interpretation of the results may be doubtful about the mode of production, generally presented in an opaque manner in patents (Seymore, 2018), as is reminded by the Cibus herbicide tolerant canola's recent case. Aware of this problem, the European Patent Office (EPO) has recently clarified the claims to be made by applicants (Part F IV 23): 'If a technical feature of a claimed plant or animal, e.g. a single nucleotide exchange in the genome, might be the result of either a technical intervention (e.g. directed mutagenesis) or an essentially biological process (a natural allele), a disclaimer is necessary to delimit the claimed subject matter to the technically produced product (see examples in G-II, 5.4.2.1, and G-II, 5.4). For the general principles governing disclaimers see $\mathrm{H}-\mathrm{V}, 3.5$, and $\mathrm{H}-\mathrm{V}, 4^{\prime}$.

In other words, due to the extreme lack of transparency by companies, applicants will have to specify with their patent claims the techniques which they effectively used to obtain their product.

\section{Transmission of detection targets towards commercial varieties}

GMO proponents generally argue that unintended changes due to GMO production on non-recalcitrant genotypes and explants will be discarded during the time-consuming and costly backcrosses toward Elite varieties, which are the head of germplasms and commercial cultivars (European Group on Ethics in Science and New Technologies (EGE), 2021; Haut Conseil des Biotechnologies (HCB), 2017; Scientific Advice Mechanism (SAM), 2017). 
However, the claim about the interest of this 'cleaning' step is counterbalanced by the contradictory wish of breeders to transform Elite varieties directly. In any event, the currently available data are not in favour of the efficiency of backcrosses to discard unintended changes, as we will see below.

\subsection{Examples of the persistence of genomic and epigenomic scars and signatures through the backcrosses}

Genetic and epigenetic modifications are primarily carried out on 'laboratory varieties', whose specific explant material is easily transformable and regenerable (Bidabadi and Jain, 2020; Birch, 1997; Rao et al., 2009). New trait(s) of interest are then introduced by backcrossing into Elite varieties before their transmission, through elaborate breeding schemes, into germplasm and commercial varieties (e.g. B73 is a founder of the Stiff Stalk germplasm pool of maize, while PH207 is a founder of lodent germplasm). These 'laboratory varieties' (such as Hi-ll (High type II callus production) for maize, Topaze for rapeseed, Golden Promise for barley, etc.) are quite widely used in the same way, according to the breeding companies' practices and know-how (Harwood, 2012; Lowe et al., 2016; Yadava et al., 2016). Therefore, it would be possible to trace back to Elite varieties and 'laboratory varieties' using the subsets of the markers used in the ISO and UPOV ${ }^{13}$ standards of cultivars' identifications, as already seen for lab source and selection signatures (ISO, 2019a,b,c, 2015; UPOV, 2019a, b,c,d,e; 2011).

The general absence of whole-genome sequencing of transformed, Elite and commercial varieties and the wider consideration of the weaknesses in genome-wide variability and sequencing procedures make it impossible to judge the reality of the theoretical efficiency of genome cleaning by backcrossing, (Bayer et al., 2020; Danilevicz et al., 2020; Faino and Thomma, 2014; Golicz et al., 2020; Kang et al., 2020). Imperfect consensus genomes are also used for 'unbiased' approaches for detecting off-targets and other unintended modifications. Sequencing depths generally remain too shallow, while fragment assembly and sequence comparison still show many weaknesses (Bertheau, 2019; Cleary et al., 2015; Datta et al., 2010; Steinegger and Salzberg, 2020). Thus, the sequence biases remain too numerous to assert that non intentional mutations are eliminated by backcrossing.

The national and regional agencies require several plant generations to assess the genomes' stability of 'transformation events' in risk assessment. However, seven backcrosses are generally considered necessary, in an ideal genetic context (i.e. with only sequences segregating according to Mendelian laws), to achieve $96-98 \%$ genome similarity between the 'converted' variety

13 https://www.upov.int/meetings/en/details.jsp?meeting_id=50791 . 
and the original Elite line, which would then be near-isogenic, ${ }^{14}$ according to the accepted expression. Even in the case of backcrossing, of supposedly fully independant traits or genes i.e. without haplotype etc., to reach the theoretical limit of about $98 \%$ varietal purity, more than 500 million base pairs in the case of wheat would not be affected by this genome 'cleaning' (Baltes et al., 2017; Bertheau, 2019; Glenn et al., 2017; Hedman et al., 2018; Holland, 2007; Hollick, 2017; Kumar et al., 2014).

Generally speaking, the number of backcrosses needed to approach this theoretical purity varies according to numerous factors such as (i) the size of the haploid genomes, (ii) the pangenomes and (iii) degrees of ploidy, (iv) the alleles and pseudoalleles involved, ( $v$ ) the number of known traits to be introgressed and conserved, ( $v i)$ the sizes and loci present in the non-Mendelian segregated regions, (vii) the proximity between the trait to be introduced (linkage drag) and those to be eliminated, (viii) the type of gene involved (plant defence reaction genes), (ix) the autogamy or not of the species or ( $x$ ) the meiotic drive, among others (Ashapkin et al., 2016; Bertheau, 2019; Dulieu, 2005; Flint-Garcia, 2013; Flint-Garcia et al., 2003; Gao et al., 2016; Glenn et al., 2017; Golicz et al., 2020; Liu et al., 2018; Kumar et al., 2014; Rodgers-Melnick et al., 2015; Xue et al., 2019). This 'purification' of the genome by backcrossing is finally more complicated with non-dominant traits. Hence, the use of selection by molecular markers and in vitro techniques such as immature embryo cultures, to avoid or simplify this lengthy and costly backcrossing. The relative interest of this long enumeration of factors affecting the theoretical value stated for back-crossings was just to remind us of some of the very many factors affecting this value. In most cases, genome cleaning by backcrossing will remain well below this theoretical value, as most of the elements are not carefully evaluated despite the companies' know-how. Thus in the majority of cases, many scars will be conserved and passed on to subsequent generations, i.e. toward the cultivar.

The lack of standardised binding guidelines for examining unintended modifications and their subsequent elimination or transmission is a significant shortcoming of applied mutagenesis. As Jansing ${ }^{15}$ reminds us regarding the detection and elimination of unintended changes, 'It is a question of which method you have the equipment and the know-how for'.

Accordingly, numerous examples show that the Elite and commercial varieties can still incorporate the scars and signatures of the transformed lines. The profiles of the recombination hotspots of these 'laboratory varieties' (variable-rate by a factor of 1000 within the maize genome) can be established (Rodgers-Melnick et al., 2015; Rodgers-Melnick et al., 2016). Changes in sites with low recombination rates would thus signal artefactual changes. Despite its 
technical weaknesses, variety sequencing can trace breeding history through SNPs, and probably SMP and MNV (Liu, Z. et al., 2020; Wachsman et al., 2017; Wilkesa et al., 2016).

More prosaically, scars can be preserved in the offspring for cost reasons and market conquest or conservation, by carrying out an insufficient number of backcrosses (Briggs, 1938; Glenn et al., 2017; Luna and Dowd-Uribe, 2020). Genome cleaning by backcrosses is also rather impossible for slow-growing plants such as trees. It is also inapplicable to vegetatively propagated plants, for which various alternatives are being tested (Ahmad et al., 2020).

As the 'memory' of water stress reminds us, many of these modifications, unintentional, even of somatic origin, are transmitted to the descendants, and therefore, are usable in detection (Hofmeister et al., 2020; McCarthy et al., 2020; Plomion et al., 2018; Wang et al., 2019). Unlike animals, somatic mutations in plants can be transmitted to their progeny (Schoen and Schultz, 2019; Simberloff and Leppanen, 2019), while these spontaneous mutations are dependent on the parents of the hybrids (Bashir et al., 2014). Conversely, the heritability of the modifications due to CRISPR-Cas9 and its efficacy varies (Mao et al., 2017). More generally, the estimation of the heritability of the traits of interest, and the unintended changes, is highly variable, which weakens what is expected from the theoretical efficiency of backcrosses (Visscher et al., 2008).

The intergenerational transmission of unintentional changes also applies to epigenomes (Sharma, 2013). Indeed, DNA methylation polymorphism due to in vitro cultures can be preserved after more than six backcrosses (Filipecki and Malepszy, 2006; Kumar et al., 2014). Conservation over 13 generations of expected transient modifications is also observable in animals (Svoboda, 2020). Part of the non-Mendelian heritability, such as maternal effect, is now attributed to transmissible RNAs, never reported in risk-evaluation studies. These paramutations are responsible for at least some transmissible epigenetic regulation (Bonduriansky and Day, 2009; Grandjean et al., 2013; Liebers et al., 2014; Roach and Wulff, 1987). Moreover, it has long been recognised that methylation blocks, the DMR's, present patterns characteristic of species and cultivars influenced by the cells' history (Ashapkin et al., 2016; Eichten and Borevitz, 2013; Eichten et al., 2013; Li, Y. et al., 2017; Xu et al., 2020). The degree of DNA methylation is one of the causes of the recombination hotspots, self-recognition, and signature of sequence insertions, as mentioned earlier.

GWAS studies allow the analysis of the many past events that have affected genomes. New elements are expected to become available with the sequencing in progress (1000 and 10000 genome projects) followed by the 1000 epigenomes already proposed (Ashapkin et al., 2016; Koch, 2016; The 1001 Genomes Consortium, 2016; Van de Peer and Pires, 2018). The resulting 
evolutionary selection signatures ${ }^{16}$ can then differentiate between natural and artefactual mutations (Ayalew et al., 2020; Stephan, 2019; Xie et al., 2015). More generally speaking, the cell lines can be distinguished by the inheritance of certain traits almost independently of (back)crosses (Bertheau, 2019; Braatz et al., 2017; Burian et al., 2016; McKenna et al., 2016; Yuan et al., 2018a,b). These modifications can be so well preserved that the laboratory at the origin of the induced changes can be identified (Alley et al., 2020; Nielsen and Voigt, 2018).

These scars and signatures, which participate in identifying Elite varieties and cultivars and their past, despite (back)crosses, were previously mentioned about inbred lines, mostly due to breeders' habits, know-how and available material. Such biomarkers are part of the identification methods of varieties currently standardised at the ISO and UPOV.

\subsection{Distinguishing natural and non-natural modifications}

One of the arguments often put forward against the regulation of NBT products is the inability to distinguish natural mutations, which are mutations that appear spontaneously without direct human intervention on the cells, from artefactual modifications caused by the techniques behind GMOs - whether exempt or not - an impossible distinction that might thus make this regulation inapplicable (European Group on Ethics in Science and New Technologies (EGE), 2021; Haut Conseil des Biotechnologies (HCB), 2017; Scientific Advice Mechanism (SAM), 2017). However, these views do not consider the genomes and epigenomes from a holistic viewpoint but rather on the individual constituent levels. Several arguments have been provided above for differentiating artefactual from natural changes if the context is taken into consideration. Moreover, in vitro mutations can be distinguished from in vivo-induced changes by the lower frequency of the organisms' chimaerism and mosaicism (Frank and Chitwood, 2016).

Biotic and abiotic stress-induced mutations and epimutations are transmissible and distinguishable from the spontaneous ones (Ashapkin et al., 2016; Bednarek and Orłowska, 2020; Editorial, 2017b; Goldschmidt, 2014; Hahn and Nekrasov, 2019; He and Li, 2018; Kellenberger et al., 2018; Li, S. et al., 2017; Niederhuth et al., 2016; Perrone and Martinelli, 2020; Quadrana and Colot, 2016; Rath, 2018; Shahryary et al., 2020; Springer and Schmitz, 2017; Vitti et al., 2013; Yaish, 2017).

The spontaneous mutation frequencies, neutral or not, classically reported would be $10^{-7}$ to $10^{-8}$, depending on the sequence considered. However, it is essential to clearly distinguish the mutation rates observed during experiments from the substitution rates, which are retained changes; a confusion often made

16 Signatures of selection are defined as the reduction, elimination or change of genetic variation in genomic regions that are adjacent to causative variants in response to natural or artificial selective pressure. 
in expert reports (Exposito-Alonso et al., 2018). The substitution rates in plants are between $10^{-8}$ and $10^{-9}$ per site and generation, independent of the plants' annual or perennial character (Dulieu, 2005; Exposito-Alonso et al., 2018; Whittle and Johnston, 2003). Moreover, the somatic mutations transmitted from the hybrids are dependent on the parents (Bashir et al., 2014; Dulieu, 2005; Schoen and Schultz, 2019). In conclusion, the frequency of conserved spontaneous mutation is about one point mutation per haploid genome per generation for almost 700 epimutations per generation, which allows us to understand the excellent conservation of the tree genomes previously mentioned (Ashapkin et al., 2016; Kuhlemeier, 2017).

The molecular traces left in progeny define and identify histotypes, cell stratifications and lineages (Benítez et al., 2018; Bertheau, 2019; Burian et al., 2016; Ledford, 2017; McKenna et al., 2016; Scheres, 2001; Zhou et al., 2020). Several tissue markers are thus able to trace the history of cells across generations. These induced markers have been effectively used in plant breeding since the 2000s, with the development of the TILLING technique and the corresponding variety identification by markers and selection signatures (Anderson et al., 2016; Gregory et al., 2008; Till et al., 2009; Flint-Garcia, 2013; McCallum et al., 2000a, b; Unterseer et al., 2014;).

In summary, any stress, biotic or abiotic, induces genetic and epigenetic modifications transmitted to the descendants, and the rest of this chapter aims to identify these unintentional modifications, verify that they are transferred to the descendants even in commercialised plants, and organise the resulting data to determine the corresponding GMOs and the technique behind them.

Epigenetic scars and signatures accompany all genomic scars and signatures of transgenic GMOs but are never documented in the risk assessment files (Ashapkin et al., 2016; Ben Ali et al., 2014; Doerfler, 2019; Filipecki and Malepszy, 2006; Vilperte et al., 2016; Waminal et al., 2013), while epimutations are known to favour mutations and vice-versa (Mendizabal et al., 2014; Ritter, and Niederhuth, 2021). As Doerfler (2019) pointed out, the genomic and epigenomic, temporary or transgenerational, sequelae of manipulations have never been systematically investigated while inducing genetic mutation susceptibility (Mendizabal et al., 2014).

As previously stated, current risk assessment has remained at the genetic knowledge level of the 1970s. In conclusion, a holistic view of genomes and epigenomes can easily differentiate traits from natural changes from traits due to artefacts.

\section{Gathering the data into manageable decision tools}

Identifying these signatures and their grouping into coherent sets is a science that remains to be developed despite the matrix approach's routine successes (see 
Chapter 4). The organisation and use of these coherent sets would be based on the multiparametric combination of signatures and scars, following the biometric strategies ${ }^{17}$ of the facial, iris or fingerprint recognition methods that are widely used (Bertheau, 2019; Liew et al., 2005; Menotti et al., 2015; Unar et al., 2014).

\subsection{Databases and decision tools}

In the case of NBT products, this screening could integrate the claimed traits, or even, according to the databases built and the feedback, other targets such as factors for identifying the families of varieties such as breeding signatures. The detection of other molecular targets to verify the artefactual nature of the NBT product would only be implemented occasionally, in the event of a challenge to the detected product's GM nature. The convergent beam of evidence, possibly integrated into decision support systems, would make it possible to remove any ambiguity regarding natural or artefactual mutations.

\subsection{Routine detection of 'hidden', transgenic and 'new' GMOs}

Ideally, the identification and quantification of all kinds of GMOs should be performed without any additional cost. Thus, the best case would be that notifiers provide the reference material and methods to identify and quantify their products according to the current legislative frame on GMOs. We will consider below the worst case, that of unapproved GMOs, by considering all the biomarkers made available through the above text. A very simplified routine scheme is proposed in Fig. 2, using the matrix approach already described in another chapter in this book.

The situation for detecting unknown new GMOs is essentially similar to that for transgenic GMOs and biothreats targeted by biodefense (Hedman et al., 2018; Walper et al., 2018). The European experience with unknown transgenic GMOs proves its worth. Knowledge management and the matrix approach are already functioning (Arulandhu et al., 2016; Barbau-Piednoir et al., 2015; Cankar et al., 2008; Chaouachi et al., 2005; Debode et al., 2019; Fraiture et al., 2020; Gerdes et al., 2012a; Holst-Jensen et al., 2013; Holst-Jensen et al., 2011; Holst-Jensen et al., 2012; Milbury et al., 2009; Nesvold et al., 2005; Prins et al., 2016; Ruttink et al., 2010; Tengs et al., 2010). The scientific and technological watch already plays a significant role in detecting uncontrolled dissemination, but NGOs and whistle-blowers are also essential and welcomed sources of information. It is up to the ENGL and the third countries' scientists to take up these 'new' and 'hidden GMOs' for developing the necessary body of knowledge, as previously done for transgenic GMOs, and then to pass the validated methods to routine labs for compliance with the rules of the Cartagena protocol on Biodiversity . 


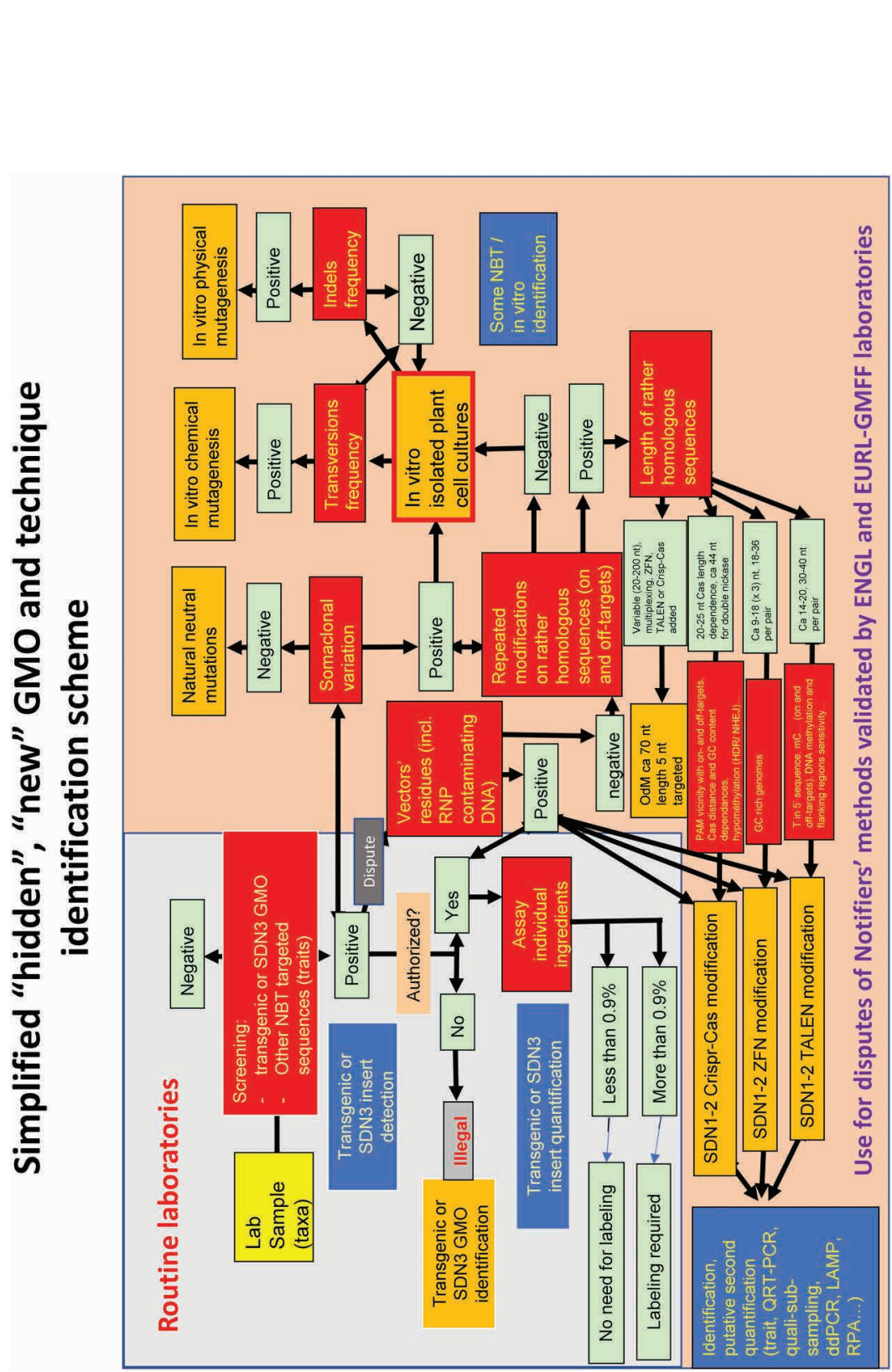




两 0

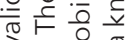
एं $ह \subseteq$ प ब วิํํㅊ बे d ज的市 으뭉 a $\frac{1}{5}$ 的 ه 勿了 당 은 o थ $\varepsilon$ w ठ

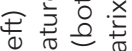
ᄃ क $\frac{0}{\pi} \pi$ 용ㄷㄴ 굴.


O एक ज 응 응 용

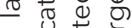
(1) $\frac{\pi}{5} \frac{\pi}{0}$

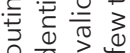
- $\underline{0}$ is $\stackrel{5}{\oplus}$ $+z U$ 일 जी

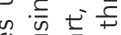
ब 5 范 구ㅇㅝㅝ ه



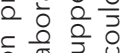
등

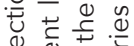
ब 웜 \& ब

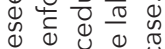
¿ $)$ U 워능 1) $+2 \div$ 0 응



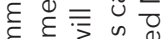
的的章常



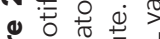

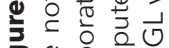
온 요을 
Accordingly, from a practical viewpoint, the routine labs would have only to use a quantitative PCR targeting the claimed trait(s). In the event of a dispute on the natural or artefactual origin of the feature, they could refer to the enforcement labs' validation. It is only in the very few expectable cases of an intense dispute that the routine labs would have to perform some additional PCR on a few scars or signatures of the presumed GMO. The analysis costs would thus not drastically increase because, after a very probable phase of tests by the operators to assess the methods' robustness, the results of the matrix approach identification scheme will not be questioned for long.

\subsection{Signatures and scars in processed products}

Processed food products often result in a mixture of components, making species no longer recognisable while reducing to extractible nucleic acids sizes. As GMO detection has proven so far, the biomarkers (species present) can be detected, and, above all, organised and used in a matrix approach. Identifying a GMO in a food processed from several species means that the analysts have to manage a larger matrix than previously performed. Design of experiments (DOE), machine learning, artificial neural networks, fuzzy logic, or genetic algorithms are some of the available tools to manage the big data that knowledge matrices could become (Alley et al., 2020; Nielsen and Voigt, 2018; Sivarajah et al., 2017; Yang et al., 2020; Yin et al., 2017). The management of millions of SNPs used in genomic selection show it is easily manageable.

Figure 1 of the previous chapter and Fig. 2 present very simplified data analyses schemes for identifying the GMOs of an agri-food product. Some determination criteria such as epigenetic and epitranscriptomic modifications have not been incorporated, for ease of reading. However, the principle remains the same: after organising the data, the analyses by dichotomous choices classically used in the detection of transgenic GMOs will allow, with the help of decision support tools (tables, DSS, artificial intelligence), to detect an NBT product, to verify that the traits used in the detection and quantification are not natural because they are integrated into an artefactual context, the unequivocal signature of the GMOs. The convergent flow of evidence given as an example in Fig. 2 is particularly illustrated in the case of an SDN1 or SDN2 modification; an SDN3 change would be identified by the univocal signature of the insert's edge fragments, as for transgenic GMOs.

\subsection{The issue of reference material}

The availability of reference material could face two issues.

The first concerns the availability itself. Companies could refuse to provide reference material while arguing that third countries do not consider the 
products of NBT as GMOs. Contentious situations will probably rise rapidly until the consumers' attitudes towards those GMOs will be straightforward enough and the opportunities of the European markets considered relevant by the companies.

The second concerns the nature of the reference material.

The recent trend to develop alternative cost-effective and replicable reference materials, such as plasmids or amplicons, will hamper GMO detection capabilities. The newly defined GMOs need to be analysed in terms of the entire genome, and probably later the epigenome or even the epitranscriptome. Only DNA and RNA directly extracted from whole plant tissue could provide the several selection signatures, and the techniques, scars and signatures related to the method of mutagenesis, required by the several analyses to be performed in case of litigation. This need was already discernible for transgenic GMOs when considering the whole set of targets for the matrix approach (Ben Ali et al., 2018; Collonnier and Bertheau, 2004; Gruden et al., 2013; Taverniers et al., 2013). This general need to preserve reference materials comprising a complete, original genome and not PCR-amplified erroneous copies without specific epigenetic patterns will be just as prevalent with non-transgenic GMOs. Some promising screening techniques will facilitate these matrix approaches (Takabatake et al., 2020a,b).

Therefore, it is fundamental that the EU should reject, by appropriate regulation or recommendation, any reference material that does not provide a complete representation of the organism's genome and epigenome, sensu lato. This obligation would make it possible to avoid the misadventures recently experienced with certain reference materials.

\section{Proof of concept}

We have provided numerous examples and references showing that the identification of artefactually induced or introduced traits could identify any GMOs without additional cost in routine. However, experimental proof is generally needed for proving these considerations.

At least two independent approaches are available to build up the proof of concept that scars and signatures of raw plant products can identify the natural, artefactual or mixed origin of a presumed GM product. The first one consists of an experimental approach for which ultra-deep sequencing differences will be sought between the presumed GMO and its closest supposed relative, to establish its identification/quantification profile. The ideal is a series of in extenso reproducible comparisons of different techniques on the same model organism. Data accumulation could also be achieved by comparing the numerous transgenic GMO-certified reference materials and their corresponding quasi-isogenic varieties. NBT products would then be added, 
such as the non-browning GM fungus obtained by in vitro transient expression (data are not available to confirm that there is no unintended insertion) in protoplasts of a CRISPR-Cas insert, from the University of Pennsylvania.

The first products applying for NBT recognition might allow the study of the effects of several types of techniques. However, it has to be kept in mind that all those NBT products have been obtained by Agrobacterium delivery, with an additional in vitro stage, and are, therefore, for these two reasons, above all, GMOs. It is indeed the case for the DP-915635-4 maize to be examined by EFSA. DP-915635-4 is essentially a GMO for which CRISPR-Cas9 was used in one of the processing steps to facilitate further introgressions. Those case studies could include: (i) the Calyxt soybean accepted as a 'null segregant' via a TALEN insertion mediated by an Agrobacterium insert, (ii) the Del Monte 'Rosé' pineapple GMO with its pineapple and tangerine genes inserted via Agrobacterium, ${ }^{18}$ and (iii) Arctic $^{\circledR}$ Fuji non-browning apple from Okanagan Specialty Fruit Inc. obtained by RNA interference and 'cisgenesis' via Agrobacterium plasmid insertion, (iv) the 'cisgenic' alfalfa KK179 from Monsanto and Forage Genetics International with altered lignin content via insertions by Agrobacterium, or finally ( $v$ ) the antibrowning ${ }^{19}$ potato lines Innate ${ }^{\mathrm{TM}}$ from Simplot Co. obtained through 'intragenesis' and RNA interference mediated by several sequences inserted via Agrobacterium, potato lines that take over an already long series of failures. ${ }^{20}$ All these products show scars resulting from in vitro cultures, and for the most part, from the effects induced by the transformation of a modified Agrobacterium plasmid, itself a stress inducer, by double-stranded DNA cleavage, a biological mutagenesis tool as used for the Arabidopsis insertional mutagenesis collection by INRA Versailles (Gelvin, 2017; Kleinboelting et al., 2015).

A second approach would gather the curated sequences of all GMO types present in the international databases. These big data could then be analysed by the species and mutagenesis category used to distinguish the similarities and differences, at least genetic, caused to species not mutated by man. Despite the numerous errors present in the sequence bases (Bertheau, 2019; Steinegger and Salzberg, 2020; Tang, 2020), the large number of sequences available, whether or not from GMOs, should, with a reasoned use of various statistical and DSS software and artificial intelligence, make it possible to distinguish scars and signatures (Alley et al., 2020; Block et al., 2013; Cadzow et al., 2014; Guillot et al., 2014; Interdonato et al., 2020; Koumakis, 2020; Nielsen and Voigt, 2018; Yang et al., 2020). Finally, some experiments should be enough to demonstrate the universality of the concept.

18 After 6 years of work

19 Less prone to bruising and black spot browning with a lower asparagine content, that turns under very high temperatures into acrylamide.

20 https://en.wikipedia.org/wiki/Genetically_modified_potato 


\section{Conclusion}

Non-exempt GMOs are derived from mutagenesis techniques that had not been proven safe for an extended period before 2001. In vitro somaclonal variation and random-induced mutagenesis release well-known differentiable GMOs. NBTs are a heterogeneous set of techniques ranging from backcrossing between GM and non-GM varieties to grafting between GMOs and nonGMOs, and cell transformation by nucleic acids with or without nucleases. The circulating molecules and genomic and epigenomic residues are crucial elements in the analytical traceability of these GMOs. Transgenesis and genome editing techniques share common basic in vitro techniques and biases, which, with other NBT techniques, make them currently GMOs.

The SDN1, ${ }^{21}$ SDN2 and SDN3 (Sprink et al., 2016) modifications do not fundamentally differ from each other. They all rely on natural and error prone DNA repair processes (NHEJ, Microhomology-Mediated End-Joining (MMEJ), or Homology Directed Recombination (HDR)) that are not mastered by related empirical techniques such as cell transformation conditions. These NBT techniques induce off- and on-target errors, from point mutation and indels to structural chromosomal mutations. The SDNs generate numerous genetic stresses at the origin of, for example, (i) transpositions of mobile elements, (ii) distal genetic modifications, (iii) epimutations, (iv) copy number variations, (iv) integration of plasmid vector and chromosome sequences such as Agrobacterium (the most efficient and still most widely used vector) or biolistically fragmented inserts transcribed in different sizes. SDN3 modifications are the holy grail for users of these nuclease techniques, a goal that is difficult to achieve because they are highly dependent on cell conditions (cell history, phasis and origin, transformation, and culture conditions), all of which contribute to the creation of specific scars and signatures.

Off-targets are generally poorly detected due to their research biased by misusing imperfect prediction software and comparator genomes or using inappropriate prediction and $\mathrm{NGS}^{22}$. The numerous modifications and combinations of the various enzymes (hifiCas9, dCas9, i.e., nickase, base editing, prime editing, Cas12a, Cas12b, etc.) make it even more complicated to predict unintended effects, but always with scars and signatures. Moreover, some dramatic unintended changes such as chromothripsis look to be induced by related techniques and CRISPR-Cas9.

As Germini et al. (2018) pointed out, the comparison of techniques on the same plant models has unfortunately never been carried out. It would, 
however, shed light on the types of scars and signatures of all NBT examples. It would allow scientific verification of whether the matrix approach to scars and signatures enables identifying the NBT products and their techniques, following the example of what is done at ISO and UPOV to identify varieties. These same tools and strategies used for years by firms can manage several millions of SNPs, which gives an idea of their capacity, adaptable for SMPs and MNVs, and usable in identifying GMOs of all kinds.

It is almost certain that efficient management of the numerous different characteristics of the GMOs, from random mutagenesis to genome editing, would endly allow analysts to identify the technique at the origin of each GMO.

While we are only beginning to be concerned about detecting products from techniques that are about a decade old, new candidates could once again shake up the landscape of genome editing. The question of whether other elements of genome integrity preservation, such as the new 'retrons' or old 'targetrons' or the Cre-Lox recombinase system, will still be relevant in the context of a 'retrohoming ${ }^{23}$ with restricted or problematic fields of application, takes the forefront (Andrusaite and Milling, 2020; Cech, 1990; Enyeart et al., 2013; Lambowitz and Zimmerly, 2004; Millman et al., 2020; Pennisi, 2020a,b; Vakulskas and Behlke, 2019).

Such a proliferation of molecular tools modified in all directions by numerous laboratories without rigorous controls or reproducibility studies pleads for a strict application of the precautionary principle. All the scientific and technical elements for reliable traceability of 'hidden' and 'new' GMOs are available, only the political will to implement this traceability required by consumers is missing. But the problem with NBT products is probably more economical than in terms of unintended environmental or health effects and modifications. Not considering NBT products as GMOs would mean not having to provide the sequences of the inbred or modified traits and their origin. This absence of control by risk assessment agencies would allow these companies to benefit from the digital information available in private and public sequence databases and not have to share the benefits with other countries and communities, especially indigenous ones, according to the International Treaty on Plant Genetic Resources for Food and Agriculture (ITPGRFA) agreements, which are part of the biodiversity protocol. Without access to these detectable sequences and analysis by the CBD, countries and communities would be hard-pressed to prove that their genetic resources have been plundered. 


\section{Where to look for further information}

Beyond considerations of risk and application of the precautionary principle claimed by the European Union (https://eur-lex.europa.eu/legal-content/EN/TX T/?uri=LEGISSUM\%3AI32042), understanding the political and economic stakes underlying the absence of reactions from the European Commission between 2007 (https://www.wur.nl/en/Publication-details.htm?publicationld=publication -way-333838353939) and 2020 is essential to understand its repeated refusal of the ENGL's proposals to work on the analytical traceability of NBT products. (https ://www.infogm.org/7228-commission-a-refuse-travail-experts-tracabilite-nouv eau-ogm, https://ec.europa.eu/food/plants/genetically-modified-organisms/new -techniques-biotechnology_en, https://publications.jrc.ec.europa.eu/repository/ handle/JRC67059, https://publications.jrc.ec.europa.eu/repository/handle/JRC9 5246, https://publications.jrc.ec.europa.eu/repository/handle/JRC69121).

The position of the Commission and of some Member States seems to be a faithful reflection of the positions of the seed industry and other lobbies, who claim that any labelling would be discriminatory (https://www.nbtplatform.org/, https://www.sci encedirect.com/journal/new-biotechnology/vol/40/part/PA, https://www.european scientist.com/en/features/the-place-of-europe-in-the-new-plant-breeding-landscap e-evolution-of-field-trials/, https://www.europabio.org/genome-editing-faq/, https:// onlinelibrary.wiley.com/doi/full/10.1111/ropr.12366, https://euroseeds.eu/the-socio -economic-and-environmental-value-of-plant-breeding-in-the-eu-key-findings/).

The current absence of analytical methods to control GMO and non-GMO products will hamper the ability to segregate products and therefore to ensure the coexistence of $\mathrm{GMO}$ and non-GMO supply chains between products intended for food, industry or pharmaceutical production. It will also hamper the freedom of choice of European consumers (Bertheau, 2013, 2019).

\section{References}

Aguilera, A. and García-Muse, T. (2013). Causes of genome instability. Annual Review of Genetics 47, 1-32.

Ahmad, N., Rahman, M. U., Mukhtar, Z., Zafar, Y. and Zhang, B. (2020). A critical look on CRISPR-based genome editing in plants. Journal of Cellular Physiology 235(2), 666-682.

Ahmar, S., Gill, R. A., Jung, K. H., Faheem, A., Qasim, M. U., Mubeen, M. and Zhou, W. (2020). Conventional and molecular techniques from simple breeding to Speed Breeding in crop plants: recent advances and future outlook. International Journal of Molecular Sciences 21(7), 2590.

Alley, E. C., Turpin, M., Liu, A. B., Kulp-McDowall, T., Swett, J., Edison, R., Von Stetina, S. E., Church, G. M. and Esvelt, K. M. (2020). A machine learning toolkit for genetic engineering attribution to facilitate biosecurity. Nature Communications 11(1), 6293. 
Altpeter, F., Springer, N. M., Bartley, L. E., Blechl, A. E., Brutnell, T. P., Citovsky, V., Conrad, L. J., Gelvin, S. B., Jackson, D. P., Kausch, A. P., Lemaux, P. G., Medford, J. I., OrozcoCárdenas, M. L., Tricoli, D. M., Van Eck, J., Voytas, D. F., Walbot, V., Wang, K., Zhang, Z. J. and Stewart, C. N. (2016). Advancing crop transformation in the era of genome editing. The Plant Cell 28(7), 1510-1520.

Anderson, E. M., Birmingham, A., Baskerville, S., Reynolds, A., Maksimova, E., Leake, D., Fedorov, Y., Karpilow, J. and Khvorova, A. (2008). Experimental validation of the importance of seed complement frequency to siRNA specificity. RNA 14(5), 853-861.

Anderson, J. E., Michno, J. M., Kono, T. J. Y., Stec, A. O., Campbell, B. W., Curtin, S. J. and Stupar, R. M. (2016). Genomic variation and DNA repair associated with soybean transgenesis: a comparison to cultivars and mutagenised plants. BMC Biotechnology 16(1), 41.

Andrusaite, A. and Milling, S. (2020). Should we be more cre-tical? A cautionary tale of recombination. Immunology 159(2), 131-132.

Anonymous (2006). The sound of a silent mutation. In Science. https://www.sciencemag .org/news/2006/12/sound-silent-mutation.

Aravanopoulos, F. A. (2003). Molecular identification of micropropagated plants. In: Proceedings of the First International Symposium on Acclimatization and Establishment of Micropropagated Plants Economou, A. S. (Ed). (Leuven 1, International Society Horticultural Science), pp. 25-47. http://www.gbv.de/dms/goe ttingen/384670989.pdf.

Arulandhu, A. J., Dijk, J. P., Dobnik, D., Holst-Jensen, A., Shi, J., Zel, J. and Kok, E. J. (2016). DNA enrichment approaches to identify unauthorized genetically modified organisms (GMOs). Analytical and Bioanalytical Chemistry 408(17), 1-19.

Ashapkin, V. V., Kutueva, L. I. and Vanyushin, B. F. (2016). Epigenetic variability in plants: heritability, adaptability, evolutionary significance. Russian Journal of Plant Physiology 63(2), 181-192.

Ates, I., Rathbone, T., Stuart, C., Bridges, P. H. and Cottle, R. N. (2020). Delivery approaches for therapeutic genome editing and challenges. Genes 11(10), 1113.

Ayalew, H., Sorrells, M. E., Carver, B. F., Baenziger, P. S. and Ma, X. F. (2020). Selection signatures across seven decades of hard winter wheat breeding in the Great Plains of the United States. The Plant Genome 13(3), e20032.

Bado, S., Yamba, N. G. G., Sesay, J. V., Laimer, M. and Forster, B. P. (2017). Plant mutation breeding for the improvement of vegetatively propagated crops: successes and challenges. CAB Reviews: Perspectives in Agriculture, Veterinary Science, Nutrition and Natural Resources 12(28), 1-21.

Bairu, M. W., Aremu, A. O. and Van Staden, J. (2011). Somaclonal variation in plants: causes and detection methods. Plant Growth Regulation 63(2), 147-173.

Balestrazzi, A., Yoshiyama, K. O. and Sakamoto, A. N. (2020). Editorial: The maintenance of genome integrity in plants: novel challenges in basic and applied research. Frontiers in Plant Science 11, 585.

Ballouz, S., Dobin, A. and Gillis, J. A. (2019). Is it time to change the reference genome? Genome Biology 20(1), 159.

Baltes, N. J., Gil-Humanes, J. and Voytas, D. F. (2017). Chapter One: Genome engineering and agriculture: opportunities and challenges. In: Progress in Molecular Biology and Translational Science Weeks, D. P. and Yang, B. (Eds). (Academic Press), pp. 1-26. http://www.sciencedirect.com/science/article/pii/S1877117317300431. 
Baralle, F. E. and Giudice, J. (2017). Alternative splicing as a regulator of development and tissue identity. Nature Reviews. Molecular Cell Biology 18(7), 437-451.

Barbau-Piednoir, E., De Keersmaecker, S. C. J., Delvoye, M., Gau, C., Philipp, P. and Roosens, N. H. (2015). Use of next generation sequencing data to develop a qPCR method for specific detection of EU-unauthorized genetically modified Bacillus subtilis overproducing riboflavin. BMC Biotechnology 15, 103.

Bashir, T., Sailer, C., Gerber, F., Loganathan, N., Bhoopalan, H., Eichenberger, C., Grossniklaus, U. and Baskar, R. (2014). Hybridization alters spontaneous mutation rates in a parent-of-origin-dependent fashion in Arabidopsis. Plant Physiology 165(1), 424-437.

Batista, R., Fonseca, C., Planchon, S., Negrão, S., Renaut, J. and Oliveira, M. M. (2017). Environmental stress is the major cause of transcriptomic and proteomic changes in GM and non-GM plants. Scientific Reports 7(1), 10624.

Bayer, P. E., Golicz, A. A., Scheben, A., Batley, J. and Edwards, D. (2020). Plant pangenomes are the new reference. Nature Plants 6(8), 914-920.

Becker, C., Hagmann, J., Müller, J., Koenig, D., Stegle, O., Borgwardt, K. and Weigel, D. (2011). Spontaneous epigenetic variation in the Arabidopsis thaliana methylome. Nature 480(7376), 245-249.

Beckett, T. J., Morales, A. J., Koehler, K. L. and Rocheford, T. R. (2017). Genetic relatedness of previously Plant-Variety-Protected commercial maize inbreds. Plos One 12(12), e0189277.

Bednarek, P. T. and Orłowska, R. (2020). Plant tissue culture environment as a switch-key of (epi)genetic changes. Plant Cell, Tissue and Organ Culture (PCTOC) 140(2), 245-257.

Beetham, P. R., Kipp, P. B., Sawycky, X. L., Arntzen, C. J. and May, G. D. (1999). A tool for functional plant genomics: chimeric RNA/DNA oligonucleotides cause in vivo genespecific mutations. Proceedings of the National Academy of Sciences of the United States of America 96(15), 8774-8778.

Beetham, P. R., Schopke, C. and Greg, F. W. (2014). RTDS (TM)-an oligonucleotidedirected mutagenesis for trait development. In Vitro Cellular and Developmental Biology-Animal 50, S4-S5.

Ben Ali, S. E., Madi, Z. E., Hochegger, R., Quist, D., Prewein, B., Haslberger, A. G. and Brandes, C. (2014). Mutation scanning in a single and a stacked Genetically Modified (GM) event by real-time PCR and High Resolution Melting (HRM) analysis. International Journal of Molecular Sciences 15(11), 19898-19923.

Ben Ali, S.-E., Schamann, A., Dobrovolny, S., Indra, A., Agapito-Tenfen, S. Z., Hochegger, R., Haslberger, A. G. and Brandes, C. (2018). Genetic and epigenetic characterization of the cry $1 \mathrm{Ab}$ coding region and its $3^{\prime}$ flanking genomic region in MON810 maize using next-generation sequencing. European Food Research and Technology 244, 1473-1485.

Benítez, M., Hernández-Hernández, V., Newman, S. A. and Niklas, K. J. (2018). Dynamical patterning modules, biogeneric materials, and the evolution of multicellular plants. Frontiers in Plant Science 9, 871.

Bennetzen, J. L., Coleman, C., Liu, R., Ma, J. and Ramakrishna, W. (2004). Consistent overestimation of gene number in complex plant genomes. Current Opinion in Plant Biology 7(6), 732-736.

Bertheau, Y. (2013). GM and non-GM supply chain co-existence and traceability: context and perspectives. In: Genetically Modified and Non-Genetically Modified Food 
Supply Chains: Co-Existence and Traceability Bertheau, Y. (Ed), pp. 619-642. https:// onlinelibrary.wiley.com/doi/abs/10.1002/9781118373781.ch32.

Bertheau, Y. (2019). New breeding techniques: detection and identification of the techniques and derived products. In: Encyclopedia of Food Chemistry, Reference Module in Food Science Stadler, R. H. (Ed). (Elsevier), pp. 320-336. https://www.sci encedirect.com/science/article/pii/B9780081005965218349.

Bhargava, M. and Sharma, A. (2013). DNA barcoding in plants: evolution and applications of in silico approaches and resources. Molecular Phylogenetics and Evolution 67, 631-641.

Bhat, A. and Ryu, C. M. (2016). Plant perceptions of extracellular DNA and RNA. Molecular Plant 9(7), 956-958.

Bidabadi, S. S. and Jain, S. M. (2020). Cellular, molecular, and physiological aspects of in vitro plant regeneration. Plants 9(6), 702.

Billon, P., Nambiar, T. S., Hayward, S. B., Zafra, M. P., Schatoff, E. M., Oshima, K., Dunbar, A., Breinig, M., Park, Y. C., Ryu, H. S., Tschaharganeh, D. F., Levine, R. L., Baer, R., Ferrando, A., Dow, L. E. and Ciccia, A. (2020). Detection of marker-free precision genome editing and genetic variation through the capture of genomic signatures. Cell Reports 30(10), 3280-3295.e6.

Birch, R. G. (1997). Plant transformation: problems and strategies for practical application. Annual Review of Plant Physiology and Plant Molecular Biology 48, 297-326.

Biswas, S., Tian, J., Li, R., Chen, X., Luo, Z., Chen, M., Zhao, X., Zhang, D., Persson, S., Yuan, Z. and Shi, J. (2020). Investigation of CRISPR/Cas9-induced SD1 rice mutants highlights the importance of molecular characterization in plant molecular breeding. Journal of Genetics and Genomics 47(5), 273-280.

Block, A., Debode, F., Grohmann, L., Hulin, J., Taverniers, I., Kluga, L., Barbau-Piednoir, E., Broeders, S., Huber, I., Van den Bulcke, M., Heinze, P., Berben, G., Busch, U., Roosens, N., Janssen, E., Žel, J., Gruden, K. and Morisset, D. (2013). The GMOseek matrix: a decision support tool for optimising the detection of genetically modified plants. BMC Bioinformatics 14(1), 1-14.

Boettcher, M. and McManus, M. T. (2015). Choosing the right tool for the job: RNAi, TALEN, or CRISPR. Molecular Cell 58(4), 575-585.

Bolukbasi, M. F., Gupta, A. and Wolfe, S. A. (2016). Creating and evaluating accurate CRISPR-Cas9 scalpels for genomic surgery. Nature Methods 13(1), 41-50.

Bonduriansky, R. and Day, T. (2009). Nongenetic inheritance and its evolutionary implications. Annual Review of Ecology, Evolution, and Systematics 40(1), 103-125.

Bonfini, L., Heinze, P., Kay, S. and Eede, G. V. D. (2002). Review of GMO Detection and Quantification Techniques. p. 67.

Bortesi, L. and Fischer, R. (2015). The CRISPR/Cas9 system for plant genome editing and beyond. Biotechnology Advances 33(1), 41-52.

Braatz, J., Harloff, H.-J., Mascher, M., Stein, N., Himmelbach, A. and Jung, C. (2017). CRISPR-Cas9 induced mutations in polyploid oilseed rape. Plant Physiology, 174(2), 935-942.

Brash, D. E. (2015). UV signature mutations. Photochemistry and Photobiology 91(1), 15-26.

Bregitzer, P., Halbert, S. E. and Lemaux, P. G. (1998). Somaclonal variation in the progeny of transgenic barley. TAG. Theoretical and Applied Genetics. Theoretische und Angewandte Genetik 96(3-4), 421-425. 
Briggs, F. N. (1938). The use of the backcross in crop improvement. The American Naturalist 72(740), 285-292.

Buehler, E., Khan, A. A., Marine, S., Rajaram, M., Bahl, A., Burchard, J. and Ferrer, M. (2012). siRNA off-target effects in genome-wide screens identify signaling pathway members. Scientific Reports 2, 428.

Burgio, G. and Teboul, L. (2020). Anticipating and identifying collateral damage in genome editing. Trends in Genetics 36(12), 905-914.

Burian, A., Barbier de Reuille, P. and Kuhlemeier, C. (2016). Patterns of stem cell divisions contribute to plant longevity. Current Biology 26(11), 1385-1394.

Burns, P. A., Allen, F. L. and Glickman, B. W. (1986). DNA sequence analysis of mutagenicity and site specificity of ethyl methanesulfonate in $\operatorname{Uvr}(+)$ and $\operatorname{UvrB}(-)$ strains of Escherichia coli. Genetics 113(4), 811-819.

Caboche, M. (2010). Specificities of plant development. Comptes Rendus Biologies 333, 288-289.

Cadzow, M., Boocock, J., Nguyen, H. T., Wilcox, P., Merriman, T. R. and Black, M. A. (2014). A bioinformatics workflow for detecting signatures of selection in genomic data. Frontiers in Genetics 5, 293.

Cankar, K., Chauvensy-Ancel, V., Fortabat, M. N., Gruden, K., Kobilinsky, A., Zel, J. and Bertheau, Y. (2008). Detection of nonauthorized genetically modified organisms using differential quantitative polymerase chain reaction: application to $35 \mathrm{~S}$ in maize. Analytical Biochemistry 376(2), 189-199.

Canny, M. D., Moatti, N., Wan, L. C. K., Fradet-Turcotte, A., Krasner, D., Mateos-Gomez, P. A., Zimmermann, M., Orthwein, A., Juang, Y. C., Zhang, W., Noordermeer, S. M., Seclen, E., Wilson, M. D., Vorobyov, A., Munro, M., Ernst, A., Ng, T. F., Cho, T., Cannon, P. M., Sidhu, S. S., Sicheri, F. and Durocher, D. (2018). Inhibition of 53BP1 favors homology-dependent DNA repair and increases CRISPR-Cas9 genome-editing efficiency. Nature Biotechnology 36(1), 95-102.

Canto, T. (2016). Transient expression systems in plants: potentialities and constraints. In: Advanced Technologies for Protein Complex Production and Characterization Vega, M. C. (Ed). (Cham: Springer International Publishing), pp. 287-301.

Cantos, C., Francisco, P., Trijatmiko, K. R., Slamet-Loedin, I. and Chadha-Mohanty, P. K. (2014). Identification of "safe harbor" loci in indica rice genome by harnessing the property of zinc-finger nucleases to induce DNA damage and repair. Frontiers in Plant Science 5, 302.

Cattoni, D. I., Gizzi, A. M. C., Georgieva, M., Di Stefano, M., Valeri, A., Chamousset, D., Houbron, C., Déjardin, S., Fiche, J. B., González, I., Chang, J. M., Sexton, T., MartiRenom, M. A., Bantignies, F., Cavalli, G. and Nollmann, M. (2017). Single-cell absolute contact probability detection reveals chromosomes are organised by multiple low-frequency yet specific interactions. Nature Communications 8(1), 1753.

Cattoni, D. I., Valeri, A., Le Gall, A. and Nollmann, M. (2015). A matter of scale: how emerging technologies are redefining our view of chromosome architecture. Trends in Genetics 31(8), 454-464.

Ceccarelli, S. and Grando, S. (2020). Evolutionary plant breeding as a response to the complexity of climate change. iScience 23(12), 101815.

Cech, T. R. (1990). Self-splicing of group I introns. Annual Review of Biochemistry 59, 543-568. 
Chamary, J. V. and Hurst, L. D. (2009). The price of silent mutations (vol 300, pg 46, 2009). Scientific American 301, 12-12.

Chaouachi, M., Giancola, S., Kobilinsky, A., Ayadi, M., Haen, S., Duplan-Fortabat, M.-N., Audéon, C., Couture, C., Romaniuk, M., Ancel, V., Bartegi, A., Brunel, D. and Bertheau, Y. (2005). Detection of approved and unapproved GMO by the "matrix approach". Paper presented at: Second International Conference on Co-Existence Between GM and non-GM Based Agricultural Supply Chain (Montpellier, France, Agropolis Editions).

Chaudhary, S., Khokhar, W., Jabre, I., Reddy, A. S. N., Byrne, L. J., Wilson, C. M. and Syed, N. H. (2019). Alternative splicing and protein diversity: plants versus animals. Frontiers in Plant Science 10, 708.

Chen, C., Zabad, S., Liu, H., Wang, W. and Jeffery, C. (2018). MoonProt 2.0: an expansion and update of the moonlighting proteins database. Nucleic Acids Research 46(D1), D640-D644.

Chen, T., Gao, D., Zhang, R., Zeng, G., Yan, H., Lim, E. and Liang, F. S. (2017). Chemically controlled epigenome editing through an inducible dCas9 system. Journal of the American Chemical Society 139(33), 11337-11340.

Chhalliyil, P., Ilves, H., Kazakov, S. A., Howard, S. J., Johnston, B. H. and Fagan, J. (2020). A Real-Time Quantitative PCR method specific for detection and quantification of the first commercialized genome-edited plant. Foods 9(9), 1245.

Clark, S., Yu, F., Gu, L. and Min, X. J. (2019). Expanding alternative splicing identification by integrating multiple sources of transcription data in tomato. Frontiers in Plant Science 10, 689.

Cleary, J. G., Braithwaite, R., Gaastra, K., Hilbush, B. S., Inglis, S., Irvine, S. A., Jackson, A., Littin, R., Rathod, M., Ware, D., et al. (2015). Comparing variant call files for performance benchmarking of next-generation sequencing variant calling pipelines. bioRxiv. https://www.biorxiv.org/content/10.1101/023754v2.article-info.

Cobb, J. N., Juma, R. U., Biswas, P. S., Arbelaez, J. D., Rutkoski, J., Atlin, G., Hagen, T., Quinn, M. and Ng, E. H. (2019). Enhancing the rate of genetic gain in public-sector plant breeding programs: lessons from the breeder's equation. TAG. Theoretical and Applied Genetics. Theoretische und Angewandte Genetik 132(3), 627-645.

Collonnier, C. and Bertheau, Y. (2004). Caractérisation de quelques inserts d'OGM commerciaux. In: La fluidité des génomes et ses conséquences (La modification génétique change-t'elle la stabilité génétique des plantes ?) CGB (Ed). (Paris, France: Commission du Génie Biomoléculaire), pp. 50-59.

Comai, L. and Tan, E. H. (2019). Haploid induction and genome instability. Trends in Genetics 35(11), 791-803.

Commission du Génie Biomoléculaire (CGB) (2004). Variation de la séquence des transgènes végétaux. Paper presented at: Variation de la séquence des transgènes végétaux (Paris, Commission du Génie Biomoléculaire).

Corrado, G. (2016). Advances in DNA typing in the agro-food supply chain. Trends in Food Science and Technology 52, 80-89.

Crossa, J., Pérez-Rodríguez, P., Cuevas, J., Montesinos-López, O., Jarquín, D., de los Campos, G., Burgueño, J., González-Camacho, J. M., Pérez-Elizalde, S., Beyene, Y., Dreisigacker, S., Singh, R., Zhang, X., Gowda, M., Roorkiwal, M., Rutkoski, J. and Varshney, R. K. (2017). Genomic selection in plant breeding: methods, models, and perspectives. Trends in Plant Science 22(11), 961-975. 
Cullot, G., Boutin, J., Toutain, J., Prat, F., Pennamen, P., Rooryck, C., Teichmann, M., Rousseau, E., Lamrissi-Garcia, I., Guyonnet-Duperat, V., Bibeyran, A., Lalanne, M., Prouzet-Mauléon, V., Turcq, B., Ged, C., Blouin, J. M., Richard, E., Dabernat, S., Moreau-Gaudry, F. and Bedel, A. (2019). CRISPR-Cas9 genome editing induces megabase-scale chromosomal truncations. Nature Communications 10(1), 1136.

Dalakouras, A., Wassenegger, M., Dadami, E., Ganopoulos, I., Pappas, M. L. and Papadopoulou, K. (2020). Genetically Modified Organism-free RNA interference: exogenous application of RNA molecules in plants. Plant Physiology 182(1), 38-50.

Dalla Costa, L., Piazza, S., Pompili, V., Salvagnin, U., Cestaro, A., Moffa, L., Vittani, L., Moser, C. and Malnoy, M. (2020). Strategies to produce T-DNA free CRISPRed fruit trees via Agrobacterium tumefaciens stable gene transfer. Scientific Reports 10(1), 20155.

Daneva, A., Gao, Z., Durme, M. V. and Nowack, M. K. (2016). Functions and regulation of programmed cell death in plant development. Annual Review of Cell and Developmental Biology 32, 441-468.

Danilevicz, M. F., Tay Fernandez, C. G., Marsh, J. I., Bayer, P. E. and Edwards, D. (2020). Plant pangenomics: approaches, applications and advancements. Current Opinion in Plant Biology 54, 18-25.

Datta, S., Datta, S., Kim, S., Chakraborty, S. and Gill, R. S. (2010). Statistical analyses of Next Generation Sequence data: a partial overview. Journal of Proteomics and Bioinformatics 3(6), 183-190.

Davidson, A. R., Lu, W. T., Stanley, S. Y., Wang, J., Mejdani, M., Trost, C. N., Hicks, B. T., Lee, J. and Sontheimer, E. J. (2020). Anti-CRISPRs: protein inhibitors of CRISPR-Cas systems. Annual Review of Biochemistry 89, 309-332.

Davison, J. and Bertheau, Y. (2008). The theory and practice of European traceability regulations for GM food and feed. Cereal Foods World 53, 186-196.

De Saeger, J., Park, J., Chung, H. S., Hernalsteens, J.-P., Van Lijsebettens, M., Inzé, D., Van Montagu, M. and Depuydt, S. (2020). Agrobacterium strains and strain improvement: present and outlook. Biotechnology Advances, 107677.

Debode, F., Hulin, J., Charloteaux, B., Coppieters, W., Hanikenne, M., Karim, L. and Berben, G. (2019). Detection and identification of transgenic events by next generation sequencing combined with enrichment technologies. Scientific Reports 9(1), 15595.

Degalez, F., Jehl, F., Muret, K., Bernard, M., Lecerf, F., Lagoutte, L., Désert, C., Pitel, F., Klopp, C. and Lagarrigue, S. (2021). Watch out for a second SNP: focus on Multi-Nucleotide Variants in coding regions and rescued stop-gained. Frontiers in Genetics 12.

dela Paz, J. S., Stronghill, P. E., Douglas, S. J., Saravia, S., Hasenkampf, C. A. and Riggs, C. D. (2012). Chromosome fragile sites in Arabidopsis harbor matrix attachment regions that may be associated with ancestral chromosome rearrangement events. PLoS Genetics 8(12), e1003136.

Deng, P., Zhou, X., Yang, D., Hou, H., Yang, X., Li, Y., Yang, Y., Wang, X., Fang, S., Wu, S., et al. (2008). The definition, source, manifestation and assessment of unintended effects in genetically modified plants. Journal of the Science of Food and Agriculture 88, 2401-2413.

Destefanis, E., Avşar, G., Groza, P., Romitelli, A., Torrini, S., Pir, P., Conticello, S. G., Aguilo, F. and Dassi, E. (2021). A mark of disease: how mRNA modifications shape genetic and acquired pathologies. RNA 27(4), 367-389.

Doerfler, W. (2019). Epigenetic consequences of genome manipulations: caveats for human germline therapy and genetically modified organisms. Epigenomics 11(3), 247-250. 
Doitsidou, M., Jarriault, S. and Poole, R. J. (2016). Next-generation sequencing-based approaches for mutation mapping and identification in Caenorhabditis elegans. Genetics 204(2), 451-474.

Dong, C. and Sharp, P. (2007). Oligonucleotide-directed gene repair: promises and limitations for plant gene modification. Transgenic Plant Journal 1, 10-16.

Dulieu, H. (2005). La variation somatique et l'évolution chez les plantes supérieures. Acta Botanica Gallica 152(3), 293-324.

Durkin, S. G. and Glover, T. W. (2007). Chromosome fragile sites. Annual Review of Genetics 41, 169-192.

Dvinge, H. (2018). Regulation of alternative mRNA splicing: old players and new perspectives. FEBS Letters 592(17), 2987-3006.

Dvořáčková, M., Fojtová, M. and Fajkus, J. (2015). Chromatin dynamics of plant telomeres and ribosomal genes. The Plant Journal : for Cell and Molecular Biology 83(1), 18-37.

Dwinger, R. H., Golden, T. E., Hatakka, M. and Daelman, W. (2007). The "Hygiene Package"-a new approach to food safety. In: XIIIth International Congress in Animal Hygiene (ISAH), A. Aland (Ed.), pp. 24-30 (Tartu, Estonia: ISAH).

Editorial (2015). Seeds of change. Nature 520(7546), 131-132.

Editorial (2017a). Gene editing in legal limbo in Europe. Nature 542(7642), 392.

Editorial (2017b). Remembrance of epigenomes past. Nature Genetics 49(6), 815-815.

Eichten, S. and Borevitz, J. (2013). Epigenomics: methylation's mark on inheritance. Nature 495, 181-182.

Eichten, S. R., Briskine, R., Song, J., Li, Q., Swanson-Wagner, R., Hermanson, P. J., Waters, A. J., Starr, E., West, P. T., Tiffin, P., Myers, C. L., Vaughn, M. W. and Springer, N. M. (2013). Epigenetic and genetic influences on DNA methylation variation in maize populations. The Plant Cell 25(8), 2783-2797.

Ekblom, R. and Wolf, J. B. W. (2014). A field guide to whole-genome sequencing, assembly and annotation. Evolutionary Applications 7(9), 1026-1042.

Enyeart, P. J., Chirieleison, S. M., Dao, M. N., Perutka, J., Quandt, E. M., Yao, J., Whitt, J. T., Keatinge-Clay, A. T., Lambowitz, A. M. and Ellington, A. D. (2013). Generalized bacterial genome editing using mobile group II introns and Cre-lox. Molecular Systems Biology 9, 685.

European Group on Ethics in Science and New Technologies (EGE) (2021). Ethics on Genome Editing. (Luxembourg: Directorate-General for Research and Innovation, European Commission), p. 112.

Evangelou, A., Ignatiou, A., Antoniou, C., Kalanidou, S., Chatzimatthaiou, S., Shianiou, G., Ellina, S., Athanasiou, R., Panagi, M., Apidianakis, Y. and Pitsouli, C. (2019). Unpredictable effects of the genetic background of transgenic lines in physiological quantitative traits. G3 9(11), 3877-3890.

Evans, D. A. (1989). Somaclonal variation-genetic basis and breeding applications. Trends in Genetics 5(2), 46-50.

Exposito-Alonso, M., Becker, C., Schuenemann, V. J., Reiter, E., Setzer, C., Slovak, R., Brachi, B., Hagmann, J., Grimm, D. G., Chen, J., Busch, W., Bergelson, J., Ness, R. W., Krause, J., Burbano, H. A. and Weigel, D. (2018). The rate and potential relevance of new mutations in a colonizing plant lineage. PLoS Genetics 14(2), e1007155.

Faino, L. and Thomma, B. P. H. J. (2014). Get your high-quality low-cost genome sequence. Trends in Plant Science 19(5), 288-291. 
Farris, M. H., Texter, P. A., Mora, A. A., Wiles, M. V., Mac Garrigle, E. F., Klaus, S. A. and Rosfjord, K. (2020). Detection of CRISPR-mediated genome modifications through altered methylation patterns of CpG islands. BMC Genomics 21(1), 856.

Fehér, A. (2015). Somatic embryogenesis-stress-induced remodeling of plant cell fate. Biochimica et Biophysica Acta 1849(4), 385-402.

Filipecki, M. and Malepszy, S. (2006). Unintended consequences of plant transformation: a molecular insight. Journal of Applied Genetics 47(4), 277-286.

Finn, E. H. and Misteli, T. (2019). Molecular basis and biological function of variability in spatial genome organization. Science 365(6457), eaaw9498.

Fitzgerald, D. M., Hastings, P. J. and Rosenberg, S. M. (2017). Stress-induced mutagenesis: implications in cancer and drug resistance. Annual Review of Cancer Biology 1, 119-140.

Fladung, M. (2016). Cibus' herbicide-resistant canola in European limbo. Nature Biotechnology 34(5), 473-474.

Fleta-Soriano, E. and Munné-Bosch, S. (2016). Stress memory and the inevitable effects of drought: a physiological perspective. Frontiers in Plant Science 7, 143.

Flibotte, S., Edgley, M. L., Chaudhry, I., Taylor, J., Neil, S. E., Rogula, A., Zapf, R., Hirst, M., Butterfield, Y., Jones, S. J., Marra, M. A., Barstead, R. J. and Moerman, D. G. (2010). Whole-genome profiling of mutagenesis in Caenorhabditis elegans. Genetics 185(2), 431-441.

Flint-Garcia, S. A. (2013). Genetics and consequences of crop domestication. Journal of Agricultural and Food Chemistry 61(35), 8267-8276.

Flint-Garcia, S. A., Thornsberry, J. M. and Buckler, E. S. t. (2003). Structure of linkage disequilibrium in plants. Annual Review of Plant Biology 54, 357-374.

Fossi, M., Amundson, K., Kuppu, S., Britt, A. and Comai, L. (2019). Regeneration of Solanum tuberosum plants from protoplasts induces widespread genome instability. Plant Physiology 180(1), 78-86.

Fraiture, M. A., Bogaerts, B., Winand, R., Deckers, M., Papazova, N., Vanneste, K., De Keersmaecker, S. C. J. and Roosens, N. H. C. (2020). Identification of an unauthorized genetically modified bacteria in food enzyme through whole-genome sequencing. Scientific Reports 10(1), 7094.

Frank, M. H. and Chitwood, D. H. (2016). Plant chimeras: the good, the bad, and the 'Bizzaria'. Developmental Biology 419(1), 41-53.

Freedman, D. H. (2010). Lies, damned lies, and medical science. The Atlantic. https://ww w.theatlantic.com/magazine/archive/2010/11/lies-damned-lies-and-medical-sci ence/308269/.

Frewer, L. J., van der Lans, I. A., Fischer, A. R. H., Reinders, M. J., Menozzi, D., Zhang, X. Y., van den Berg, I. and Zimmermann, K. L. (2013). Public perceptions of agri-food applications of genetic modification-a systematic review and meta-analysis. Trends in Food Science and Technology 30(2), 142-152.

Frock, R. L., Hu, J., Meyers, R. M., Ho, Y. J., Kii, E. and Alt, F. W. (2015). Genome-wide detection of DNA double-stranded breaks induced by engineered nucleases. Nature Biotechnology 33(2), 179-186.

Fu, W., Zhu, P., Qu, M., Zhi, W., Zhang, Y., Li, F. and Zhu, S. (2021). Evaluation on reprogramed biological processes in transgenic maize varieties using transcriptomics and metabolomics. Scientific Reports 11(1), 2050.

Gao, X., Chen, J., Dai, X., Zhang, D. and Zhao, Y. (2016). An effective strategy for reliably isolating heritable and Cas9-free Arabidopsis mutants generated by CRISPR/Cas9mediated genome editing. Plant Physiology 171(3), 1794-1800. 
Gauchier, M., van Mierlo, G., Vermeulen, M. and Déjardin, J. (2020). Purification and enrichment of specific chromatin loci. Nature Methods 17(4), 380-389.

Gelvin, S. B. (2003). Agrobacterium-mediated plant transformation: the biology behind the "gene-jockeying" tool. Microbiology and Molecular Biology Reviews 67, 16-37.

Gelvin, S. B. (2008). Agrobacterium-mediated DNA transfer, and then some. Nature Biotechnology 26(9), 998-1000.

Gelvin, S. B. (2017). Integration of Agrobacterium T-DNA into the plant genome. Annual Review of Genetics 51, 195-217.

Gerdes, L., Busch, U. and Pecoraro, S. (2012a). GMOfinder-a GMO screening database. Food Analytical Methods 5(6), 1368-1376.

Germini, D., Tsfasman, T., Zakharova, V. V., Sjakste, N., Lipinski, M. and Vassetzky, Y. (2018). A comparison of techniques to evaluate the effectiveness of genome editing. Trends in Biotechnology 36(2), 147-159.

Gerstein, M. B., Bruce, C., Rozowsky, J. S., Zheng, D., Du, J., Korbel, J. O., Emanuelsson, O., Zhang, Z. D., Weissman, S. and Snyder, M. (2007). What is a gene, post-ENCODE? History and updated definition. Genome Research 17(6), 669-681.

Gerstein, M. B., Kundaje, A., Hariharan, M., Landt, S. G., Yan, K. K., Cheng, C., Mu, X. J., Khurana, E., Rozowsky, J., Alexander, R., Min, R., Alves, P., Abyzov, A., Addleman, N., Bhardwaj, N., Boyle, A. P., Cayting, P., Charos, A., Chen, D. Z., Cheng, Y., Clarke, D., Eastman, C., Euskirchen, G., Frietze, S., Fu, Y., Gertz, J., Grubert, F., Harmanci, A., Jain, P., Kasowski, M., Lacroute, P., Leng, J. J., Lian, J., Monahan, H., O'Geen, H., Ouyang, Z., Partridge, E. C., Patacsil, D., Pauli, F., Raha, D., Ramirez, L., Reddy, T. E., Reed, B., Shi, M., Slifer, T., Wang, J., Wu, L., Yang, X., Yip, K. Y., Zilberman-Schapira, G., Batzoglou, S., Sidow, A., Farnham, P. J., Myers, R. M., Weissman, S. M. and Snyder, M. (2012). Architecture of the human regulatory network derived from ENCODE data. Nature 489(7414), 91-100.

Gepts, P. (2006). Plant genetic resources conservation and utilisation: the accomplishments and future of a societal insurance policy. Crop Science 46(5), 2278-2292.

Glenn, K. C., Alsop, B., Bell, E., Goley, M., Jenkinson, J., Liu, B., Martin, C., Parrott, W., Souder, C., Sparks, O., Urquhart, W., Ward, J. M. and Vicini, J. L. (2017). Bringing new plant varieties to market: plant breeding and selection practices advance beneficial characteristics while minimising unintended changes. Crop Science 57(6), 2906-2921.

Gocal, G. (2014). Non-transgenic trait development in crop plants using oligo-Directed Mutagenesis: cibus' Rapid Trait Development System. In: New DNA-Editing Approaches: Methods, Applications and Policy for Agriculture Eaglesham, A. and Hardy, R. W. F. (Eds). (Ithaca, NY: Cornell University and Boyce Thompson Institute, North American Agricultural Biotechnology Council), pp. 97-106.

Goldschmidt, E. E. (2014). Plant grafting: new mechanisms, evolutionary implications. Frontiers in Plant Science 5, 727.

Golicz, A. A., Bayer, P. E., Bhalla, P. L., Batley, J. and Edwards, D. (2020). Pangenomics comes of age: from bacteria to plant and animal applications. Trends in Genetics $36(2), 132-145$.

Gorbunova, V. and Levy, A. A. (1999). How plants make ends meet: DNA double-strand break repair. Trends in Plant Science 4, 263-269.

Grabowska, A. and Filipecki, M. (2004). Infiltration with Agrobacterium - the method for stable transformation avoiding tissue culture. Acta Physiol Plant 26, 451-458. 
Grainger, C. M., Letarte, J., Rajcan, I. and Willenborg, C. (2018). Using soybean pedigrees to identify genomic selection signatures associated with long-term breeding for cultivar improvement. Canadian Journal of Plant Science 98(5), 1176-1187.

Grandjean, V., Badro, D. A. and Kiani, J. (2013). RNA: a possible contributor to the 'missing heritability'. Basic and Clinical Andrology 23, 9.

Gregory, B. D., Yazaki, J. and Ecker, J. R. (2008). Utilising tiling microarrays for whole-genome analysis in plants. The Plant Journal: For Cell and Molecular Biology 53(4), 636-644.

Gruden, K., Allnutt, T. R., Ayadi, M., Baeumler, S., Bahrdt, C., Berben, G., Berdal, K. G., Bertheau, Y., Bøydler Andersen, C., Brodmann, P., Buh Gašparič, M., Burns, M. J., Burrel, A. M., Cankar, K., Esteve, T., Holst-Jensen, A., Kristoffersen, A. B., La Paz, J., Lee, D., Løvseth, A., Macarthur, R., Morisset, D., Pla, M., Rud, R. B., Skjæret, C., Tengs, T., Valdivia, H., Wulff, D., Zhang, D. and Žel, J. (2013). Reliability and cost of GMO detection. In: Genetically Modified and Non-Genetically Modified Food Supply Chains: Co-Existence and Traceability Bertheau, Y. (Ed). (Wiley-Blackwell), pp. 307-332. https://onlinelibrary. wiley.com/doi/abs/10.1002/9781118373781.ch18.

Guillot, G., Vitalis, R., Rouzic, A. I. and Gautier, M. (2014). Detecting correlation between allele frequencies and environmental variables as a signature of selection: a fast computational approach for genome-wide studies. Spatial Statistics 8, 145-155.

Hahn, F. and Nekrasov, V. (2019). CRISPR/Cas precision: do we need to worry about offtargeting in plants? Plant Cell Reports 38(4), 437-441.

Hake, S. and Ross-lbarra, J. (2015). Genetic, evolutionary and plant breeding insights from the domestication of maize. eLife 4, e05861.

Hamada, H., Linghu, Q., Nagira, Y., Miki, R., Taoka, N. and Imai, R. (2017). An in planta biolistic method for stable wheat transformation. Scientific Reports 7(1), 11443.

Han, Z., Crisp, P. A., Stelpflug, S., Kaeppler, S. M., Li, Q. and Springer, N. M. (2018). Heritable epigenomic changes to the maize methylome resulting from tissue culture. Genetics 209(4), 983-995.

Harkess, A. (2019). Smashing barriers in biolistic plant transformation. The Plant Cell 31, 273-274.

Hart, T., Brown, K. R., Sircoulomb, F., Rottapel, R. and Moffat, J. (2014). Measuring error rates in genomic perturbation screens: gold standards for human functional genomics. Molecular Systems Biology 10, 733.

Hartung, U. (2020). Inside lobbying on the regulation of New Plant Breeding Techniques in the European Union: determinants of venue choices. Review of Policy Research 37(1), 92-114.

Harwood, W. A. (2012). Advances and remaining challenges in the transformation of barley and wheat. Journal of Experimental Botany 63(5), 1791-1798.

Haut Conseil des Biotechnologies (HCB) (2017). Scientific Opinion on New Plant Breeding Techniques, p. 86. http://www.hautconseildesbiotechnologies.fr/en/avis/avis-surnouvelles-techniques-dobtention-plantes-new-plant-breeding-techniques-npbt

$\mathrm{He}, \mathrm{Y}$. and Li, Z. (2018). Epigenetic environmental memories in plants: establishment, maintenance, and reprogramming. Trends in Genetics 34(11), 856-866.

Hedman, J., Lavander, M., Salomonsson, E. N., Jinnerot, T., Boiso, L., Magnusson, B. and Rådström, P. (2018). Validation guidelines for PCR workflows in bioterrorism preparedness, food safety and forensics. Accreditation and Quality Assurance 23(3), 133-144.

Henikoff, S. and Greally, J. M. (2016). Epigenetics, cellular memory and gene regulation. Current Biology 26(14), R644-R648. 
Hennig, S. L., Owen, J. R., Lin, J. C., Young, A. E., Ross, P. J., Van Eenennaam, A. L. and Murray, J. D. (2020). Evaluation of mutation rates, mosaicism and off target mutations when injecting Cas9 mRNA or protein for genome editing of bovine embryos. Scientific Reports 10, 22309.

Henry, I. M., Comai, L. and Tan, E. H. (2018). Detection of chromothripsis in plants. Methods in Molecular Biology 1769, 119-132.

Hertle, A. P., Haberl, B. and Bock, R. (2021). Horizontal genome transfer by cell-to-cell travel of whole organelles. Science Advances 7(1), eabd8215.

Hill, C. B., Angessa, T. T., Zhang, X.-Q., Chen, K., Zhou, G., Tan, C., Wang, P., Westcott, S. and Li, C. (2021). A global barley panel revealing genomic signatures of breeding in modern cultivars. The Plant Journal 106, 419-434.

Hilscher, J., Bürstmayr, H. and Stoger, E. (2017). Targeted modification of plant genomes for precision crop breeding. Biotechnology Journal 12, 1600173.

Hinman, V. and Cary, G. (2017). The evolution of gene regulation. eLife 6, e27291.

Hofmeister, B. T., Denkena, J., Colomé-Tatché, M., Shahryary, Y., Hazarika, R., Grimwood, J., Mamidi, S., Jenkins, J., Grabowski, P. P., Sreedasyam, A., Shu, S., Barry, K., Lail, K., Adam, C., Lipzen, A., Sorek, R., Kudrna, D., Talag, J., Wing, R., Hall, D. W., Jacobsen, D., Tuskan, G. A., Schmutz, J., Johannes, F. and Schmitz, R. J. (2020). A genome assembly and the somatic genetic and epigenetic mutation rate in a wild long-lived perennial Populus trichocarpa. Genome Biology 21(1), 259-259.

Holland, J. B. (2007). Genetic architecture of complex traits in plants. Current Opinion in Plant Biology 10(2), 156-161.

Hollick, J. B. (2017). Paramutation and related phenomena in diverse species. Nature Reviews. Genetics 18(1), 5-23.

Holst-Jensen, A., Berdal, K. G., Bertheau, Y., Bohanec, M., Bohlin, J., Chaouachi, M., Gruden, K., Hamels, S., Kok, E. J., Krech, A., Kristoffersen, A. B., Laval, V., Leimanis, S., Løvoll, M., Morisset, D., Nemeth, A., Papazova, N., Prins, T. W., Remacle, J., Richl, P., Ruttink, T., Taverniers, I., Tengs, T., van Dijk, J. P., Wulff, D., Žel, J., Zhang, H. and Žnidaršič, M. (2013). Towards detection of unknown GMOs. In: Genetically Modified and Non-Genetically Modified Food Supply Chains: Co-Existence and Traceability Bertheau, Y. (Ed). (Wiley-Blackwell), pp. 367-382. https://onlinelibrary.wiley.com/ doi/abs/10.1002/9781118373781.ch20.

Holst-Jensen, A., Bertheau, Y., Alnutt, T., Broll, H., De Loose, M., Grohmann, L., Henry, C., Hougs, L., Moens, W., Morisset, D., Prins, T.W., Suter, D. and Zhang, D. (2011). Overview on the detection, interpretation and reporting on the presence of unauthorised genetically modified materials. Guidance document from the European Network of GMO Laboratories (ENGL). ENGL ad hoc working group on "unauthorised GMOs". In Scientific and Technical Research Series (European Commission, Joint research Centre. IHCP), p. 58. https://op.europa.eu/en/publication-detail/-/publication/ ab08bdab-c4eb-4d10-bf17-108a0d5eeba4/language-en.

Holst-Jensen, A., Bertheau, Y., de Loose, M., Grohmann, L., Hamels, S., Hougs, L., Morisset, D., Pecoraro, S., Pla, M., Van den Bulcke, M. and Wulff, D. (2012). Detecting un-authorized genetically modified organisms (GMOs) and derived materials. Biotechnology Advances 30(6), 1318-1335.

Holst-Jensen, A., Spilsberg, B., Arulandhu, A. J., Kok, E., Shi, J. and Žel, J. (2016). Application of whole genome shotgun sequencing for detection and characterization of genetically modified organisms and derived products. Analytical and Bioanalytical Chemistry 408(17), 4595-4614. 
Housden, B. E. and Perrimon, N. (2016). Comparing CRISPR and RNAi-based screening technologies. Nature Biotechnology 34(6), 621-623.

Hu, S., Ding, Y. and Zhu, C. (2020). Sensitivity and responses of chloroplasts to heat stress in plants. Frontiers in Plant Science 11, Art 375.

Hurgobin, B. and Edwards, D. (2017). SNP discovery using a pangenome: has the single reference approach become obsolete? Biology 6(1), 21.

Interdonato, R., Magnani, M., Perna, D., Tagarelli, A. and Vega, D. (2020). Multilayer network simplification: approaches, models and methods. Computer Science Review 36, 100246.

ISO (International Organisation for Standardization, ISO/TC 34/SC 16) (2015). Molecular biomarker analysis-SSR analysis of maize (ISO/TR 17623:2015) (International Standard Organization), pp. 6.

ISO (International Organisation for Standardization) (2019a). Foodstuffs-principles of selection and criteria of validation for varietal identification methods using specific nucleic acid (ISO 13495:2013).

ISO (International Organisation for Standardization) (2019b). Molecular biomarker analysis-determination of the performance characteristics of qualitative measurement methods and validation of methods (ISO/TS 16393), pp. 28.

ISO (International Organisation for Standardization) (2019c). Molecular biomarker analysis-methods of analysis for the detection and identification of animal species in foods and food products (nucleic acid-based methods)-general requirements and definitions (ISO 20813:2019) (ISO), pp. 27.

Ito, M. and Machida, Y. (2015). Reprogramming of plant cells induced by $6 \mathrm{~b}$ oncoproteins from the plant pathogen Agrobacterium. Journal of Plant Research 128, 423-435.

Ivashuta, S., Zhang, Y., Wiggins, B. E., Ramaseshadri, P., Segers, G. C., Johnson, S., Meyer, S. E., Kerstetter, R. A., McNulty, B. C., Bolognesi, R. and Heck, G. R. (2015). Environmental RNAi in herbivorous insects. RNA 21(5), 840-850.

Jain, S., Shukla, S., Yang, C., Zhang, M., Fatma, Z., Lingamaneni, M., Abesteh, S., Lane, S. T., Xiong, X., Wang, Y., Schroeder, C. M., Selvin, P. R. and Zhao, H. (2021). TALEN outperforms Cas 9 in editing heterochromatin target sites. Nature Communications $12(1), 606$.

Jakobson, C. M., She, R. and Jarosz, D. F. (2019). Pervasive function and evidence for selection across standing genetic variation in S. cerevisiae. Nature Communications 10(1), 1222.

Jaligot, E. and Rival, A. (2016). Applying epigenetics in plant breeding: balancing genome stability and phenotypic plasticity. In: Advances in Plant Breeding Strategies: Breeding, Biotechnology and Molecular Tools Al-Khayri, J. M., Jain, S. M. and Johnson, D. V. (Eds). (Switzerland: Springer International Publishing), pp. 159-192.

Janik, E., Niemcewicz, M., Ceremuga, M., Krzowski, L., Saluk-Bijak, J. and Bijak, M. (2020). Various aspects of a gene editing system-CRISPR-Cas9. International Journal of Molecular Sciences 21(24), 9604.

Jansing, J., Schiermeyer, A., Schillberg, S., Fischer, R. and Bortesi, L. (2019). Genome editing in agriculture: technical and practical considerations. International Journal of Molecular Sciences 20(12), 2888.

Jeffery, C. J. (2015). Why study moonlighting proteins? Frontiers in Genetics 6, 211.

Jin, S., Zong, Y., Gao, Q., Zhu, Z., Wang, Y., Qin, P., Liang, C., Wang, D., Qiu, J. L., Zhang, F. and Gao, C. (2019). Cytosine, but not adenine, base editors induce genome-wide off-target mutations in rice. Science 364(6437), 292-295. 
Jonsson, H., Magnusdottir, E., Eggertsson, H. P., Stefansson, O. A., Arnadottir, G. A., Eiriksson, O., Zink, F., Helgason, E. A., Jonsdottir, I., Gylfason, A., Jonasdottir, A., Jonasdottir, A., Beyter, D., Steingrimsdottir, T., Norddahl, G. L., Magnusson, O. T., Masson, G., Halldorsson, B. V., Thorsteinsdottir, U., Helgason, A., Sulem, P., Gudbjartsson, D. F. and Stefansson, K. (2021). Differences between germline genomes of monozygotic twins. Nature Genetics 53(1), 27-34.

Kang, S. H., Lee, W. J., An, J. H., Lee, J. H., Kim, Y. H., Kim, H., Oh, Y., Park, Y. H., Jin, Y. B., Jun, B. H., Hur, J. K., Kim, S. U. and Lee, S. H. (2020). Prediction-based highly sensitive CRISPR off-target validation using target-specific DNA enrichment. Nature Communications 11(1), 3596.

Karp, A. (1995). Somaclonal variation as a tool for crop improvement. Euphytica 85(1-3), 295-302.

Kawall, K., Cotter, J. and Then, C. (2020). Broadening the GMO risk assessment in the $\mathrm{EU}$ for genome editing technologies in agriculture. Environmental Sciences Europe 32(1), 106.

Keane, P., Kerr, A. and New, P. (1970). Crown gall of stone fruit II. Identification and nomenclature of Agrobacterium isolates. Australian Journal of Biological Sciences 23, 585-596.

Kedziora, K. M. and Purvis, J. E. (2017). Cell biology: the persistence of memory. Nature $549,343-344$.

Kellenberger, R. T., Desurmont, G. A., Schlüter, P. M. and Schiestl, F. P. (2018). Transgenerational inheritance of herbivory-induced phenotypic changes in Brassica rapa. Scientific Reports 8(1), 3536.

Khajuria, C., Ivashuta, S., Wiggins, E., Flagel, L., Moar, W., Pleau, M., Miller, K., Zhang, Y., Ramaseshadri, P., Jiang, C., Hodge, T., Jensen, P., Chen, M., Gowda, A., McNulty, B., Vazquez, C., Bolognesi, R., Haas, J., Head, G. and Clark, T. (2018). Development and characterization of the first dsRNA-resistant insect population from western corn rootworm, Diabrotica virgifera virgifera LeConte. PLoS ONE 13(5), e0197059.

Khalil, A. M. (2020). The genome editing revolution: review. Journal, Genetic Engineering and Biotechnology 18(1), 68.

Khan, Z., Khan, S. H., Mubarik, M. S., Sadia, B. and Ahmad, A. (2017). Use of TALEs and TALEN technology for genetic improvement of plants. Plant Molecular Biology Reporter 35(1), 1-19.

Kim, K. D., Kang, Y. and Kim, C. (2020). Application of genomic big data in plant breeding: past, present, and future. Plants (Basel) 9(11), 1454.

Kim, Y., Schumaker, K. S. and Zhu, J. K. (2006). EMS mutagenesis of Arabidopsis. Methods in Molecular Biology 323, 101-103.

Kimberland, M. L., Hou, W., Alfonso-Pecchio, A., Wilson, S., Rao, Y., Zhang, S. and Lu, Q. (2018). Strategies for controlling CRISPR/Cas9 off-target effects and biological variations in mammalian genome editing experiments. Journal of Biotechnology 284, 91-101.

Kimchi-Sarfaty, C., Oh, J. M., Kim, I.-W., Sauna, Z. E., Calcagno, A. M., Ambudkar, S. V. and Gottesman, M. M. (2007). A "Silent" polymorphism in the MDR 1 gene changes substrate specificity. Science 315, 525-528.

Kishikawa, T., Momozawa, Y., Ozeki, T., Mushiroda, T., Inohara, H., Kamatani, Y., Kubo, M. and Okada, Y. (2019). Empirical evaluation of variant calling accuracy using ultradeep whole-genome sequencing data. Scientific Reports 9(1), 1784. 
Kleinboelting, N., Huep, G., Appelhagen, I., Viehoever, P., Li, Y. and Weisshaar, B. (2015). The structural features of thousands of T-DNA insertion sites are consistent with a double-strand break repair-based insertion mechanism. Molecular Plant 8(11), 1651-1664.

Koch, L. (2016). Plant genomics: 1001 genomes and epigenomes. Nature Review of Genetics 17(9), 503-503.

Koltsova, A. S., Pendina, A. A., Efimova, O. A., Chiryaeva, O. G., Kuznetzova, T. V. and Baranov, V. S. (2019). On the complexity of mechanisms and consequences of chromothripsis: an update. Frontiers in Genetics 10, 393.

Komarova, T. V., Baschieri, S., Donini, M., Marusic, C., Benvenuto, E. and Dorokhov, Y. L. (2010). Transient expression systems for plant-derived biopharmaceuticals. Expert Review of Vaccines 9(8), 859-876.

Korir, N. K., Han, J., Shangguan, L., Wang, C., Kayesh, E., Zhang, Y. and Fang, J. (2013). Plant variety and cultivar identification: advances and prospects. Critical Reviews in Biotechnology 33, 111-125.

Kosicki, M., Tomberg, K. and Bradley, A. (2018). Repair of double-strand breaks induced by CRISPR-Cas9 leads to large deletions and complex rearrangements. Nature Biotechnology 36(8), 765-771.

Koumakis, L. (2020). Deep learning models in genomics; are we there yet? Computational and Structural Biotechnology Journal 18, 1466-1473.

Kovalchuk, O., Dubrova, Y. E., Arkhipov, A., Hohn, B. and Kovalchuk, I. (2000). Wheat mutation rate after Chernobyl. Nature 407(6804), 583-584.

Krishna, H., Alizadeh, M., Singh, D., Singh, U., Chauhan, N., Eftekhari, M. and Sadh, R. K. (2016). Somaclonal variations and their applications in horticultural crops improvement. 3 Biotech 6(1), 54.

Kucab, J. E., Zou, X., Morganella, S., Joel, M., Nanda, A. S., Nagy, E., Gomez, C., Degasperi, A., Harris, R., Jackson, S. P., Arlt, V. M., Phillips, D. H. and Nik-Zainal, S. (2019). A compendium of mutational signatures of environmental agents. Cell 177(4), 821836.e16.

Kuhlemeier, C. (2017). How to get old without aging. Nature Plants 3(12), 916-917.

Kumar, S., Kumari, R. and Sharma, V. (2014). Plants genetically engineered by use of tissue culture based transgenosis and regeneration procedures require genetic background purification by backcross breeding before their application. National Academy Science Letters 37(6), 573-577.

Kurowska, M., Daszkowska-Golec, A., Gruszka, D., Marzec, M., Szurman, M., Szarejko, I. and Maluszynski, M. (2011). Tilling-a shortcut in functional genomics. Journal of Applied Genetics 52(4), 371-390.

Kwon, Y.-S., Lee, J.-M., Yi, G.-B., Yi, S.-I., Kim, K.-M., Soh, E.-H., Bae, K.-M., Park, E.-K., Song, I.H. and Kim, B.-D. (2005). Use of SSR Markers to complement tests of Distinctiveness, Uniformity, and Stability (DUS) of pepper (Capsicum annuum L.) varieties. Molecules and Cells 19, 428-435.

Lacroix, B. and Citovsky, V. (2020). Biolistic approach for transient gene expression studies in plants. Methods in Molecular Biology 2124, 125-139.

Ladics, G. S., Bartholomaeus, A., Bregitzer, P., Doerrer, N. G., Gray, A., Holzhauser, T., Jordan, M., Keese, P., Kok, E., Macdonald, P., Parrott, W., Privalle, L., Raybould, A., Rhee, S. Y., Rice, E., Romeis, J., Vaughn, J., Wal, J. M. and Glenn, K. (2015). Genetic basis and detection of unintended effects in genetically modified crop plants. Transgenic Research 24(4), 587-603. 
Lambowitz, A. M. and Zimmerly, S. (2004). Mobile group II introns. Annual Review of Genetics 38, 1-35.

Lang, L. and Schnittger, A. (2020). Endoreplication-a means to an end in cell growth and stress response. Current Opinion in Plant Biology 54, 85-92.

Latham, J. R., Wilson, A. K. and Steinbrecher, R. A. (2006). The mutational consequences of plant transformation. Journal of Biomedicine and Biotechnology ID 25376, 1-7.

Ledford, H. (2016). Plant-genome hackers seek better ways to produce customised crops. Nature 539(7627), 16-17.

Ledford, H. (2017). Ancient oak's youthful genome surprises biologists. Nature 546(7659), 460.

Ledford, H. (2020). Crispr gene editing in human embryos wreaks chromosomal mayhem. Nature 583(7814), 17-18.

Lee, K. and Seo, P. J. (2018). Dynamic epigenetic changes during plant regeneration. Trends in Plant Science 23(3), 235-247.

Lehrbach, N. J., Ji, F. and Sadreyev, R. (2017). Next-generation sequencing for identification of EMS-induced mutations in Caenorhabditis elegans. In: Current Protocols in Molecular Biology. 117, 7.29.1-7.29.12. doi: 10.1002/cpmb.27.

Leibowitz, M. L., Papathanasiou, S., Doerfler, P. A., Blaine, L. J., Sun, L., Yao, Y., Zhang, C. Z., Weiss, M. J. and Pellman, D. (2021). Chromothripsis as an on-target consequence of CRISPR-Cas9 genome editing. Nature Genetics 53(6), 895-905.

Leibowitz, M. L., Zhang, C. Z. and Pellman, D. (2015). Chromothripsis: a new mechanism for rapid karyotype evolution. Annual Review of Genetics 49, 183-211.

Leva, A., Petrucelli, R. and Rinladi, L. M. R. (2012). Somaclonal variation in tissue culture: a case study with olive. In: Recent Advances in Plant In Vitro Culture Leva, A. and Rinaldi, L. M. R. (Eds). (London: IntechOpen), pp. 123-150.

Leva, A. and Rinaldi, L. (Eds.) (2012). Recent Advances in Plant In Vitro Culture. (London: IntechOpen).

Li, G., Zhou, Z., Liang, L., Song, Z., Hu, Y., Cui, J., Chen, W., Hu, K. and Cheng, J. (2020). Genome-wide identification and analysis of highly specific CRISPR/Cas9 editing sites in pepper (Capsicum annuum L.). Plos One 15(12), e0244515.

Li, S., Xia, Q., Wang, F., Yu, X., Ma, J., Kou, H., Lin, X., Gao, X. and Liu, B. (2017). Laser irradiation-induced DNA methylation changes are heritable and accompanied with transpositional activation of mPing in rice. Frontiers in Plant Science $8,363$.

Li, S., Zheng, Y.-C., Cui, H.-R., Fu, H.-W., Shu, Q.-Y. and Huang, J.-Z. (2016). Frequency and type of inheritable mutations induced by gamma rays in rice as revealed by whole genome sequencing. Journal of Zhejiang University-SCIENCE B 17(12), 905-915.

Li, X.-Q. (2016). Natural attributes and agricultural implications of somatic genome variation. Current Issues in Molecular Biology 20, 29-46.

$\mathrm{Li}$, X.-Q. (2017). Hypotheses for interpreting somatic genome variation. In: Somatic Genome Variation in Animals, Plants, and Microorganisms Li, X. Q. (Ed) (WileyBlackwell), pp. 351-362. https://onlinelibrary.wiley.com/doi/abs/10.1002/9781118 $647110 . c h 16$.

Li, X., Scanlon, M. J. and Yu, J. (2015). Evolutionary patterns of DNA base composition and correlation to polymorphisms in DNA repair systems. Nucleic Acids Research 43(7), 3614-3625.

Li, Y., Ding, X., Wang, X., He, T., Zhang, H., Yang, L., Wang, T., Chen, L., Gai, J. and Yang, S. (2017). Genome-wide comparative analysis of DNA methylation between 
soybean cytoplasmic male-sterile line NJCMS5A and its maintainer NJCMS5B. BMC Genomics 18(1), 596.

Li, Y., Wu, X., Chen, T., Wang, W., Liu, G., Zhang, W., Li, S., Wang, M., Zhao, C., Zhou, H. and Zhang, G. (2018). Plant phenotypic traits eventually shape its microbiota: a common garden test. Frontiers in Microbiology 9, 2479.

Liberatore, K. L., Dukowic-Schulze, S., Miller, M. E., Chen, C. and Kianian, S. F. (2016). The role of mitochondria in plant development and stress tolerance. Free Radical Biology and Medicine 100, 238-256.

Liebers, R., Rassoulzadegan, M. and Lyko, F. (2014). Epigenetic regulation by heritable RNA. PLoS Genetics 10(4), e1004296.

Liew, A. W.-C., Yan, H. and Yang, M. (2005). Pattern recognition techniques for the emerging field of bioinformatics: A review. Pattern Recognition 38, 2055-2073.

Liu, H. J., Jian, L., Xu, J., Zhang, Q., Zhang, M., Jin, M., Peng, Y., Yan, J., Han, B., Liu, J., Gao, F., Liu, X., Huang, L., Wei, W., Ding, Y., Yang, X., Li, Z., Zhang, M., Sun, J., Bai, M., Song, W., Chen, H., Sun, X., Li, W., Lu, Y., Liu, Y., Zhao, J., Qian, Y., Jackson, D., Fernie, A. R. and Yan, J. (2020). High-throughput CRISPR/Cas9 mutagenesis streamlines trait gene identification in maize. The Plant Cell 32(5), 1397 $-1413$.

Liu, H., Tessema, B. B., Jensen, J., Cericola, F., Andersen, J. R. and Sørensen, A. C. (2018). ADAM-Plant: a software for stochastic simulations of plant breeding from molecular to phenotypic level and from simple selection to complex Speed Breeding programs. Frontiers in Plant Science 9, 1926.

Liu, J., Nannas, N. J., Fu, F. F., Shi, J., Aspinwall, B., Parrott, W. A. and Dawe, R. K. (2019). Genome-scale sequence disruption following biolistic transformation in rice and maize. The Plant Cell 31(2), 368-383.

Liu, Z., Li, Y., Zhao, J., Chen, X., Jian, G., Peng, Y. and Qi, F. (2012). Differentially expressed genes distributed over chromosomes and implicated in certain biological processes for site insertion genetically modified rice Kemingdao. International Journal of Biological Sciences 8(7), 953-963.

Liu, Z., Zhu, H., Zhou, J., Jiang, S., Wang, Y., Kuang, J., Ji, Q., Peng, J., Wang, J., Gao, L., Bai, M., Jian, J. and Ke, W. (2020). Resequencing of 296 cultivated and wild lotus accessions unravels its evolution and breeding history. The Plant Journal : for Cell and Molecular Biology 104(6), 1673-1684.

Lomov, N. A., Viushkov, V. S., Petrenko, A. P., Syrkina, M. S. and Rubtsov, M. A. (2019). Methods of evaluating the efficiency of CRISPR/Cas genome editing. Molecular Biology 53, 862-875.

Louwaars, N. P. (2018). Plant breeding and diversity: a troubled relationship? Euphytica 214(7), 114.

Lowe, K., Wu, E., Wang, N., Hoerster, G., Hastings, C., Cho, M. J., Scelonge, C., Lenderts, B., Chamberlin, M., Cushatt, J., Wang, L., Ryan, L., Khan, T., Chow-Yiu, J., Hua, W., Yu, M., Banh, J., Bao, Z., Brink, K., Igo, E., Rudrappa, B., Shamseer, P. M., Bruce, W., Newman, L., Shen, B., Zheng, P., Bidney, D., Falco, C., Register, J., Zhao, Z. Y., Xu, D., Jones, T. and Gordon-Kamm, W. (2016). Morphogenic regulators Baby boom and Wuschel improve monocot transformation. The Plant Cell 28(9), 1998 $-2015$.

Luna, J. K. and Dowd-Uribe, B. (2020). Knowledge politics and the Bt cotton success narrative in Burkina Faso. World Development 136, 105127. 
Lv, Z., Jiang, R., Chen, J. and Chen, W. (2020). Nanoparticle-mediated gene transformation strategies for plant genetic engineering. The Plant Journal: For Cell and Molecular Biology 104(4), 880-891.

Maher, M. F., Nasti, R. A., Vollbrecht, M., Starker, C. G., Clark, M. D. and Voytas, D. F. (2020). Plant gene editing through de novo induction of meristems. Nature Biotechnology 38(1), 84-89.

Maluszynski, M., Ahloowalia, B. S. and Sigurbjörnsson, B. (1995). Application of in vivo and in vitro mutation techniques for crop improvement. Euphytica 85(1-3), 303-315.

Maluszynski, M., Nichterlein, K., Van Zanten, L. and Ahloowalia, B. S. (2000). Officially Released Mutant Varieties-The FAO/IAEA Database. (Vienna: International Atomic Energy Agency). https://inis.iaea.org/collection/NCLCollectionStore/_ Public/32/006/32006534.pdf?r=1.

Manghwar, H., Li, B., Ding, X., Hussain, A., Lindsey, K., Zhang, X. and Jin, S. (2020). CRISPR/ Cas systems in genome editing: methodologies and tools for sgRNA design, offtarget evaluation, and strategies to mitigate off-target effects. Advanced Science 7(6), 1902312.

Manimaran, P., Ramkumar, G., Sakthivel, K., Sundaram, R. M., Madhav, M. S. and Balachandran, S. M. (2011). Suitability of non-lethal marker and marker-free systems for development of transgenic crop plants: present status and future prospects. Biotechnology Advances 29(6), 703-714.

Mao, Y., Botella, J. R. and Zhu, J. K. (2017). Heritability of targeted gene modifications induced by plant-optimized CRISPR systems. Cellular and Molecular Life Sciences 74(6), 1075-1093.

Mao, Y., Yang, X., Zhou, Y., Zhang, Z., Botella, J. R. and Zhu, J. K. (2018). Manipulating plant RNA-silencing pathways to improve the gene editing efficiency of CRISPR/Cas9 systems. Genome Biology 19(1), 149-149.

Mardis, E. R. (2013). Next-generation sequencing platforms. Annual Review of Analytical Chemistry 6, 287-303.

Marine, S., Bahl, A., Ferrer, M. and Buehler, E. (2012). Common seed analysis to identify offtarget effects in siRNA screens. Journal of Biomolecular Screening 17(3), 370-378.

Marino, N. D., Pinilla-Redondo, R., Csörgő, B. and Bondy-Denomy, J. (2020). Anti-CRISPR protein applications: natural brakes for CRISPR-Cas technologies. Nature Methods 17(5), 471-479.

Martin, F., Sánchez-Hernández, S., Gutiérrez-Guerrero, A., Pinedo-Gomez, J. and Benabdellah, K. (2016). Biased and unbiased methods for the detection of OffTarget cleavage by CRISPR/Cas9: an overview. International Journal of Molecular Sciences 17(9), 1507.

Martínez, O. (2018). Selection of molecular markers for the estimation of somaclonal variation. In: Plant Cell Culture Protocols Loyola-Vargas, V. M. and Ochoa-Alejo, N. (Eds). (New York, NY: Springer), pp. 103-129. https://link.springer.com/protocol/10. 1007\%2F978-1-4939-8594-4_6.

Marx, V. (2015). Cell biology: delivering tough cargo into cells. Nature Methods 13(1), $37-40$.

Matsaunyane, L. B. T. and Dubery, I. A. (2018). Molecular approaches to address intended and unintended effects and substantial equivalence of Genetically Modified Crops. In: Transgenic Crops-Emerging Trends and Future Perspectives Khan, M. S. and Malik, K. A. (Eds). (London: IntechOpen), pp. 115-131. https://api.intechopen.com/ chapter/pdf-download/62946.pdf. 
Matsuo, K., Fukuzawa, N. and Matsumura, T. (2016). A simple agroinfiltration method for transient gene expression in plant leaf discs. Journal of Bioscience and Bioengineering 122(3), 351-356.

McCallum, C. M., Comai, L., Greene, E. A. and Henikoff, S. (2000a). Targeting induced local lesions in genomes (TILLING) for plant functional genomics. Plant Physiology 123(2), 439-442.

McCallum, C. M., Comai, L., Greene, E. A. and Henikoff, S. (2000b). Targeted screening for induced mutations. Nature Biotechnology 18(4), 455-457.

McCarthy, D. J., Rostom, R., Huang, Y., Kunz, D. J., Danecek, P., Bonder, M. J., Hagai, T., Lyu, R., HipSci Consortium, Wang, W., Gaffney, D. J., Simons, B. D., Stegle, O. and Teichmann, S. A. (2020). Cardelino: computational integration of somatic clonal substructure and single-cell transcriptomes. Nature Methods 17(4), 414-421.

McKenna, A., Findlay, G. M., Gagnon, J. A., Horwitz, M. S., Schier, A. F. and Shendure, J. (2016). Whole organism lineage tracing by combinatorial and cumulative genome editing. Science 353(6298), 462.

McLean-Rodríguez, F. D., Costich, D. E., Camacho-Villa, T. C., Pè, M. E. and Dell'Acqua, M. (2021) Genetic diversity and selection signatures in maize landraces compared across 50 years of in situ and ex situ conservation. Heredity 126(6), 913-928.

Meins Jr., F. (1983). Heritable variation in plant cell culture. Annual Review of Plant Physiology 34(1), 327-346.

Mendizabal, I., Keller, T. E., Zeng, J. and Yi, S. V. (2014). Epigenetics and evolution. Integrative and Comparative Biology 54(1), 31-42.

Menotti, D., Chiachia, G., Pinto, A., Robson Schwartz, W., Pedrini, H., Xavier Falcao, A. and Rocha, A. (2015). Deep representations for iris, face, and fingerprint spoofing detection. IEEE Transactions on Information Forensics and Security 10(4), 864-879.

Meyer, R. S., DuVal, A. E. and Jensen, H. R. (2012). Patterns and processes in crop domestication: an historical review and quantitative analysis of 203 global food crops. New Phytologist 196(1), 29-48.

Michael, T. P. and VanBuren, R. (2020). Building near-complete plant genomes. Current Opinion in Plant Biology 54, 26-33.

Miguel, C. and Marum, L. (2011). An epigenetic view of plant cells cultured in vitro: somaclonal variation and beyond. Journal of Experimental Botany 62(11),3713-3725.

Miki, B. and McHugh, S. (2004). Selectable marker genes in transgenic plants: applications, alternatives and biosafety. Journal of Biotechnology 107(3), 193-232.

Milbury, C. A., Li, J. and Makrigiorgos, G. M. (2009). PCR-based methods for the enrichment of minority alleles and mutations. Clinical Chemistry 55(4), 632-640.

Millman, A., Bernheim, A., Stokar-Avihail, A., Fedorenko, T., Voichek, M., Leavitt, A., Oppenheimer-Shaanan, Y. and Sorek, R. (2020). Bacterial retrons function in antiphage defense. Cell 183(6), 1551-1561.e12.

Miyao, A., Nakagome, M., Ohnuma, T., Yamagata, H., Kanamori, H., Katayose, Y., Takahashi, A., Matsumoto, T. and Hirochika, H. (2012). Molecular spectrum of somaclonal variation in regenerated rice revealed by whole-genome sequencing. Plant and Cell Physiology 53(1), 256-264.

Monticolo, F., Palomba, E., Termolino, P., Chiaiese, P., de Alteriis, E., Mazzoleni, S. and Chiusano, M. L. (2020). The role of DNA in the extracellular environment: a focus on NETs, RETs and biofilms. Frontiers in Plant Science 11, 589837. 
Modrzejewski, D., Hartung, F., Lehnert, H., Sprink, T., Kohl, C., Keilwagen, J. and Wilhelm, R. (2020). Which factors affect the occurrence of off-target effects caused by the use of CRISPR/Cas: a systematic review in plants. Frontiers in Plant Science 11, 574959.

Modrzejewski, D., Hartung, F., Sprink, T., Krause, D., Kohl, C., Schiemann, J. and Wilhelm, R. (2018). What is the available evidence for the application of genome editing as a new tool for plant trait modification and the potential occurrence of associated offtarget effects: a systematic map protocol. Environmental Evidence 7(1), 18.

Modrzejewski, D., Hartung, F., Sprink, T., Krause, D., Kohl, C. and Wilhelm, R. (2019). What is the available evidence for the range of applications of genome-editing as a new tool for plant trait modification and the potential occurrence of associated off-target effects: a systematic map. Environmental Evidence 8(1), 27.

Molla, K. A. and Yang, Y. (2020). Predicting CRISPR/Cas9-induced mutations for precise genome editing. Trends in Biotechnology 38(2), 136-141.

Momose, T., De Cian, A., Shiba, K., Inaba, K., Giovannangeli, C. and Concordet, J. P. (2018). High doses of CRISPR/Cas9 ribonucleoprotein efficiently induce gene knockout with low mosaicism in the hydrozoan Clytia hemisphaerica through microhomologymediated deletion. Scientific Reports 8(1), 11734.

Moon, S. B., Kim, D. Y., Ko, J. H., Kim, J. S. and Kim, Y. S. (2019). Improving CRISPR genome editing by engineering guide RNAs. Trends in Biotechnology 37(8), 870-881.

Morrow, J. (1975). On the relationship between spontaneous mutation rates in vivo and in vitro. Mutation Research 33(2-3), 367-372.

Mumm, R. H. (2013). A look at product development with genetically modified crops: examples from maize. Journal of Agricultural and Food Chemistry 61(35), 8254-8259.

Naeem, M., Majeed, S., Hoque, M. Z. and Ahmad, I. (2020). Latest developed strategies to minimize the off-target effects in CRISPR-Cas-mediated genome editing. Cells 9(7), 1608.

Nathans, J. F., Cornwell, J. A., Afifi, M. M., Paul, D. and Cappell, S. D. (2021). Cell cycle inertia underlies a bifurcation in cell fates after DNA damage. Science Advances 7(3), eabe3882.

Nesvold, H., Kristoffersen, A. B., Holst-Jensen, A. and Berdal, K. G. (2005). Design of a DNA chip for detection of unknown genetically modified organisms (GMOs). Bioinformatics 21(9), 1917-1926.

Newman, A., Starrs, L. and Burgio, G. (2020). Cas9 cuts and consequences; detecting, predicting, and mitigating CRISPR/Cas9 On- and Off-target damage. BioEssays: News and Reviews in Molecular, Cellular and Developmental Biology 42(9), e2000047.

Niederhuth, C. E., Bewick, A. J., Ji, L., Alabady, M. S., Kim, K. D., Li, Q., Rohr, N. A., Rambani, A., Burke, J. M., Udall, J. A., Egesi, C., Schmutz, J., Grimwood, J., Jackson, S. A., Springer, N. M. and Schmitz, R. J. (2016). Widespread natural variation of DNA methylation within angiosperms. Genome Biology 17(1), 194.

Nielsen, A. A. K. and Voigt, C. A. (2018). Deep learning to predict the lab-of-origin of engineered DNA. Nature Communications 9(1), 3135.

Nisa, M. U., Huang, Y., Benhamed, M. and Raynaud, C. (2019). The plant DNA damage response: signaling pathways leading to growth inhibition and putative role in response to stress conditions. Frontiers in Plant Science 10, 653.

Norris, A. L., Lee, S. S., Greenlees, K. J., Tadesse, D. A., Miller, M. F. and Lombardi, H. A. (2020). Template plasmid integration in germline genome-edited cattle. Nature Biotechnology 38(2), 163-164. 
Odorico, A., Rünneburger, E. and Le Rouzic, A. (2018). Modelling the influence of parental effects on gene-network evolution. Journal of Evolutionary Biology 31, 687-700.

Oh, T. J. and May, G. D. (2001). Oligonucleotide-directed plant gene targeting. Current Opinion in Biotechnology 12(2), 169-172.

Olsen, K. M. and Wendel, J. F. (2013a). A bountiful harvest: genomic insights into crop domestication phenotypes. Annual Review of Plant Biology 64, 47-70.

Olsen, K. M. and Wendel, J. F. (2013b). Crop plants as models for understanding plant adaptation and diversification. Frontiers in Plant Science 4, 290.

Ono, R., Yasuhiko, Y., Aisaki, K. I., Kitajima, S., Kanno, J. and Hirabayashi, Y. (2019). Exosome-mediated horizontal gene transfer occurs in double-strand break repair during genome editing. Communications Biology 2, 57.

Orr, A. J., Padovan, A., Kainer, D., Külheim, C., Bromham, L., Bustos-Segura, C., Foley, W., Haff, T., Hsieh, J. F., Morales-Suarez, A., Cartwright, R. A. and Lanfear, R. (2020). A phylogenomic approach reveals a low somatic mutation rate in a long-lived plant. Proceedings. Biological Sciences 287(1922), 20192364.

Papapetrou, E. P. and Schambach, A. (2016). Gene insertion into genomic safe harbors for human gene therapy. Molecular Therapy: the Journal of the American Society of Gene Therapy 24(4), 678-684.

Park, E., Pan, Z., Zhang, Z., Lin, L. and Xing, Y. (2018). The expanding landscape of alternative splicing variation in human populations. American Journal of Human Genetics 102(1), 11-26.

Peng, R., Lin, G. and Li, J. (2016). Potential pitfalls of CRISPR/Cas9-mediated genome editing. FEBS Journal 283(7), 1218-1231.

Pennisi, E. (2020a). Like CRISPR, mystery gene editor began as a virus fighter. Science 370(6519), 898-899.

Pennisi, E. (2020b). Microbes' mystery DNA helps defeat viruses-and has genomeediting potential. Science. https://www.sciencemag.org/news/2020/11/microbes -mystery-dna-helps-defeat-viruses-and-has-genome-editing-potential.

Pérez-González, A. and Caro, E. (2019). Benefits of using genomic insulators flanking transgenes to increase expression and avoid positional effects. Scientific Reports 9(1), 8474-8474.

Perrone, A. and Martinelli, F. (2020). Plant stress biology in epigenomic era. Plant Science $294,110376$.

Plomion, C., Aury, J. M., Amselem, J., Leroy, T., Murat, F., Duplessis, S., Faye, S., Francillonne, N., Labadie, K., Le Provost, G., Lesur, I., Bartholomé, J., Faivre-Rampant, P., Kohler, A., Leplé, J. C., Chantret, N., Chen, J., Diévart, A., Alaeitabar, T., Barbe, V., Belser, C., Bergès, H., Bodénès, C., Bogeat-Triboulot, M. B., Bouffaud, M. L., Brachi, B., Chancerel, E., Cohen, D., Couloux, A., Da Silva, C., Dossat, C., Ehrenmann, F., Gaspin, C., Grima-Pettenati, J., Guichoux, E., Hecker, A., Herrmann, S., Hugueney, P., Hummel, I., Klopp, C., Lalanne, C., Lascoux, M., Lasserre, E., Lemainque, A., Desprez-Loustau, M. L., Luyten, I., Madoui, M. A., Mangenot, S., Marchal, C., Maumus, F., Mercier, J., Michotey, C., Panaud, O., Picault, N., Rouhier, N., Rué, O., Rustenholz, C., Salin, F., Soler, M., Tarkka, M., Velt, A., Zanne, A. E., Martin, F., Wincker, P., Quesneville, H., Kremer, A. and Salse, J. (2018). Oak genome reveals facets of long lifespan. Nature Plants 4(7), 440-452.

Portin, P. and Wilkins, A. (2017). The evolving definition of the term "Gene". Genetics 205(4), 1353-1364. 
Potrykus, I. (1991). Gene transfer to plants: assessment of published approaches and results. Annual Review of Plant Physiology and Plant Molecular Biology 42(1), 205-225.

Prins, T. W., Scholtens, I. M. J., Bak, A. W., van Dijk, J. P., Voorhuijzen, M. M., Laurensse, E. J. and Kok, E. J. (2016). A case study to determine the geographical origin of unknown GM papaya in routine food sample analysis, followed by identification of papaya events 16-0-1 and 18-2-4. Food Chemistry 213, 536-544.

Probst, A. V. and Mittelsten Scheid, O. (2015). Stress-induced structural changes in plant chromatin. Current Opinion in Plant Biology 27, 8-16.

Quadrana, L. and Colot, V. (2016). Plant transgenerational epigenetics. Annual Review of Genetics 50, 467-491.

Quambusch, M. and Winkelmann, T. (2018). Bacterial endophytes in plant tissue culture: mode of action, detection, and control. In: Plant Cell Culture Protocols Loyola-Vargas, V. M. and Ochoa-Alejo, N. (Eds). (New York, NY, Springer), pp. 69-88.

Que, Q., Elumalai, S., Li, X., Zhong, H., Nalapalli, S., Schweiner, M., Fei, X., Nuccio, M., Kelliher, T., Gu, W., Chen, Z. and Chilton, M. D. (2014). Maize transformation technology development for commercial event generation. Frontiers in Plant Science 5, 379.

Quiroga, G., Erice, G., Aroca, R., Chaumont, F. and Ruiz-Lozano, J. M. (2017). Enhanced drought stress tolerance by the arbuscular mycorrhizal symbiosis in a droughtsensitive maize cultivar is related to a broader and differential regulation of host plant aquaporins than in a drought-tolerant cultivar. Frontiers in Plant Science 8, 1056.

Raitskin, O., Schudoma, C., West, A. and Patron, N. J. (2019). Comparison of efficiency and specificity of CRISPR-associated (Cas) nucleases in plants: an expanded toolkit for precision genome engineering. Plos One 14(2), e0211598.

Ramesh, S. V. (2013). Non-coding RNAs in crop genetic modification: considerations and predictable environmental risk assessments (ERA). Molecular Biotechnology 55(1), 87-100.

Ramon, M., Devos, Y., Lanzoni, A., Liu, Y., Gomes, A., Gennaro, A. and Waigmann, E. (2014). RNAi-based GM plants: food for thought for risk assessors. Plant Biotechnology Journal 12(9), 1271-1273.

Rao, A. Q., Bakhsh, A., Kiani, S., Shahzad, K., Shahid, A. A., Husnain, T. and Riazuddin, S. (2009). The myth of plant transformation. Biotechnology Advances 27(6), 753-763.

Rath, J. (2018). Safety and security risks of CRISPR/Cas9. In: Ethics Dumping: Case Studies from North-South Research Collaborations Schroeder, D., Cook, J., Hirsch, F., Fenet, S. and Muthuswamy, V. (Eds). (Cham: Springer International Publishing), pp. 107113. https://link.springer.com/chapter/10.1007\%2F978-3-319-64731-9_13.

Ravindran, S. (2018). New methods to detect CRISPR off-target mutations. In: The Scientist. https://www.the-scientist.com/lab-tools/new-methods-to-detect-crispr-off -target-mutations-30013.

Raynal, B., Lenormand, P., Baron, B., Hoos, S. and England, P. (2014). Quality assessment and optimization of purified protein samples: why and how? Microbial Cell Factories $13,180$.

Reddy, A. S. N., Huang, J. and Syed, N. H. (2020). Decoding co-/post-transcriptional complexities of plant transcriptomes and epitranscriptome using next-generation sequencing technologies. Biochemical Society Transactions 48, 2399-2414. 
Regalado, A. (2015). As patents expire, farmers plant generic GMOs. In: MIT's Technology Review (MIT), 539746. http://www.technologyreview.com/news/539746/as-patentsexpire-farmers-plant-generic-gmos/.

Renny-Byfield, S., Rodgers-Melnick, E. and Ross-lbarra, J. (2017). Gene fractionation and function in the ancient subgenomes of maize. Molecular Biology and Evolution 34(8), 1825-1832.

Rezza, A., Jacquet, C., Le Pillouer, A., Lafarguette, F., Ruptier, C., Billandon, M., Isnard Petit, P., Trouttet, S., Thiam, K., Fraichard, A. and Chérifi, Y. (2019). Unexpected genomic rearrangements at targeted loci associated with CRISPR/Cas9-mediated knock-in. Scientific Reports 9(1), 3486.

Riba, A., Emmenlauer, M., Chen, A., Sigoillot, F., Cong, F., Dehio, C., Jenkins, J. and Zavolan, M. (2017). Explicit modeling of siRNA-dependent on- and off-target repression improves the interpretation of screening results. Cell Systems 4(2), 182 -193.e4.

Ritter, E. J. and Niederhuth, C. E. (2021). Intertwined evolution of plant epigenomes and genomes. Current Opinion in Plant Biology 61, 101990.

Roach, D. A. and Wulff, R. D. (1987). Maternal effect in plants. Annual Review of Ecology and Systematics 18(1), 209-235.

Roberts, S. A. and Gordenin, D. A. (2014). Hypermutation in human cancer genomes: footprints and mechanisms. Nature Reviews. Cancer 14(12), 786-800.

Robin, J. D., Ludlow, A. T., LaRanger, R., Wright, W. E. and Shay, J. W. (2016). Comparison of DNA quantification methods for next generation sequencing. Scientific Reports 6, 24067.

Rodgers-Melnick, E., Bradbury, P. J., Elshire, R. J., Glaubitz, J. C., Acharya, C. B., Mitchell, S. E., Li, C., Li, Y. and Buckler, E. S. (2015). Recombination in diverse maize is stable, predictable, and associated with genetic load. Proceedings of the National Academy of Sciences 112(12), 3823-3828.

Rodgers-Melnick, E., Vera, D. L., Bass, H. W. and Buckler, E. S. (2016). Open chromatin reveals the functional maize genome. Proceedings of the National Academy of Sciences 113(22), E3177-E3184.

Ruffoni, B. and Savona, M. (2013). Physiological and biochemical analysis of growth abnormalities associated with plant tissue culture. Horticulture, Environment, and Biotechnology 54(3), 191-205.

Ruiter, R., Van Den Brande, I., Stals, E., Delauré, S., Cornelissen, M. and D'Halluin, K. (2003). Spontaneous mutation frequency in plants obscures the effect of chimeraplasty. Plant Molecular Biology 53(5), 675-689.

Ruttink, T., Morisset, D., Van Droogenbroeck, B., Lavrac, N., Van den Eede, G. L. M., Zel, J. and De Loose, M. (2010). Knowledge-technology-based discovery of unauthorized genetically modified organisms. Analytical and Bioanalytical Chemistry 396(6), 1951-1959.

Saini, N., Sterling, J. F., Sakofsky, C. J., Giacobone, C. K., Klimczak, L. J., Burkholder, A. B., Malc, E. P., Mieczkowski, P. A. and Gordenin, D. A. (2020). Mutation signatures specific to DNA alkylating agents in yeast and cancers. Nucleic Acids Research 48(7), 3692-3707.

Salk, J. J., Schmitt, M. W. and Loeb, L. A. (2018). Enhancing the accuracy of next-generation sequencing for detecting rare and subclonal mutations. Nature Reviews. Genetics 19(5), 269-285. 
Sauer, N. J., Narváez-Vásquez, J., Mozoruk, J., Miller, R. B., Warburg, Z. J., Woodward, M. J., Mihiret, Y. A., Lincoln, T. A., Segami, R. E., Sanders, S. L., Walker, K. A., Beetham, P. R., Schöpke, C. R. and Gocal, G. F. (2016). Oligonucleotide-mediated genome editing provides precision and function to engineered nucleases and antibiotics in plants. Plant Physiology 170(4), 1917-1928.

Scahill, M. D., Pastar, I. and Cross, G. A. M. (2008). CRE recombinase-based positivenegative selection systems for genetic manipulation in Trypanosoma brucei. Molecular and Biochemical Parasitology 157(1), 73-82.

Schaart, J. G., van de Wiel, C. C. M., Lotz, L. A. P. and Smulders, M. J. M. (2016). Opportunities for products of new plant breeding techniques. Trends in Plant Science 21(5), 438-449.

Schaart, J. G. and Visser, R. G. F. (2009). Novel plant breeding techniques. Consequences of new genetic modification-based plant breeding techniques in comparison to conventional plant breeding (COGEM), p. 60.

Scheres, B. (2001). Plant cell identity: the role of position and lineage. Plant Physiology 125(1), 112-114.

Scherrer, K. and Jost, J. (2007). Gene and genon concept: coding versus regulation. A conceptual and information-theoretic analysis of genetic storage and expression in the light of modern molecular biology. Theory in Biosciences 126(2-3), 65-113.

Schillberg, S. and Finnern, R. (2021). Plant molecular farming for the production of valuable proteins-critical evaluation of achievements and future challenges. Journal of Plant Physiology 258-259, 153359.

Schmid-Siegert, E., Sarkar, N., Iseli, C., Calderon, S., Gouhier-Darimont, C., Chrast, J., Cattaneo, P., Schütz, F., Farinelli, L., Pagni, M., Schneider, M., Voumard, J., Jaboyedoff, M., Fankhauser, C., Hardtke, C. S., Keller, L., Pannell, J. R., Reymond, A., RobinsonRechavi, M., Xenarios, I. and Reymond, P. (2017). Low number of fixed somatic mutations in a long-lived oak tree. Nature Plants 3(12), 926-929.

Schmitz, R. J., Schultz, M. D., Urich, M. A., Nery, J. R., Pelizzola, M., Libiger, O., Alix, A., McCosh, R. B., Chen, H., Schork, N. J. and Ecker, J. R. (2013). Patterns of population epigenomic diversity. Nature 495(7440), 193-198.

Schnell, J., Steele, M., Bean, J., Neuspiel, M., Girard, C., Dormann, N., Pearson, C., Savoie, A., Bourbonniere, L. and Macdonald, P. (2015). A comparative analysis of insertional effects in genetically engineered plants: considerations for pre-market assessments. Transgenic Research 24(1), 1-17.

Schoen, D. J. and Schultz, S. T. (2019). Somatic mutation and evolution in plants. Annual Review of Ecology, Evolution, and Systematics 50(1), 49-73.

Scientific advice mechanism (SAM) (2017). New techniques in agricultural biotechnology. In Explanatory Note, High Level Group of Scientific Advisors, ed. (European Commission), pp. 152. https://ec.europa.eu/info/research-and-innovation/strategy /support-policy-making/scientific-support-eu-policies/group-chief-scientific-advis ors/new-techniques-agricultural-biotechnology_en.

Segovia, R., Tam, A. S. and Stirling, P. C. (2015). Dissecting genetic and environmental mutation signatures with model organisms. Trends in Genetics 31(8), 465-474.

Sentmanat, M. F., Peters, S. T., Florian, C. P., Connelly, J. P. and Pruett-Miller, S. M. (2018). A survey of validation strategies for CRISPR-Cas9 editing. Scientific Reports 8(1), 888.

Serrano-Benítez, A., Cortés-Ledesma, F. and Ruiz, J. F. (2020). "An End to a Means": how DNA-end structure shapes the Double-Strand Break repair process. Frontiers in Molecular Biosciences 6, 153. 
Seymore, S. B. (2018). Patenting around failure. University of Pennsylvania Law Review 166, 1139-1187. https://papers.ssrn.com/sol3/papers.cfm?abstract_id=2922167.

Shahryary, Y., Symeonidi, A., Hazarika, R. R., Denkena, J., Mubeen, T., Hofmeister, B., van Gurp, T., Colomé-Tatché, M., Verhoeven, K. J. F., Tuskan, G., Schmitz, R. J. and Johannes, F. (2020). AlphaBeta: computational inference of epimutation rates and spectra from high-throughput DNA methylation data in plants. Genome Biology 21(1), 260.

Sharma, A. (2013). Transgenerational epigenetic inheritance: focus on soma to germline information transfer. Progress in Biophysics and Molecular Biology 113(3), 439-446.

Sheel, A. and Xue, W. (2016). Genomic amplifications cause false positives in CRISPR screens. Cancer Discovery 6(8), 824-826.

Sikora, P., Chawade, A., Larsson, M., Olsson, J. and Olsson, O. (2011). Mutagenesis as a tool in plant genetics, functional genomics, and breeding. International Journal of Plant Genomics 2011, 314829.

Simberloff, D. and Leppanen, C. (2019). Plant somatic mutations in nature conferring insect and herbicide resistance. Pest Management Science 75(1), 14-17.

Simon, M. M., Moresco, E. M. Y., Bull, K. R., Kumar, S., Mallon, A. M., Beutler, B. and Potter, P. K. (2015). Current strategies for mutation detection in phenotype-driven screens utilising next generation sequencing. Mammalian Genome 26(9-10), 486-500.

Sims, D., Sudbery, I., llott, N. E., Heger, A. and Ponting, C. P. (2014). Sequencing depth and coverage: key considerations in genomic analyses. Nature Reviews Genetics 15(2), 121-132.

Singh, N. and Bhalla, N. (2020). Moonlighting proteins. Annual Review of Genetics 54, 265-285.

Singh, R., lquebal, M. A., Mishra, C. N., Jaiswal, S., Kumar, D., Raghav, N., Paul, S., Sheoran, S., Sharma, P., Gupta, A., Tiwari, V., Angadi, U. B., Kumar, N., Rai, A., Singh, G. P., Kumar, D. and Tiwari, R. (2019). Development of model web-server for crop variety identification using throughput SNP genotyping data. Scientific Reports 9, 5122.

Sivarajah, U., Kamal, M. M., Irani, Z. and Weerakkody, V. (2017). Critical analysis of big data challenges and analytical methods. Journal of Business Research 70, 263-286.

Skryabin, B. V., Kummerfeld, D. M., Gubar, L., Seeger, B., Kaiser, H., Stegemann, A., Roth, J., Meuth, S. G., Pavenstädt, H., Sherwood, J., Pap, T., Wedlich-Söldner, R., Sunderkötter, C., Schwartz, Y. B., Brosius, J. and Rozhdestvensky, T. S. (2020). Pervasive head-to-tail insertions of DNA templates mask desired CRISPR-Cas9-mediated genome editing events. Science Advances 6(7), eaax2941.

Slotte, T. (2014). The impact of linked selection on plant genomic variation. Briefings in Functional Genomics 13(4), 268-275.

Smith, H. E. and Yun, S. (2017). Evaluating alignment and variant-calling software for mutation identification in C. elegans by whole-genome sequencing. PLOS ONE 12(3), e0174446.

Smith, J. S. C. and Smith, O. S. (1992). Fingerprinting crop varieties. In Advances in Agronomy, Sparks, D. L. (Ed). (Academic Press), pp. 85-140.

Smits, A. H., Ziebell, F., Joberty, G., Zinn, N., Mueller, W. F., Clauder-Münster, S., Eberhard, D., Fälth Savitski, M., Grandi, P., Jakob, P., Michon, A. M., Sun, H., Tessmer, K., Bürckstümmer, T., Bantscheff, M., Steinmetz, L. M., Drewes, G. and Huber, W. (2019). Biological plasticity rescues target activity in CRISPR knock outs. Nature Methods 16(11), 1087-1093. 
Smulders, M. J. M. and de Klerk, G. J. (2011). Epigenetics in plant tissue culture. Plant Growth Regulation 63(2), 137-146.

Songstad, D. D., Petolino, J. F., Voytas, D. F. and Reichert, N. A. (2017). Genome editing of plants. Critical Reviews in Plant Sciences 36(1), 1-23.

Spiridonova, E., Bertheau, Y. and Kuznetsov, B. (2009). Designing the PCR markers Agrobacterium tumefaciens gall-forming strains. In Co-Extra International Conference, Bertheau, Y. (Ed). (INRA), pp. 110-111. https://hal.inrae.fr/hal-02754080/document.

Springer, N. M. and Schmitz, R. J. (2017). Exploiting induced and natural epigenetic variation for crop improvement. Nature Reviews. Genetics 18(9), 563-575.

Sprink, T., Eriksson, D., Schiemann, J. and Hartung, F. (2016). Regulatory hurdles for genome editing: process- vs. product-based approaches in different regulatory contexts. Plant Cell Reports 35(7), 1493-1506.

Stebbins, C. L., Jr. (1950). Variation and Evolution in Plants. (London: Oxford University Press (Geoffrey Cumberlege)), p. 643.

Stegemann, S. and Bock, R. (2009). Exchange of genetic material between cells in plant tissue grafts. Science 324(5927), 649-651.

Steinegger, M. and Salzberg, S. L. (2020). Terminating contamination: large-scale search identifies more than 2,000,000 contaminated entries in GenBank. Genome Biology 21(1), 115.

Stella, S. and Montoya, G. (2016). The genome editing revolution: a CRISPR-Cas TALE offtarget story. BioEssays : News and Reviews in Molecular, Cellular and Developmental Biology 38 (Suppl. 1), S4-S13.

Stephan, W. (2019). Selective sweeps. Genetics 211(1), 5-13.

Sullivan, C. J., Pendleton, E. D., Abrams, R. E., Valente, D. L., Alvarez, M. L., Griffey, R. H. and Dresios, J. (2015). Chromatin structure analysis enables detection of DNA insertions into the mammalian nuclear genome. Biochemistry and Biophysics Reports 2, 143-152.

Svitashev, S. K. and Somers, D. A. (2002). Characterization of transgene loci in plants using FISH: A picture is worth a thousand words. Plant Cell, Tissue and Organ Culture 69(3), 205-214.

Svoboda, P. (2020). Key mechanistic principles and considerations concerning RNA interference. Frontiers in Plant Science 11, 1237-1237.

Tadele, Z., Mba, C. and Till, B. J. (2009). TILLING for mutations in model plants and crops. In: Molecular Techniques in Crop Improvement Jain, S. M. and Brar, D. S. (Eds). (Dordrecht: Springer Publishing, Inc). https://link.springer.com/ chapter/10.1007/978-90-481-2967-6_13.

Takabatake, R., Kaneko, M., Yanagida, M. and Kitta, K. (2020a). Detection of 30 bp DNA fragments with a sensitive modified Southern blot analysis. Bioscience, Biotechnology, and Biochemistry 84(12), 2405-2414.

Takabatake, R., Onishi, M., Minegishi, Y., Futo, S., Soga, K., Nakamura, K., Kondo, K., Mano, J. and Kitta, K. (2020b). Development of a novel detection method targeting an ultrashort 25 bp sequence found in Agrobacterium-mediated transformed GM plants. Journal of Agricultural and Food Chemistry 68(51), 15327-15334.

Tan, S. C. and Yiap, B. C. (2009). DNA, RNA, and protein extraction: the past and the present. Journal of Biomedicine and Biotechnology 2009, 574398.

Tang, L. (2020). Contamination in sequence databases. Nature Methods 17(7), 654-654.

Taverniers, I., Papazova, N., Allnutt, T., Baumler, S., Bertheau, Y., Esteve, T., Freyer, R., Gruden, K., Kuznetzov, B., Luis La Paz, J., Nadal, A., Pla, M., Vojvoda, J., Wulff, D., 
and Zhang, D. (2013). Harmonised reference genes and PCR assays for GMO quantification. In: Genetically Modified and Non-Genetically Modified Food Supply Chains: Co-Existence and Traceability Bertheau, Y. (Ed). (Wiley-Blackwell), pp. 273292. https://onlinelibrary.wiley.com/doi/abs/10.1002/9781118373781.ch16.

Teixeira da Silva, J., Bolibok-Bragoszewska, H. and Rakoczy-Trojanowska, M. (2007). Molecular markers in micropropagation, iissue culture and in vitro plant research. Genes, Genomes and Genomics 1, 66-72.

Tello-Ruiz, M. K., Naithani, S., Gupta, P., Olson, A., Wei, S., Preece, J., Jiao, Y., Wang, B., Chougule, K., Garg, P., Elser, J., Kumari, S., Kumar, V., Contreras-Moreira, B., Naamati, G., George, N., Cook, J., Bolser, D., D’Eustachio, P., Stein, L. D., Gupta, A., Xu, W., Regala, J., Papatheodorou, I., Kersey, P. J., Flicek, P., Taylor, C., Jaiswal, P. and Ware, D. (2021). Gramene 2021: harnessing the power of comparative genomics and pathways for plant research. Nucleic Acids Research 49(D1), D1452-D1463.

Tengs, T., Kristoffersen, A. B., Zhang, H. B., Berdal, K. G., Lovoll, M. and Holst-Jensen, A. (2010). Non-prejudiced detection and characterization of genetic modifications. Food Analytical Methods 3(2), 120-128.

The 1001 Genomes Consortium (2016). 1,135 genomes reveal the global pattern of polymorphism in Arabidopsis thaliana. Cell 166(2), 481-491.

Thomas, M., Burgio, G., Adams, D. J. and lyer, V. (2019a). Collateral damage and CRISPR genome editing. PLoS Genetics 15(3), e1007994.

Thomas, M., Parry-Smith, D. and lyer, V. (2019b). Best practice for CRISPR design using current tools and resources. Methods 164-165, 3-17.

Thorpe, T. A. (2013). Chapter 1. History of plant cell culture. In: Plant Tissue Culture (3rd edn.) Smith, R. H. (Ed). (San Diego: Academic Press), pp. 1-22. https://www. sciencedirect.com/science/article/pii/B9780124159204000013.

Till, B. J., Afza, R., Bado, S., Huynh, O. A., Jankowicz-Cieslak, J., Matijevic, M., and Mba, C. (2009). Global TILLING Projects. In Proceedings of International Symposium on Induced Mutations in Plants: Induced Plant Mutations in the Genomics Era: 11-15 August 2008, Q.Y. Shu, ed. (Rome: FAO). http://www.fao.org/docrep/012/i0956e/ 10956e.pdf.

Tong, H. and Nikoloski, Z. (2021). Machine learning approaches for crop improvement: leveraging phenotypic and genotypic big data. Journal of Plant Physiology 257, 153354.

Tsaballa, A., Xanthopoulou, A., Madesis, P., Tsaftaris, A. and Nianiou-Obeidat, I. (2021). Vegetable grafting from a molecular point of view: the involvement of epigenetics in rootstock-scion interactions. Frontiers in Plant Science 11, 2129.

Tusé, D., Nandi, S., McDonald, K. A. and Buyel, J. F. (2020). The emergency response capacity of plant-based biopharmaceutical manufacturing-what it is and what it could be. Frontiers in Plant Science 11, 594019.

Tyurin, A. A., Suhorukova, A. V., Kabardaeva, K. V. and Goldenkova-Pavlova, I. V. (2020). Transient gene expression is an effective experimental tool for the research into the fine mechanisms of plant gene function: advantages, limitations, and solutions. Plants 9(9), 1187.

Ulker, B., Li, Y., Rosso, M. G., Logemann, E., Somssich, I. E. and Weisshaar, B. (2008). T-DNA-mediated transfer of Agrobacterium tumefaciens chromosomal DNA into plants. Nature Biotechnology 26, 1015-1017.

Unar, J. A., Seng, W. C. and Abbasi, A. (2014). A review of biometric technology along with trends and prospects. Pattern Recognition 47(8), 2673-2688. 
Unterseer, S., Bauer, E., Haberer, G., Seidel, M., Knaak, C., Ouzunova, M., Meitinger, T., Strom, T. M., Fries, R., Pausch, H., Bertani, C., Davassi, A., Mayer, K. F. and Schön, C. C. (2014). A powerful tool for genome analysis in maise: development and evaluation of the high density $600 \mathrm{k}$ SNP genotyping array. BMC Genomics $15,823$.

UPOV (2019a). Advances in the Construction and Application of DNA Fingerprinting Database in Maize, UPOV, ed. (Geneva, Switzerland: International Union for the Protection of New Varieties of Plants), p. 12.

UPOV (2019b). DNA-Based Methods for Variety Testing: ISTA Approach, UPOV, ed. (Geneva, Switzerland: International Union for the Protection of New Varieties of Plants), p. 9.

UPOV (2019c). Guidance for Newtypes and Species. (Geneva, Switzerland: International Union for the Protection of New Varieties of Plants ), p. 13.

UPOV (2019d). Guidance on the Use of Biochemical and Molecular Markers in the Examination of Distinctness, Unifority and Stabilty (DUS). (Geneva, Switzerland: International Union for the Protection of New Varieties of Plants), p. 12.

UPOV (2019e). Guidance on the Use of Biochemical and Molecular Markers in the Examination of Distinctness, Uniformity and Stabilty (DUS). (Geneva, Switzerland: International Union for the Protection of New Varieties of Plants), p. 12.

UPOV WG (Working Group on Biochemical and Molecular Techniques and DNA-profiling in particular) (2019). DNA-Based Methods for Variety Testing: ISTA Approach, UPOV, ed. (Geneva, Switzerland: International Union for the Protection of New Varieties of Plants), p. 9.

UPOV (2011). Guidelines for DNA-profiling: Molecular markers and Database construction ("BMT Guidelines") (International Union for the Protection of New Varieties of Plants), p. 16.

Vakulskas, C. A. and Behlke, M. A. (2019). Evaluation and reduction of CRISPR off-target cleavage events. Nucleic Acid Therapeutics 29(4), 167-174.

Van de Peer, Y. and Pires, J. C. (2018). Editorial overview: genome studies and molecular genetics: treasure troves of evolution. Current Opinion in Plant Biology 42, iii-v.

van Heerwaarden, J., Hufford, M. B. and Ross-lbarra, J. (2012a). Historical genomics of North American maize. Proceedings of the National Academy of Sciences of the United States of America 109(31), 12420-12425.

van Heerwaarden, J., Ortega Del Vecchyo, D., Alvarez-Buylla, E. R. and Bellon, M. R. (2012b). New genes in traditional seed systems: diffusion, detectability and persistence of transgenes in a maize metapopulation. Plos One 7(10), e46123.

van Tassel, D. L., Tesdell, O., Schlautman, B., Rubin, M. J., DeHaan, L. R., Crews, T. E. and Streit Krug, A. (2020). New food crop domestication in the age of gene editing: genetic, agronomic and cultural change remain co-evolutionarily entangled. Frontiers in Plant Science 11, 789.

Vilperte, V., Agapito-Tenfen, S. Z., Wikmark, O. G. and Nodari, R. O. (2016). Levels of DNA methylation and transcript accumulation in leaves of transgenic maize varieties. Environmental Sciences Europe 28(1), 29.

Visscher, P. M., Hill, W. G. and Wray, N. R. (2008). Heritability in the genomics era-concepts and misconceptions. Nature Reviews. Genetics 9(4), 255-266.

Vítor, A. C., Huertas, P., Legube, G. and de Almeida, S. F. (2020). Studying DNA doublestrand break repair: an ever-growing toolbox. Frontiers in Molecular Biosciences 7, 24. 
Vitti, J. J., Grossman, S. R. and Sabeti, P. C. (2013). Detecting natural selection in genomic data. Annual Review of Genetics 47, 97-120.

Volkova, N. V., Meier, B., González-Huici, V., Bertolini, S., Gonzalez, S., Vöhringer, H., Abascal, F., Martincorena, I., Campbell, P. J., Gartner, A. and Gerstung, M. (2020). Mutational signatures are jointly shaped by DNA damage and repair. Nature Communications 11(1), 2169.

Voosen, P. (2010). 1.26 Mutation advances set to flip biotech crop debate. In Plant Breeding News, GIPB-Global Partnership Initiative for Plant Breeding Capacity Building Cornell University, eds. (Platform facilitated by FAO). https://archive.nytimes.com/ www.nytimes.com/gwire/2010/11/16/16greenwire-mutation-advances-set-to-flipbiotech-crop-deb-78201.html.

Wachsman, G., Modliszewski, J. L., Valdes, M. and Benfey, P. N. (2017). A SIMPLE pipeline for mapping point mutations. Plant Physiology 174(3), 1307-1313.

Wada, N., Ueta, R., Osakabe, Y. and Osakabe, K. (2020). Precision genome editing in plants: state-of-the-art in CRISPR/Cas9-based genome engineering. BMC Plant Biology 20(1), 234-234.

Wallace, D. C. (2016). Genetics: mitochondrial DNA in evolution and disease. Nature 535(7613), 498-500.

Walper, S. A., Aragonés, G. L., Sapsford, K. E., III, C. W. B., Rowland, C. E., Breger, J. C. and Medintz, I. L. (2018). A multi-parametric approach towards biological threat detection. ACS Sensors 3, 1894-2024.

Waminal, N. E., Ryu, K. H., Choi, S. H. and Kim, H. H. (2013). Randomly detected genetically modified (GM) maize (Zea mays L.) near a transport route revealed a fragile 45S rDNA phenotype. PLoS ONE 8(9), e74060.

Wang, H. and Yang, H. (2019). Gene-edited babies: what went wrong and what could go wrong. PLoS Biology 17(4), e3000224.

Wang, L., Ji, Y., Hu, Y., Hu, H., Jia, X., Jiang, M., Zhang, X., Zhao, L., Zhang, Y., Jia, Y., Qin, C., Yu, L., Huang, J., Yang, S., Hurst, L. D. and Tian, D. (2019). The architecture of intraorganism mutation rate variation in plants. PLoS Biology 17(4), e3000191.

Warschefsky, E. J., Klein, L. L., Frank, M. H., Chitwood, D. H., Londo, J. P., von Wettberg, E. J. B. and Miller, A. J. (2016). Rootstocks: diversity, domestication, and impacts on shoot phenotypes. Trends in Plant Science 21(5), 418-437.

Weckwerth, W., Loureiro, M. E., Wenzel, K. and Fiehn, O. (2004). Differential metabolic networks unravel the effects of silent plant phenotypes. Proceedings of the National Academy of Sciences of the United States of America 101, 7809-7814.

Wei, L., Christensen, S. R., Fitzgerald, M. E., Graham, J., Hutson, N. D., Zhang, C., Huang, Z., Hu, Q., Zhan, F., Xie, J., Zhang, J., Liu, S., Remenyik, E., Gellen, E., Colegio, O. R., Bax, M., Xu, J., Lin, H., Huss, W. J., Foster, B. A. and Paragh, G. (2021). Ultradeep sequencing differentiates patterns of skin clonal mutations associated with sunexposure status and skin cancer burden. Science Advances 7(1), eabd7703.

Weigel, D. and Colot, V. (2012). Epialleles in plant evolution. Genome Biology 13(10), 249. Whittle, C. A. and Johnston, M. O. (2003). Broad-scale analysis contradicts the theory that generation time affects molecular evolutionary rates in plants. Journal of Molecular Evolution 56(2), 223-233.

Wibowo, A., Becker, C., Marconi, G., Durr, J., Price, J., Hagmann, J., Papareddy, R., Putra, H., Kageyama, J., Becker, J., Weigel, D. and Gutierrez-Marcos, J. (2016). Hyperosmotic stress memory in Arabidopsis is mediated by distinct epigenetically labile sites in 
the genome and is restricted in the male germline by DNA glycosylase activity. eLife 5, e13546.

Wienert, B., Wyman, S. K., Richardson, C. D., Yeh, C. D., Akcakaya, P., Porritt, M. J., Morlock, M., Vu, J. T., Kazane, K. R., Watry, H. L., Judge, L. M., Conklin, B. R., Maresca, M. and Corn, J. E. (2019). Unbiased detection of CRISPR off-targets in vivo using DISCoverSeq. Science 364(6437), 286-289.

Wilkesa, T., Nixona, G. and Burns, M. (2016). Recent developments in DNA-based screening approaches for detection of GMO's. Journal of the Association of Public Analysts 44, 40-50.

Witcombe, J. R., Gyawali, S., Subedi, M., Virk, D. S. and Joshi, K. D. (2013). Plant breeding can be made more efficient by having fewer, better crosses. BMC Plant Biology 13, 22-22.

Wu, Z., Waneka, G., Broz, A. K., King, C. R. and Sloan, D. B. (2020). MSH1 is required for maintenance of the low mutation rates in plant mitochondrial and plastid genomes. Proceedings of the National Academy of Sciences of the United States of America 117(28), 16448-16455.

Xie, W., Wang, G., Yuan, M., Yao, W., Lyu, K., Zhao, H., Yang, M., Li, P., Zhang, X., Yuan, J., Wang, Q., Liu, F., Dong, H., Zhang, L., Li, X., Meng, X., Zhang, W., Xiong, L., He, Y., Wang, S., Yu, S., Xu, C., Luo, J., Li, X., Xiao, J., Lian, X. and Zhang, Q. (2015). Breeding signatures of rice improvement revealed by a genomic variation map from a large germplasm collection. Proceedings of the National Academy of Sciences of the United States of America 112(39), E5411-E5419.

Xu, G., Lyu, J., Li, Q., Liu, H., Wang, D., Zhang, M., Springer, N. M., Ross-lbarra, J. and Yang, J. (2020). Evolutionary and functional genomics of DNA methylation in maize domestication and improvement. Nature Communications 11(1), 5539-5539.

Xu, J., Tanino, K. K. and Robinson, S. J. (2016). Stable epigenetic variants selected from an induced hypomethylated Fragaria vesca population. Frontiers in Plant Science 7, 1768.

Xue, W., Anderson, S. N., Wang, X., Yang, L., Crisp, P. A., Li, Q., Noshay, J., Albert, P. S., Birchler, J. A., Bilinski, P., Stitzer, M. C., Ross-lbarra, J., Flint-Garcia, S., Chen, X., Springer, N. M. and Doebley, J. F. (2019). Hybrid decay: a transgenerational epigenetic decline in vigor and viability triggered in backcross populations of teosinte with maise. Genetics 213(1), 143-160.

Yadava, P., Abhishek, A., Singh, R., Singh, I., Kaul, T., Pattanayak, A. and Agrawal, P. K. (2016). Advances in maize transformation technologies and development of transgenic maize. Frontiers in Plant Science 7, 1949.

Yaish, M. W. (2017). Editorial: epigenetic modifications associated with abiotic and biotic stresses in plants: an implication for understanding plant evolution. Frontiers in Plant Science 8, 1983.

Yang, A., Zhang, W., Wang, J., Yang, K., Han, Y. and Zhang, L. (2020). Review on the application of machine learning algorithms in the sequence Data Mining of DNA. Frontiers in Bioengineering and Biotechnology 8, 1032.

Yang, H. W., Chung, M., Kudo, T. and Meyer, T. (2017). Competing memories of mitogen and p53 signalling control cell-cycle entry. Nature 549(7672), 404-408.

Yau, Y. Y. and Stewart, C. N. (2013). Less is more: strategies to remove marker genes from transgenic plants. BMC Biotechnology 13, 36.

Yee, J. K. (2016). Off-target effects of engineered nucleases. The FEBS Journal 283(17), 3239-3248. 
Yin, Z., Lan, H., Tan, G., Lu, M., Vasilakos, A. V. and Liu, W. (2017). Computing platforms for big biological data analytics: perspectives and challenges. Computational and Structural Biotechnology Journal 15, 403-411.

Yuan, J., Gordon, A., Speyer, D., Aufrichtig, R., Zielinski, D., Pickrell, J. and Erlich, Y. (2018a). DNA.land is a framework to collect genomes and phenomes in the era of abundant genetic information. Nature Genetics 50(2), 160-165.

Yuan, Y., Lee, H., Hu, H., Scheben, A. and Edwards, D. (2018b). Single-cell genomic analysis in plants. Genes 9(1), 50.

Zampieri, M., Weissteiner, C. J., Grizzetti, B., Toreti, A., van den Berg, M. and Dentener, F. (2020a). Estimating resilience of crop production systems: from theory to practice. Science of the Total Environment 735, 139378.

Zampieri, R., Brozzetti, A., Pericolini, E., Bartoloni, E., Gabrielli, E., Roselletti, E., Lomonosoff, G., Meshcheriakova, Y., Santi, L., Imperatori, F., Merlin, M., Tinazzi, E., Dotta, F., Nigi, L., Sebastiani, G., Pezzotti, M., Falorni, A. and Avesani, L. (2020b). Prevention and treatment of autoimmune diseases with plant virus nanoparticles. Science Advances 6(19), eaaz0295.

Zhang, C., Wohlhueter, R. and Zhang, H. (2016). Genetically modified foods: a critical review of their promise and problems. Food Science and Human Wellness 5(3), 116-123.

Zhang, X. P. and Heyer, W. D. (2011). Quality control of purified proteins involved in homologous recombination. Methods in Molecular Biology 745, 329-343.

Zhang, Y., Chen, M., Siemiatkowska, B., Toleco, M. R., Jing, Y., Strotmann, V., Zhang, J., Stahl, Y. and Fernie, A. R. (2020). A highly efficient Agrobacterium-mediated method for transient gene expression and functional studies in multiple plant species. Plant Communications 1(5), 100028.

Zhao, C., Zhang, Y., Du, J., Guo, X., Wen, W., Gu, S., Wang, J. and Fan, J. (2019). Crop phenomics: current status and perspectives. Frontiers in Plant Science 10, 714.

Zhou, X., Liu, Z., Shen, K., Zhao, P. and Sun, M. X. (2020). Cell lineage-specific transcriptome analysis for interpreting cell fate specification of proembryos. Nature Communications 11(1), 1366.

Żmieńko, A., Guzowska-Nowowiejska, M., Urbaniak, R., Pląder, W., Formanowicz, P. and Figlerowicz, M. (2011). A tiling microarray for global analysis of chloroplast genome expression in cucumber and other plants. Plant Methods 7, 29.

Zuo, E., Sun, Y., Wei, W., Yuan, T., Ying, W., Sun, H., Yuan, L., Steinmetz, L. M., Li, Y. and Yang, H. (2019). Cytosine base editor generates substantial off-target single-nucleotide variants in mouse embryos. Science 364(6437), 289-292. 